\title{
Metabolism within the tumor microenvironment and its implication on cancer progression: an ongoing therapeutic target
}

Metabolism within the tumor microenvironment and its implication on cancer progression: an ongoing therapeutic target

$\mathrm{M}^{\mathrm{a}}$ Carmen Ocaña ${ }^{1}$, Beatriz Martínez-Poveda ${ }^{1}$, Ana R. Quesada ${ }^{1,2}$, Miguel Ángel

Medina ${ }^{1,2}$

${ }^{1}$ Universidad de Málaga, Andalucía Tech, Departamento de Biología Molecular y Bioquímica, Facultad de Ciencias, and IBIMA (Biomedical Research Institute of Málaga), Spain.

${ }^{2}$ UNIT 741, CIBER de Enfermedades Raras (CIBERER), E-29071 Málaga, Spain

\section{Acknowledgments}

We thank Miguel Robles Picasso for helping with figure design. $\mathrm{M}^{\mathrm{a}}$ Carmen Ocaña is recipient of a predoctoral FPU grant from the Spanish Ministry of Education, Culture and Sport. Supported by grants BIO2014-56092-R (MINECO and FEDER), P12-CTS1507 (Andalusian Government and FEDER) and funds from group BIO-267 (Andalusian Government). The "CIBER de Enfermedades Raras" is an initiative from the ISCIII (Spain). The funders had no role in the study design, data collection and analysis, decision to publish or preparation of the manuscript.

\section{Conflict of Interest Statement}

Authors declare that they have no actual or potential competing financial interest.

Running title: Metabolism within tumor microenvironment

This is the preprint version of our manuscript, corresponding to the article that has been published in final form at MEDICINAL RESEARCH REVIEWS with DOI: 10.1002/med.21511 


\section{ABSTRACT}

Since reprogramming energy metabolism is considered a new hallmark of cancer, tumor metabolism is again in the spotlight of cancer research. Many studies have been carried out and many possible therapies have been developed in the last years. However, tumor cells are not alone. A series of extracellular components and stromal cells, such as endothelial cells, cancer-associated fibroblasts, tumor-associated macrophages and tumor-infiltrating $\mathrm{T}$ cells, surround tumor cells in the so-called tumor microenvironment. Metabolic features of these cells are being studied in deep in order to find relationships between metabolism within the tumor microenvironment and tumor progression. Moreover, it cannot be forgotten that tumor growth is able to modulate host metabolism and homeostasis, so that tumor microenvironment is not the whole story. Importantly, the metabolic switch in cancer is just a consequence of the flexibility and adaptability of metabolism and should not be surprising. Treatments of cancer patients with combined therapies including anti-tumor agents with those targeting stromal cell metabolism, anti-angiogenic drugs and/or immunotherapy are being developed as promising therapeutics.

\section{Keywords}

Metabolism; tumor microenvironment; endothelial cells; immune cells; stromal cells; angiogenesis; immunosuppression

Abbreviations: Arg1, arginase 1; ASNS, asparagine synthetase; bFGF, basic fibroblast growth factor; CAFs, cancer-associated fibroblasts; CPT1, carnitine palmitoyltransferase 1; ECs, endothelial cells; ECM, extracellular matrix; FAO, fatty acid oxidation; FAS, fatty acid synthase; G6PDH, glucose-6-phosphate dehydrogenase; GLS, glutaminase; GS, glutamine synthetase; HBP, hexosamine biosynthesis pathway; HIF-1 $\alpha$, hypoxia inducible factor $1 \alpha$; HK, hexokinase; IDO, indoleamine-2,3dioxygenase; iNOS, inducible nitric oxide synthase; LDH, lactate dehydrogenase; MMP, matrix metalloproteinase; mTOR, mammalian target of rapamycin; NO, nitric oxide; ODC, ornithine decarboxylase; OXPHOS, oxidative phosphorylation; PCK1, phosphoenolpyruvate carboxykinase 1; PD-1, programmed death 1 receptor; PDH, pyruvate dehydrogenase; PDK1, pyruvate dehydrogenase kinase 1; PFK1, 6phosphofructokinase; PFKFB3, phosphofructokinase-2/fructose-2,6-bisphosphatase 3; PHD: prolyl hydroxylase; PK, pyruvate kinase; PPP, pentose phosphate pathway; ROS, reactive oxygen species; TAMs, tumor-associated macrophages; TCA, tricarboxylic acid cycle; TDO, tryptophan-2,3-dioxygenase; TILs, tumor-infiltrating lymphocytes; TME, tumor microenvironment; uPA, urokinase-type plasminogen activator; VEGF, vascular endothelial growth factor. 


\section{TUMOR CELLS METABOLISM: BEYOND WARBURG EFFECT}

The experiments carried out by Otto Warburg in the mid-twenties of the $20^{\text {th }}$ century were just the beginning of an advanced knowledge in cancer metabolism. As early as 
1925, he observed a huge amount of lactic acid in rat carcinoma even when oxygen was available, a process known as aerobic glycolysis. ${ }^{1}$ This contradicted the well-established Pasteur effect, based on the inhibition of glycolysis in the presence of oxygen. ${ }^{19}$ Warburg also observed that malignant tumors produced more lactic acid than benign tumors. ${ }^{1}$ Nowadays we know that the glycolytic rate can be a sign of tumor aggressiveness. For example, the non-invasive MCF7 breast cancer cell line has a lower rate of aerobic glycolysis than the highly invasive MDA-MB-231 breast cancer cell line, corresponding to lower levels of lactate dehydrogenase-A (LDH-A) and to the oxidative source of the great majority of the ATP produced by MCF-7 cells. ${ }^{3,20,21}$ However, aerobic glycolysis is not just a sign of tumor aggressiveness, since some proliferating non-transformed cells show this metabolic characteristic too. ${ }^{22} 30$ years after initial Warburg's seminal observations, when many metabolic routes had been already discovered, he noticed that cancer cells could obtain similar amounts of energy by aerobic glycolysis and by oxidative phosphorylation (OXPHOS), in spite of the lower efficiency in ATP yielded per molecule of glucose provided by glycolysis. ${ }^{2,23}$ At that moment, it was difficult to find an explanation for this fact, since high rates of tumor cell proliferation would require the production of great amounts of energy in the form of ATP molecules, and OXPHOS was the obvious road to fulfill this purpose. Now we know that, due to that high proliferation, cancer cells have a large demand of the precursors for the new daughter cells generated by mitosis, in form of nucleotides, amino acids and lipids. Thus, glucose would be diverted to the formation of acetyl-CoA for fatty acid synthesis, glycolytic intermediates for non-essential amino acids, and ribose for nucleotides. ${ }^{24}$ This explains why many types of cancer cells switch their glucose metabolism towards aerobic glycolysis. Extracellular flux analyzers are currently very popular tools for measuring basic metabolism, since they are able to estimate OXPHOS through oxygen consumption rate (OCR) and aerobic glycolysis through extracellular acidification rate (ECAR). Nevertheless, studies with isolated tumors from mice showed that although progressive tumors have higher ECAR levels than regressive ones, their proliferation rates are similar, demonstrating that proliferation is not the only reason for aerobic glycolysis in tumor cells. ${ }^{25}$

The increased glucose consumption by many cancers is the basis for the use of the glucose analogue 2-[ $\left[{ }^{18} \mathrm{~F}\right]$-fluoro-2-deoxy-D-glucose for tumor diagnostic and treatment follow-up by using positron emission tomography (PET). ${ }^{26}$ In high contrast with the affirmation that all tumor cells rely mostly on aerobic glycolysis, there is ample evidence that not all cancer cells obey this rule. For example, glutamine is the major energy source for cervix adenocarcinoma HeLa cells, and Gentric et al. have reported some examples of oxidative tumors. ${ }^{27,28}$ Furthermore, oxidative and glycolytic cancer cells can co-exist within the same tumor, and a lactate shuttle is established between both of them. ${ }^{29}$ Lactate uptaken by oxidative cancer cells (either from other cells or from the circulation) can provide carbon skeletons to be incorporated to the tricarboxylic acid cycle (TCA) in order to obtain energy. ${ }^{30}$ We would like to emphasize that in the next sections and figures of this review we will not make a distinction between oxidative and glycolytic tumor cells for the sake of simplicity. It should be 
taken into account that different metabolic events here represented in the same tumor cell might be occurring in different cancer cells, though.

Nonetheless, other substrates different to glucose are also differentially consumed by tumors as well. In particular, glutamine, the most abundant circulating amino acid in blood, has a major role regarding tumor growth, as glucose can only provide carbon skeletons for scaffolds of new molecules and glutamine would serve as a nitrogen source. ${ }^{31}$ In fact, glutamine is a non-essential amino acid for non-transformed human cells but it turns into an essential amino acid for tumor cells. ${ }^{12}$ Moreover, a host to tumor net flux of glutamine has been confirmed in mice inoculated with Ehrlich ascites tumor cells, enabled by an increased contribution made by the host tissues to circulating glutamine during tumor development. ${ }^{32,33} \mathrm{We}$ will discuss this issue in a later section of this review.

Almost 30 years ago, our group found out that Ehrlich ascites tumor cells, grown under steady state conditions, utilize both glucose and glutamine, producing two moles of lactate per mole of glucose, and one of glutamate and ammonia per mole of glutamine consumed. ${ }^{34}$ That means that cancer cells are able to use glucose and glutamine in a completely dissipative way. Both nutrients are important, as they lead to ATP production and provide intermediates for macromolecular synthesis. The roles of glutamine in intermediary metabolism have already been revised. ${ }^{35}$ Additionally, glutamine can be used for synthetizing the non-essential amino acids alanine, serine, arginine and proline and also fatty acids, although glucose is the major lipogenic substrate, as seen in glioblastoma cells. ${ }^{36,37}$ It is important to remember that glutamine can lead to lactate production through glutaminolysis. So, aerobic glycolysis is not the only way a tumor cell possesses to produce lactate, whose excretion out of the cell was first thought to be a mechanism to eliminate the pyruvate excess. ${ }^{23}$ However, lactate would have many roles in benefit of tumor progression that will be discussed in other sections of the present review. Likewise, ammonia was also thought to be just a toxic waste product. Nevertheless, it has been recently shown that this metabolite can be recycled to generate amino acids through glutamate dehydrogenase (GDH) activity, providing a nitrogen source to the tumor. ${ }^{38}$

Metabolic profiling depends on cell distribution, as cancer cells within the oxygenated periphery may consume and oxidize the lactate resulting from aerobic glycolysis by cells in the hypoxic area. ${ }^{39}$ Besides, cancer metabolic phenotypes are usually defined by the origin of the tissue, epigenetic drivers, aberrant signaling, and the TME. ${ }^{40}$ Indeed, genetics, epigenetics and metabolism interact with one another and, as a result, tumor heterogeneity is the overall result of all these changes at different levels. ${ }^{41}$ A previous review of tumor metabolism contributed by our group focused its attention in the genetic regulation of tumor metabolism. The key roles played by c-myc, K-Ras and p53 are well documented. For example, c-myc oncogene promotes expression of LDH-A, the glutamine transporter SLC1A5 and GLS glutaminase (associated to tumor malignancy), and K-Ras stimulates glucose uptake, lactate production and canalization 
of glutamine carbons to the Krebs cycle, whereas tumor suppressor gene p53 induces GLS2 glutaminase expression (typical of non-proliferative cells), OXPHOS and fatty acid oxidation (FAO), and diminishes expression of glucose transporters and some of the key glycolytic enzymes. ${ }^{42}$

Epigenetics plays also a role in tumor metabolism. For example, 2-hydroxyglutarate (2-HG), a product of the reaction catalyzed by a mutated isocitrate dehydrogenase 1 (IDH1), inhibits the binding of $\alpha$-ketoglutarate $(\alpha-\mathrm{KG})$ to tet methylcytosine dioxygenase 2 (TET2) and lysine demethylase 3A (KDM3A), two epigenetic enzymes, impairing their function. ${ }^{43}$ Another example is nitric oxide (NO), also able to drive epigenetic modifications related with tumorigenesis. ${ }^{44}$

Less attention has been paid to studying the role of fatty acids in tumor growth, since glucose and glutamine are considered the major sources of energy in these cells. A relationship between glycolysis and FAO has been found in tumors, since highly glycolytic cell lines present a low lipid oxidation and vice versa ${ }^{45,46}$ Some tumors lack carnitine palmitoyltransferase 1a (CPT1a) activity, a rate-limiting enzyme of FAO. ${ }^{47}$ In various tumor cell lines, rates of oxidation of glucose higher than those of palmitate have been documented. ${ }^{48}$ However, it has been shown that highly proliferative cancer cells have a strong lipid avidity, increasing the uptake of exogenous lipids or promoting lipogenesis and cholesterol synthesis. ${ }^{49}$ Fatty acid synthase (FAS) is overexpressed in several types of cancer. ${ }^{50-52}$ Transcription factors SREBP1 and SREBP2, involved in fatty acid and cholesterol biosynthesis, are also overexpressed in many tumors. ${ }^{53}$ On the other hand, prostate tumors display a low rate of glucose utilization; they rather have a high rate of fatty acids uptake and overexpress some $\beta$-oxidation enzymes. ${ }^{53}$ It has been shown that leukemia cells require this metabolic route for proliferation and survival. ${ }^{54}$ Additionally, there is some controversy about the role of fatty acids on metastasis and invasiveness. A published study found an inverse relationship between expression of CD36, a known transporter of long fatty acids, and the metastatic potential of tumors, whereas the authors of a more recent paper postulate a positive role of CD36 in metastasis. $^{55,56}$

Other metabolites could also play essential roles in tumor metabolism. The role of asparagine in cell survival has been well-known for many years, and several studies are being carried out nowadays regarding the importance of this amino acid. The presence of asparagine is essential for maintaining cell viability in glutamine-depletion conditions, and inhibition of asparagine synthetase (ASNS), an enzyme that catalyzes the conversion of aspartate and glutamine into asparagine, leads to cell death even in a glutamine-rich media. ${ }^{57}$ Therefore, depleting asparagine and inhibiting ASNS expression seems to be a way to stop tumor growth. Treatment with the enzyme asparaginase, which is able to undermine asparagine levels in the media, has been carried out in leukemia and lymphomas since the discovery of its anti-cancer effect in 1963. ${ }^{58}$ Later, it would be known that asparaginase treatment was effective due to the null or low expression of ASNS in these tumors. ${ }^{59,60}$ Nevertheless, most solid tumors 
present ASNS expression and therefore depletion of glutamine is also important for asparaginase-dependent therapy in ASNS-expressing tumors. ${ }^{61,62}$ Indeed, a study determined that glioblastoma cells that are not sensitive to glutamine deprivation are also insensitive to asparaginase treatment, but the treatment affected glioblastoma cells sensitive to deprivation of this amino acid. ${ }^{63}$ This may be due to the fact that most asparaginases also present glutaminase activity.

There are other amino acids that are essential for tumor growth and progression as well. Serine can be synthetized from glycolytic intermediates and later converted into glycine. Both amino acids are necessary for protein, nucleic acid and lipid synthesis. Serine can contribute to the formation of other metabolites by anaplerosis, being necessary for proliferation. Glycine, which may also derive from threonine, is related to folate metabolism (essential for tumor progression), to DNA methylation, and to the redox balance maintenance. ${ }^{64,65}$ Indeed, expression of PHGDH (phosphoglycerate dehydrogenase), the first enzyme in serine synthesis, is normally upregulated in triplenegative breast cancer, evidencing the importance of this amino acid for these tumors. ${ }^{66}$ In contrast, metabolism of other amino acids can be toxic for tumor cells. For example, proline oxidase (PRODH), the first enzyme in the catabolism of proline, is induced by p53. ${ }^{67}$ Expression of PRODH leads to cell cycle arrest and apoptosis in tumors, and it has been seen that c-myc inhibits its function. ${ }^{68}$

In addition to all this, other metabolites are also important for tumors. NO is the product of the enzymatic reaction catalyzed by nitric oxide synthase (NOS), which uses arginine as substrate, as well as NADPH. Thus, the pentose phosphate pathway (PPP) would provide the reducing agent necessary for synthetizing NO. In hypoxic tumors, hypoxia inducible factor $1 \alpha$ (HIF-1 $\alpha$ ) interacts with IFN- $\gamma$ thus inducing the expression of inducible NOS (iNOS) ${ }^{69}$ NO produced and secreted by tumor cells reprograms stromal cells to support tumor progression, although high concentrations has been shown to induce apoptosis, and it also helps drug resistance and migration of cancer cells. ${ }^{70-72}$ Moreover, NO modulates metabolism of tumor cells, inhibiting prolyl hydroxylase 2 (PHD2) and OXPHOS, hence promoting a glycolytic metabolism. ${ }^{73,74}$ Furthermore, S-nitrosylation is a mechanism of posttranslational protein modification mediated by $\mathrm{NO}$ and implied in modulating the activity of several oncogenic signaling cascades and metabolic enzymes. ${ }^{69}$

Last but not least, polyamine synthesis has been known to be essential for tumor progression since the late sixties. ${ }^{75}$ High levels of intracellular polyamines have been shown to increase cell proliferation, decrease apoptosis, enhance expression of genes affecting tumor invasion and metastasis, and they are also related to angiogenesis. ${ }^{76}$ The synthesis of these macromolecules requires conversion of arginine to ornithine through arginase activity. Then, ornithine is decarboxylated to produce putrescine, the first polyamine, in a reaction catalyzed by ornithine decarboxylase (ODC), and spermidine and spermine are synthetized using decarboxylated S-adenosylmethionine (dcSAM) as an aminopropyl group donor. ${ }^{77}$ ODC was described as a proto-oncogene as soon as 
1992, and ODC levels are higher in tumors than in non-proliferating tissues. ${ }^{78,79}$ Moreover, several oncogenes, such as myc and K-Ras, are responsible for augmented polyamine synthesis and decreased polyamine catabolism, thus promoting tumor progression. ${ }^{80-82}$ Interestingly, NO is able to inhibit ODC by nitrosylation. ${ }^{83}$ Polyamine synthesis in tumors has been classically suppressed by treatment with difluoromethylornithine (DFMO), an inhibitor of ODC. ${ }^{84}$ Recent research has found that mammalian target of rapamycin complex 1 (mTORC1) sustains polyamine synthesis in tumors through overexpression of S-adenosylmethionine decarboxylase 1 (AMD1), the enzyme responsible for SAM decarboxylation. ${ }^{85}$

The different metabolic features of tumor cells mentioned here are collected in Figure 1. Taking into account all this information, it cannot be said that all tumor cells rely just on aerobic glycolysis for its growth and progression. In fact, this depends more on the kind and stage of the tumor, as well as on its microenvironment. Metabolism of different cells of this TME will be presented throughout this review, along with a recapitulation of the feasible reasons and/or consequences of those metabolic features in cancer disease.

\section{METABOLISM OF CELLS AT THE TUMOR MICROENVIRONMENT}

\subsection{Endothelial cells}

ECs are the most studied stromal cells in the TME, since they are responsible for the angiogenic process. Angiogenesis is the formation of new blood vessels from the preexisting vascular bed. Pathological activation of angiogenesis in tumors (a process called tumor angiogenesis) allows them to grow and metastatize. This angiogenic switch is controlled by pro- and anti-angiogenic molecules secreted from different cells of the TME. ${ }^{86}$ As we discuss throughout this review, metabolic pathways regulate some of these angiogenic molecules, representing promising targets to modulate tumor angiogenesis. Therefore, targeting metabolism to inhibit tumor proliferation could be also a way to modulate the angiogenic process.

Regarding EC metabolism, there are some discrepancies among published data. Back in 1991, Spolarics et al. determined that rat liver ECs rely predominantly on aerobic metabolism rather than glycolysis, with $45 \%$ of total ATP produced by oxidation of palmitate, and $26 \%$ derived from glutamine. ${ }^{87}$ Three years before, Leighton and colleagues measured glutaminase activity in bovine pulmonary ECs, and found that it was almost 20-fold higher in comparison with that of rat lymphocytes, giving a major importance to glutamine metabolism in these cells. They also recognized some relevance to FAO, since CPT1a showed an elevated expression. However, in contrast with the results from Spolarics's group, their data showed high activity of some key glycolytic enzymes, such as hexokinase (HK), 6-phosphofructokinase (PFK1) and 
pyruvate kinase (PK), suggesting that glycolysis could play an important role in EC metabolism. ${ }^{88}$ Indeed, other groups found glycolysis to be predominant in bovine cavernous, rat coronary and human umbilical vascular ECs (HUVEC) even in the presence of oxygen. ${ }^{89-91}$ From these and other data, it has been proposed that ECs rely on glutamine and fatty acid metabolism when the supply of glucose decreases. ${ }^{92}$ Most of these differences observed in bibliography could be probably due to different isolation and culture conditions of ECs, affecting their proliferation rate and their metabolism.

The interest on EC metabolism was pushed into background for some years, until 2013, when Peter Carmeliet's laboratory found interesting data regarding the role of phosphofructokinase-2/fructose-2,6-bisphosphatase 3 (PFKFB3) activity in EC metabolism and angiogenesis. In their experiments, they observed that ECs isolated from several tissues were highly glycolytic, $>200$ fold-higher compared to oxidation of glucose, glutamine or fatty acids in the same cells, generating up to $85 \%$ of the total cellular ATP content only through this pathway. ${ }^{93}$ In addition, a reported low OCR in HUVEC may indicate that they rely more on glycolysis than on OXPHOS. ${ }^{94}$ These observations agree with previous results from other groups and disagree with other available data, as seen above. ${ }^{87-91}$

PPP is also important for ECs, since it leads to the formation of reduction equivalents as NADPH, induces the synthesis of NO, a pro-angiogenic factor, and prevents the formation of reactive oxygen species (ROS). Indeed, studies in ECs have shown that an overexpression of the limiting enzyme of the PPP, glucose-6-phosphate dehydrogenase (G6PDH), results in an increase of $\mathrm{NO}$ synthesis, whereas its downregulation drives to an elevation in ROS levels. ${ }^{95}$ On the other hand, a part of the glucose metabolic flux is derived to the hexosamine biosynthesis pathway (HBP), essential for the N-linked glycosylation process. HBP may play a role in angiogenesis switch on, since VEGFR2, the key vascular endothelial growth factor (VEGF) receptor involved in tumor angiogenesis, has to be N-glycosylated to become fully functional. ${ }^{96}$ Regarding tumor progression, glycolysis-derived lactate has also an important role on the angiogenesis process (see section 4.2 below).

In spite of the rediscovered importance on endothelial glycolysis, glutamine metabolism is still considered to have an essential role in EC survival, as well as in angiogenesis. ${ }^{97-99}$ However, glutamine helps EC proliferation but not migration. ${ }^{100} \mathrm{~A}$ part of the importance of glutamine metabolism in EC survival and angiogenesis could be due to the role of this amino acid in the synthesis of polyamines, considered to be essential to EC proliferation and angiogenesis, as well as for cell survival. ${ }^{101,102}$ In fact, in some EC lines about a $26 \%$ of ornithine, the precursor for polyamine synthesis, is formed from glutamine. ${ }^{103,104}$ In addition, glutamine is also essential for asparagine synthesis through ASNS activity, as seen above. A recent study showed that asparagine can be uptaken from the media or synthetized by ASNS in ECs, and this amino acid has 
an important role in protein synthesis, mTOR activation and endoplasmic reticulum (ER) stress suppression due to glutamine deprivation. ${ }^{99}$

As mentioned above, Spolarics et al. suggested that fatty acids could be important fuels for ECs, in high contrast with previous observations from other group. ${ }^{87,105} \mathrm{~A}$ recent study from the same group that underestimated the use of fatty acids in ECs, showed later that FAO is essential for angiogenesis by promoting the de novo synthesis of nucleotides, thus allowing ECs to proliferate. ${ }^{93,106}$ In fact, inhibition of CPT1a impaired angiogenesis in HUVEC. ${ }^{106}$ One of the long chain fatty acids transporters in ECs is CD36. Inhibition of CD36 has been shown to reduce angiogenesis, but it is not clear whether this effect is due to fatty acid uptake inhibition or not. ${ }^{107}$

Metabolism of ECs is summarized in Fig. 1. For additional information, we encourage our readers to visit some recent reviews on EC metabolism summarizing what is known about glucose, glutamine and fatty acid fate in these cells. ${ }^{107-110}$

\subsection{Cancer-associated fibroblasts}

CAFs are the most abundant cells within tumor stroma. They are recruited by tumor cell-secreted platelet-derived growth factor (PDGF). ${ }^{111}$ It is well known that CAFs promote tumor growth and invasion, although recently published works showed contradictory results regarding intestinal tumorigenesis. ${ }^{112-114}$

Although from now on we will assume the classical view, it should be clear that metabolism and signaling pathways are complex and probably there is not an absolute truth. Bearing this in mind, it has been shown that CAFs resemble myofibroblasts, as they express smooth muscle cell markers and produce transforming growth factor $\beta$ (TGF- $\beta$ ) and stromal cell-derived factor 1 (SDF1). Additionally, CAFs express the migration stimulating factor (MSF), whose overexpression leads to Akt pathway activation, which in turn induces the mTOR signaling pathway. ${ }^{115}$ CAFs expressing MSF showed elevated lactate secretion. ${ }^{115}$ Since mTOR is known to enhance glycolysis, it could be proposed that MSF increases the glycolysis rate in CAFs through mTOR signaling. This high lactate secretion by CAFs is supported by the upregulation of MCT4, a lactate exporter, observed in these cells. ${ }^{116}$ Zhang and colleagues demonstrated that IDH3 $\alpha$, a TCA enzyme, is downregulated in CAFs, and this situation leads to HIF$1 \alpha$ stabilization, resulting in a switch from OXPHOS to glycolysis. ${ }^{117}$ As we will see below, tumor cells could as well induce this glycolysis activation. Moreover, CAFs are also able to take up lactate (secreted by tumor cells) through MCT1, a lactate importer, and to oxidize it. ${ }^{118,119}$

It has been shown that CAFs have a metabolic activity higher than that of other fibroblasts, since they present higher expression levels of glutamine synthetase (GS), of several glycolysis, TCA cycle and ETC gene products, and aspartate and asparagine 
(both required for glutamine synthesis in these cells) transporters. ${ }^{120}$ A summary of CAFs metabolism is presented in Fig. 1. The importance of glutamine and fatty acid synthesis by CAFs in the TME will be discussed later.

\subsection{Tumor-associated macrophages}

Macrophages are a population of immune cells originated from bone marrow-derived monocytes (BMDM) and exhibiting a great heterogeneity in phenotype and functions. These cells help tumors to grow and invade other tissues, promoting tumor progression also by stimulating angiogenesis and inhibiting the immune response. As in the case of CAFs, the energetic metabolism of non-tumoral macrophages has been more studied than that of TAMs.

According to the activation pathway, there are two main subtypes of macrophages: M1 macrophages, activated by the canonical pathway in response to IFN- $\gamma$ and LPS stimulation, and M2 macrophages, activated by an alternative pathway in response to interleukins IL-4, IL-10 and IL-13. M1 macrophages secrete pro-inflammatory cytokines and have an anti-tumoral activity, while M2 macrophages have antiinflammatory properties. Some authors maintain that TAMs share many, but not all, features of M2 phenotype, whereas others did not find M2 markers in TAMs. ${ }^{122-125}$ However, IL-4 is sufficient for TAM polarization after monocyte recruitment by cytokines such as CCL2 and CSF-1. ${ }^{121}$ Moreover, a transcriptome study determined that TAMs shared genes with both M1 and M2 macrophages. ${ }^{126}$

It is well-established that M1 macrophages rely largely on aerobic glycolysis, maybe regulated by itaconate. ${ }^{127}$ M2 macrophages have not remarkable glucose consumption rates. In contrast, high FAO and OXPHOS have been found in these cells. On the other hand, M1 macrophages were found to have enhanced expression of PFKFB3 isoenzyme, whereas alternatively-activated macrophages express it at low rates. ${ }^{128}$ Since PFKFB3 is a signal of high glycolytic rates, as happened in ECs, it can be said that M2 macrophage energy metabolism does not rely on this route. ${ }^{93}$ Another finding suggests that succinate could be a possible indirect modulator of glycolysis. Succinate is able to inhibit PHD, leading to an increased HIF-1 $\alpha$ stabilization, as seen before in other types of cells. ${ }^{129,130}$ This high stabilization of HIF-1 $\alpha$ might have two major consequences at the transcriptional level: i) HIF-1 $\alpha$ can be translocated into the nucleus, together with the glycolytic enzyme PKM2. In the nucleus, HIF-1 $\alpha$ forms a complex with HIF-1 $\beta$ and other regulatory proteins, thus acting as a transcription factor able to activate the expression of key glycolytic enzymes, such as glucose transporter GLUT-1, pyruvate dehydrogenase kinase-1 (PDK1) and LDH-A. ${ }^{131}$ ii) The same transcription factor complex can bind to the pro-inflammatory cytokine IL-1 $\beta$ promoter gene and activate its transcription too. ${ }^{132}$ In summary, succinate would have a role enhancing aerobic glycolysis and the Warburg effect, and promoting IL-1 $\beta$ production. Both characteristics are typical features of classically-activated macrophages. Succinate may 
proceed from the anaplerotic use of glutamine, or be accumulated due to a truncated TCA cycle. Since M2 macrophages obtain energy mainly by means of FAO and OXPHOS, they do not increase succinate levels and the glycolytic pathway is not enhanced in these cells. HIF-1 $\alpha$ can also be activated through the mTOR signaling pathway. Cytokines IL-4 and IL-13, responsible for the alternative activation of macrophages, inhibit mTOR via activation of the negative regulators TSC1 and TSC2. ${ }^{133}$ Therefore, M2 macrophages are predisposed to oxidative metabolism through a glycolysis inhibition via mTOR/HIF- $1 \alpha$ inactivation.

Since M1 macrophages have an anti-tumoral activity, it should be expected that TAMs have a metabolic profile more similar to that of M2 macrophages. ${ }^{134}$ However, recent evidence reveals a high glycolytic rate in TAMs. ${ }^{135,136}$ Moreover, an elevated eicosanoid production has been found in these cells and, on the other hand, inhibition of $\beta$-oxidation did not affect cytokine production in thyroid cancer-induced macrophages, showing the importance of FA synthesis rather than catabolism in TAMs. ${ }^{135,137}$ Regarding amino acid metabolism, TAMs from glioblastoma or exposed to glioblastoma cells present an enhanced expression of genes related to glutamate transport and metabolism (Fig. 1). ${ }^{138}$

Serine has been shown to be an allosteric activator of PKM2. ${ }^{28}$ Therefore, it could seem unlikely that M2 macrophages depend on serine utilization because their metabolism does not rely on an enhanced aerobic glycolysis. However, serine metabolism has been reported as an enriched pathway in M2 macrophages by using LC/MS-based metabolomics. ${ }^{139}$ These last authors also found that Akt/mTORC1 pathway plays a role in increasing glucose metabolism in M2 macrophages as seen by both elevated OCR and ECAR. ${ }^{139}$ Therefore, there are some contradictory results from different groups. However, to our knowledge there is not available data about serine metabolism in TAMs. It would be interesting to further investigate the metabolic phenotype of these cells as well as the signaling pathways that govern them.

\subsection{Tumor-infiltrating lymphocytes}

$\mathrm{T}$ cells represent the most abundant lymphocyte population involved in the adaptive immune system. There are two major types of $\mathrm{T}$ cells: $\mathrm{CD}^{+}$and $\mathrm{CD} 8^{+}$, which are classified into different subtypes. $\mathrm{CD}^{+} \mathrm{T}$ cells often differentiate into cytotoxic $\mathrm{T}$ cells (CTLs), characterized by inducing apoptosis in targeted cells. $\mathrm{CD} 4^{+}$naïve $\mathrm{T}$ cells can become regulatory or suppressor $\mathrm{T}$ cells (Treg cells), which have immunosuppressive functions, or helper T cells (Th cells), a type of effector $\mathrm{T}$ cells that participate in the immune response. There are many subtypes of Th cells, including pro-inflammatory (Th1 and Th17 cells) and anti-inflammatory (Th2 cells) lymphocytes, according to the cytokines secreted by them. Therefore, effector T cells include CTLs and Th cells. Most of tumor-infiltrating lymphocytes (TILs) are Treg cells. 
There is clear evidence that activation of $\mathrm{T}$ cells requires a metabolic switch similar to that undergone by many tumor cells, thus exhibiting the Warburg effect and an elevated aerobic glycolysis. ${ }^{141}$ Something similar happens in the innate immune system. ${ }^{142}$ Nevertheless, this metabolic switch in $\mathrm{T}$ cells and tumor cells is based on different causes: for $\mathrm{T}$ cells, this is a physiological adaptation process, whereas for tumor cells it depends on a series of intrinsic genetic mutations and external responses to the TME. ${ }^{143}$ On the other hand, Treg and memory $\mathrm{CD}^{+} \mathrm{T}$ cells rely on FAO and OXPHOS for its survival and differentiation. Additionally, it has been reported that de novo lipogenesis is required for Treg differentiation from Th17 lymphocytes (Fig. 1). ${ }^{144}$ Effector $\mathrm{T}$ cells, nonetheless, can survive utilizing OXPHOS in case of glucose depletion, although cytokine production is diminished under these conditions. ${ }^{145}$

Phosphoenolpyruvate (PEP) has been related to the T cell receptor (TCR) activation through $\mathrm{Ca}^{2+}$ flux. Ho et al. observed that overexpression of phosphoenolpyruvate carboxykinase 1 (PCK1), the enzyme that catalyzes the conversion of oxaloacetate into $\mathrm{PEP}$, restored PEP levels and $\mathrm{Ca}^{2+}$ flux in glucose-deprived $\mathrm{T}$ cells. This can be explained by the fact that PEP undermines the activity of SERCA, an ER calcium ATPase. Under these conditions, $\mathrm{Ca}^{2+}$ escapes from ER to cytosol, increasing TCRinduced $\mathrm{Ca}^{2+}$ flux and effector function. Moreover, TCR is able to activate glucose metabolism enhancing PKM2 activity, which in turn could contribute to PEP accumulation. $^{146}$ Thus, $\mathrm{T}$ cell effector function would be partially controlled by PCK1 activity.

As for other cell types, mTOR plays a crucial role in T cell metabolism. Inhibition of mTOR results in an induction of AMPK phosphorylation and, consequently, an increase of FAO, leading to differentiation of $\mathrm{CD}^{+}{ }^{+} \mathrm{T}$ cells to Treg. Thus, mTOR would guide these cells to Th1, Th2 and Th17 phenotypes. ${ }^{147,148}$ Programmed death 1 receptor (PD1), an inhibitory checkpoint receptor present in TILs, has an important role in regulating glycolysis through mTOR signaling pathways. This issue will be clarified in sections below.

Dang et al. demonstrated that HIF-1 $\alpha$ is able to induce Th17 differentiation through transcriptional activation of ROR $\gamma \mathrm{t}$. HIF- $1 \alpha$ also binds to Foxp3, targeting it for its degradation and impairing this molecule to promote Treg development. ${ }^{149}$ Therefore, HIF-1 $\alpha$ would promote a glycolytic cell phenotype (by activating Th17 cells) while inhibiting oxidative metabolism (via Treg impairment).

However, glycolysis is not the only pathway necessary for $\mathrm{T}$ cell activation. c-Mycdependent glutaminolysis is also essential for proper $\mathrm{T}$ cell effector function, as it leads to nucleotide and polyamine synthesis, necessary for supporting cell proliferation. ${ }^{150} \mathrm{In}$ addition, glutamine regulates $\mathrm{T}$ cell proliferation as well as it increases IL-2 production and IL-2 receptor expression. ${ }^{151}$ Arginine has also been shown to improve survival and anti-tumor activity of T cells. ${ }^{152}$ An overview of TILs metabolism is presented in Fig. 1. 


\subsection{The tumor microenvironment forgotten cells}

There are many different kinds of cells in the TME, and the ones presented here up to now are just the more abundant and studied. Tumor-associated mast cells (TAMCs) and tumor-associated pericytes are also predominant cells in the TME and have an important role in tumor progression. However, their metabolism, as far as we know, have not been described to date.

\subsubsection{Tumor-associated mast cells}

TAMCs are recruited to tumors in response to stem cell factor (SCF) from tumor cells and other mast cells, as well as to VEGF from tumor cells and immune cells. ${ }^{153}$ TAMCs secrete immunosuppressive cytokines such as TGF- $\beta$ and IL-10, but their more important role in tumor progression is promoting and helping the angiogenic process. ${ }^{154}$ TAMCs produce pro-angiogenic factors such as basic fibroblast growth factor (bFGF) and VEGF, ECM modulators such as matrix metalloproteinases (MMPs) and urokinasetype plasminogen activator (uPA), as well as chimase, tryptase and histamine. ${ }^{155}$ Treatment with compound 48/80, which triggers histamine release, causes an angiogenic response in rats and mice. ${ }^{156}$ Despite the importance of TAMCs in tumor progression, their metabolism has not been studied so far. Nevertheless, several studies have been carried out in non-tumoral mast cells.

In 1965, Chakravarty suggested that rat mast cells had higher glycolytic rates than oxidative ones, and some years later he and others pointed out the importance of glucose metabolism and lactate production for histamine release. ${ }^{157-160}$ However, respiration inhibitors block histamine release, and hence energy is necessary for activation and secretion of histamine. ${ }^{161}$ On the other hand, two different studies demonstrated the inverse correlation between glutamine metabolism and mast cell function, and tryptophan conversion to kynurenine triggers mast cell degranulation. ${ }^{162-}$

${ }^{164}$ Kynurenine, in turn, promotes tumor invasion, further demonstrating the association between mast cell function and tumor progression. ${ }^{165}$

More recent works tried to shed some light on the importance of glucose metabolism for mast cell function. Sekar and co-workers studied NO metabolism in mast cells. They demonstrated that $\mathrm{NO}$ induced tyrosine nitration of aldolase A, inhibiting this glycolytic enzyme, with the consequent accumulation of fructose 1,6-biphosphate (FBP). This accumulation inhibited the degranulation of mast cells. ${ }^{166}$ Enolase, the ninth enzyme of the glycolytic pathway, has been related with mast cell differentiation, and Chakravarty saw in his studies that treatment with fluoride, an enolase inhibitor, diminished the glucose-supported histamine release. ${ }^{158,167}$ Moreover, inhibition of pyruvate dehydrogenase (PDH), the clue enzyme for the TCA, inhibits mast cell degranulation and cytokine secretion. ${ }^{168}$ These last pieces of evidence indicate a glucose-depending mast cell function. However, other works contradict these results. Fc\&RI is a receptor which leads to mast cell degranulation after its ligation with IgE. FceRI has been shown to inhibit PKM2, a process necessary for mast cell degranulation. ${ }^{169}$ Accumulation of 
FBP due to the inhibition of this enzyme ceases degranulation of mast cells. Nevertheless, these last authors mention that accumulation of FBP leads to re-activation of PKM2 and reestablishment of glycolytic normal levels, thus inhibiting mast cell function. ${ }^{169}$ Furthermore, polyamines have been detected in mast cell granules, and treatment with DFMO diminishes histamine intracellular storage and increases PKM2 expression. ${ }^{170}$ This fact establishes a positive relation between polyamine metabolism and degranulation of mast cells with some implication of the glycolytic pathway. Further studies should be performed in order to clarify the exact role of glucose metabolism in mast cell function and its connection with tumor progression.

\subsubsection{Tumor-associated pericytes}

Pericytes are responsible for morphological and functional abnormalities of tumor blood vessels, and interaction between tumor cells and pericytes has been shown to improve malignancy of glioblastoma. ${ }^{171,172}$ Tumor-associated pericytes present greater migration and proliferation rates than normal ones, and hence they are loosely attached to ECs. ${ }^{173}$

Several studies have been carried out in retinal pericytes in the context of diabetic retinopathy, but without exploring glucose metabolism in pericytes. ${ }^{174,175}$ The only work about pericyte metabolism performed to our knowledge demonstrated that lung pericytes from pulmonary arterial hypertension patients presented higher expression of PDK-1, an inhibitor of PDH, than healthy pericytes. ${ }^{176}$ Therefore, it could be considered that normal pericytes display higher rates of OXPHOS than those of glycolysis. Nevertheless, metabolism of tumor-associated pericytes and its relation with tumor progression are yet to be studied.

\section{IMPLICATIONS OF TUMOR AND ACCOMPANYING CELLS METABOLISM FOR TUMOR GROWTH AND PROGRESSION}

In the previous sections, we have reviewed the main metabolic features of different cells within the TME. However, the complex interplays among these different cells and their metabolic features should be also taken into account. It is well-known that tumor stroma contributes to tumor progression. ${ }^{177}$ Several aspects of tumor progression, such as immunosuppression and angiogenesis, depend on the metabolic and signaling pathways involved in them, also orchestrated by interactions of tumor, stromal and immune cells.

\subsection{Tumor metabolism and its contribution to immunosuppression}


Burnet and Thomas formulated the theory of cancer immunosurveillance (also called immunoediting), according to which lymphocytes would recognize and eliminate tumor cells, thus preventing tumor progression. ${ }^{178,179}$ Nevertheless, some cancer cells are able to escape the immune response by enhancing immunosuppressive activity of immune cells. In fact, escaping immune response has been identified as one of the hallmarks of cancer. ${ }^{4}$ Now we know that this immunosuppression is partially controlled by tumor metabolism, and also that of other cells of the TME.

High glucose uptake and lactate secretion have a major role in immunoediting inhibition. As seen above, T cells enhance glycolysis and this improves their effector function. ${ }^{145}$ Many types of tumor cells also present a high glycolytic activity, and thereby they avidly consume glucose. As a consequence, low levels of this molecule would be available in the extracellular media for T cells consumption (Fig. 2), and then effector function would be suppressed. ${ }^{180}$ An illustrative example is that high HK2 expression in tumor cells mitigates the transcription of the gene coding for IFN- $\gamma$, thus contributing to immune response evasion. ${ }^{146}$ IFN- $\gamma$ translation is also regulated by glycolysis through glyceraldehyde 3-phosphate dehydrogenase (GAPDH). When T cells are glucose-restricted, GAPDH becomes available to bind the 3'UTR of IFN- $\gamma$ mRNA, which results in the inhibition of translation of this cytokine. A similar mechanism occurs with IL-2 (Fig. 2). ${ }^{181}$ Furthermore, lactic acid resulting from tumor glycolysis suppresses CTL proliferation, as well as the transcription of IL- 2 and IFN- $\gamma$, leading to a diminished cytotoxicity of these cells. Probably, a high extracellular level of lactic acid could block the lactic acid export, thus inhibiting further lactate production from glycolysis by $\mathrm{T}$ cells. ${ }^{182}$ These observations underscore the relevance of aerobic glycolysis for the effector function of $\mathrm{T}$ cells. Additionally, Treg cells proliferate in response to TGF- $\beta$ from tumors. ${ }^{183}$ As a matter of fact, Treg cells are the most abundant lymphocytes in the TME. Since their energy metabolism relies on FAO and OXPHOS, they are not as vulnerable to glucose deprivation as effector T cells. In turn, Treg immunosuppressive activity contributes to overall immunosuppression within the TME.

PD-1 is an immunoinhibitory receptor expressed by chronically stimulated $\mathrm{T}$ cells. Ahmadzadeh et al., working with metastatic melanoma lesions, found that PD-1 is expressed by TILs at higher levels than those found in normal T cells. ${ }^{183}$ Expression of its ligand, PD-L1, has been reported in several human tumors. ${ }^{185}$ As PD-1/PD-L1 interaction inhibits $\mathrm{T}$ cell proliferation and cytokine production, it could be proposed that TME contributes to a weakened anti-tumor immune response. Different studies have shown that PD-1 expression causes a reduction of glycolysis and a switch to FAO in T cells by suppression of PI3K/Akt. ${ }^{186,187}$ Moreover, recent results have shown that PD-L1 not only inhibits $\mathrm{T}$ cell glycolysis but at the same time is able to enhance this pathway in tumor cells through activation of the Akt/mTOR signaling pathway, depriving glucose availability in the TME and thus increasing even further the glycolysis inhibition in these lymphocytes. ${ }^{25}$ Therefore, the interaction of PD-1 with its ligand PD-L1 results in an inhibition of effector T cell function (Fig. 2). 


\subsection{Tumor and endothelial cell metabolism and its role on angiogenesis}

As soon as 1971, Judah Folkman proposed that inhibiting angiogenesis could be a new and revolutionary therapy against tumor growth based on his own experimental observations from the sixties. ${ }^{191}$ Almost 40 years later, he reviewed the available scientific information regarding a series of different angiogenesis-modulator drugs being developed for the treatment of cancer and other angiogenesis-dependent diseases, therefore reinforcing his early visionary hypothesis and now proposing that angiogenesis could be an organizing principle for drug discovery. ${ }^{192}$ There are many factors that are related to angiogenesis (e.g. VEGF, bFGF, HIF-1 $\alpha$, and many others). Many published reviews have already revised this issue along the years. ${ }^{193-195}$ Nevertheless, limitations of anti-angiogenic therapies, mainly based on the inhibition of EC activation by angiogenic factors, especially VEGF, suggested that alternative antiangiogenic strategies might be considered. ${ }^{196}$ The fact that metabolic reprogramming can control angiogenesis opens new horizons to treat this process under pathological conditions through a metabolic approximation and not just by targeting pro-angiogenic molecules. ${ }^{197}$ In this section we will focus on the main metabolic features that regulate the angiogenic process, but it should be kept in mind that many other factors may interplay in this scenario.

We mentioned before that glycolysis-derived lactate plays a role in angiogenesis. Végran et al. showed that nuclear factor $-\kappa B(N F-\kappa B)$ is involved in this regulation through PHD inhibition. IL-8 is a pro-angiogenic cytokine expressed by ECs. They 
observed that lactate could induce IL-8 expression by these cells in a NF- $\kappa \mathrm{B}-$ dependent manner. A sequence of events leading to this is proposed: lactate would be converted to pyruvate by LDH-B, which indirectly inhibits PHD2 by competition with $\alpha$ ketoglutarate, with the consequent accumulation of IкB kinase (IKK), which phosphorylates inhibitor of kappa $\mathrm{B}(\mathrm{I} \kappa \mathrm{B} \alpha)$, thus liberating the active form of NF- $\mathrm{B}$ and allowing IL-8 transcription. ${ }^{97,198}$ Additionally, PHD inhibition enables the stabilization of HIF-1 $\alpha$ and regulation of its target genes expression. These target genes include those coding for pro-angiogenic effectors such as VEGF and for many metabolic enzymes. HIF-1 $\alpha$ can also indirectly induce VEGFR2 and bFGF expression. Furthermore, all this requires additionally that ECs incorporate extracellular lactate, secreted by tumor cells, through MCT1 transporters. ${ }^{199}$ It has been shown that lactate increases the phosphorylation of Akt, thus promoting the angiogenic process. ${ }^{200}$ VEGF plays an additional role, since it promotes fatty acid uptake by ECs, hence contributing to ECs proliferation and angiogenesis. ${ }^{201}$ Therefore, lactate uptake by ECs would induce angiogenesis through increased IL-8, VEGF, VEGFR2 and bFGF expression and Akt phosphorylation levels (Fig. 4). Furthermore, it has been seen that extracellular lactate produced by ECs acts as a vasoactive signal for pericytes. ${ }^{202}$ It could be possible that lactate secreted by tumor cells could also affect pericyte-mediated vasoconstriction and, thus, angiogenesis.

Moreover, recent studies have uncovered the role of nerve-endothelium interaction on angiogenesis. ECs express $\beta_{2}$-adrenergic receptor $\left(\mathrm{ADR} \beta_{2}\right)$, and its deletion leads to inhibition of angiogenesis. More specifically, $A D R \beta_{2}$ blockade in these cells induce a "reverse metabolic switch" towards OXPHOS, by regulation of COX10, a gene related with a cytochrome IV oxidase (Fig. 4). ${ }^{203,204}$

Finally, it has been recently seen that glutamine and asparagine are essential for angiogenesis. ${ }^{99,100}$ Indeed, glutamine deprivation impairs this process, an effect rescued by the addition of asparagine and $\alpha$-ketoglutarate. Consequently, inhibiting GLS1 and ASNS activities at the same time seems to be a good anti-angiogenic strategy. ${ }^{99}$ Nevertheless, the precise mechanism of these amino acids on the angiogenic switch should be further studied.

\subsection{Cancer-associated fibroblasts: important assistants for tumor invasiveness}

As mentioned above, CAFs rely on enhanced glycolysis. This seems to be due to an enhanced production of ROS by cancer cells. Oxidative stress spreads from cancer cells to adjacent fibroblasts, which reduce their mitochondrial activity and increase glucose uptake, becoming more dependent on aerobic glycolysis (Figs 3 and 4). ${ }^{205}$ In a clear example of cell cooperation within TME, CAFs secrete lactate to the media, and this lactate fuels tumor cells, which deliver it to OXPHOS, obtaining energy to sustain their high proliferative rates, in a phenomenon known as "reverse Warburg effect" (Fig. 3). ${ }^{206}$ 
Likely, this enhanced oxidative stress could induce MCT4 expression in CAFs. Moreover, co-culture of CAFs with MCF7 cells, which mostly rely on oxidative metabolism, results in an increase of MCT1 expression by these tumor cells. Thereby, lactate from CAFs would be incorporated by MCF7 cells, via a lactate shuttle between the stroma (MCT4 in CAFs) and tumor cells (MCT1 in MCF7), in a kind of tumorfeeding mechanism. ${ }^{116}$ Something similar has also been observed in osteosarcoma. ${ }^{207}$

Lactate secreted by CAFs could have the same effects as those of lactate produced by tumor cells. Romero-Garcia et al. reviewed lactate contribution to the TME. From their review, the following should be highlighted: i) lactate ability to induce MMP-9, an enzyme involved in migration and invasion of cells during the angiogenic process (Fig. 4); ii) immunosuppression; iii) expression of pro-angiogenic factors; and iv) activation of ECs through MCT1. ${ }^{208}$ Several of these processes are regulated, at least in part, by MSF expression in CAFs, a cytokine related to tumor growth. ${ }^{115}$ However, some authors have suggested that the effects caused by extracellular acidification are specific of tumor cells. ${ }^{18,120}$ It has been reported that lactate from cancer cells induce hyaluronic acid production by fibroblasts, contributing to tumor invasiveness (Fig. 3). ${ }^{209}$ In addition to this, CAFs express TGF- $\beta$ and SDF-1, which confer them their tumor phenotype, due to the activation of the transcriptional regulator heat shock factor 1 (HSF1), as well as pro-angiogenic features. ${ }^{115,210,211}$ Moreover, since Treg cells proliferate in response to TGF- $\beta$ from tumors, CAF-secreted TGF- $\beta$ could also help the development of immunosuppression (Fig. 2). ${ }^{183}$ It is well known that CAFs promote tumor progression and invasion, in part by secreting multiple molecules involved in ECM remodeling (Fig. 4). ${ }^{212,213}$ Regarding angiogenesis, several available data suggest a connection between CAFs and tube formation. ${ }^{214,215}$

Nonetheless, lactate is not the only metabolite from CAFs that fuels tumor cells. Recent studies have shown that CAFs are able to synthetize glutamine from glutamate, aspartate and alanine, and these cells secrete this glutamine, which is used by cancer cells (Fig. 3). Again, tumor cells are not passive, but they secrete glutamate from glutaminolysis as well as the already mentioned lactate, both contributing to glutamine secretion by CAFs. ${ }^{120}$ This interesting GS/GLS intercellular cycle within the TME deserves to be further explored. On the other hand, fatty acids are also synthetized and secreted by CAFs and taken up by breast tumor cells (Fig. 3), favoring tumor

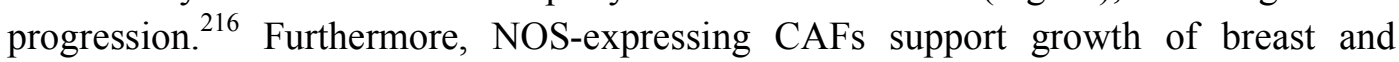
prostate cancer cells, suggesting the relevance of NO metabolism in these cells for tumor progression. ${ }^{217}$

In summary, CAFs contribute to tumor progression by fueling cancer cells, remodeling the ECM, increasing Treg proliferation and promoting angiogenesis, all in all allowing invasiveness.

\subsection{Tumor-associated macrophages and tumor progression}


We have seen that TAMs seem to rely on aerobic glycolysis, secreting large amounts of lactate. As a matter of fact, treatment of these cells with 2-deoxyglucose (2-DG) inhibits their pro-metastatic phenotype. ${ }^{218}$ Interestingly, lactate from tumor cells could help by inducing aerobic glycolysis in TAMs through the Akt/mTOR pathway (Fig. 3). ${ }^{135}$ In addition, tumor cell-derived lactate is able to induce TAM polarization by inducing Fizzl, Mgll and Mgl2 markers via HIF-1 $\alpha$. Additionally, VEGF and arginase 1 (Arg1) are upregulated in these cells also via HIF- $1 \alpha .{ }^{219}$ In the first case, TAMs can be linked to angiogenesis induction. Indeed, a relationship between TAM number and tumor angiogenesis has been documented in breast cancer. ${ }^{220}$ TAMs also produce other molecules involved in the angiogenic process, such as TNF- $\alpha$, which induces MMP-9 expression, uPA, IL-1, which, through cyclooxygenase 2 (COX2), upregulates HIF-1 $\alpha$, increasing transcription of VEGF in turn, and CCL18. ${ }^{221,222}$ Therefore, it is likely that TAMs help to induce tumor angiogenesis (Fig. 4). This pro-angiogenic effect of TAMs has been already seen, along with immunosuppressive features. ${ }^{223}$

Regarding metabolism of arginine, Arg1 has an important role in tumor progression, and participates in polyamine production, necessary for collagen synthesis, cell proliferation and tissue remodeling. ${ }^{219}$ Indeed, some evidence hint that TAMs could contribute to tumor invasion by secreting MMPs. ${ }^{224}$ There is some controversy regarding the presence of iNOS expression in TAMs. iNOS is an enzyme that produces NO from arginine. This enzyme is present in M1 macrophages whereas is absent in M2 macrophages. ${ }^{225}$ Regarding metabolic features of these cells, iNOS is able to block OXPHOS while upregulating the glycolytic rate, and therefore iNOS expression corresponds with M1 and TAM metabolic profiles. ${ }^{226}$ Some authors have found iNOS expression in TAMs while others could not. ${ }^{227,228}$ On the other hand, TAMs could have a role in immunosuppression, since depleting extracellular arginine by Arg1 activity would deprive $\mathrm{T}$ cells of this amino acid, affecting their proliferation. ${ }^{229}$ Moreover, TAMs express high levels of IDO, producing kynurenine (Fig. 3), and this tryptophan degradation impairs $\mathrm{T}$ cell function. ${ }^{230}$ These data reflect the immunosuppressive capacity of TAMs (Fig. 2), and iNOS has an immunosuppressive (as well as antiangiogenic) effect. ${ }^{14}$ Therefore, additional experiments should be performed in order to confirm the involvement of iNOS in these cells.

Furthermore, these macrophages are unable to produce IL-12, a cytokine required to activate the anti-tumor responses mediated by NK cells, Th1 cells and CTLs. Instead, they produce IL-10, inducing Th2 polarization, and these Th2 cells secrete IL-4, promoting M2 polarization to TAMs in a positive-feedback cycle. ${ }^{122} \mathrm{Th} 2$ cells release anti-inflammatory cytokines, so they do not contribute to the anti-tumor immune response. IL-10 secreted by TAMs also increases the number of Treg cells present in epithelial ovarian cancer (Fig. 2). ${ }^{231}$ It has been demonstrated recently that IL-10 inhibits mTOR activation in macrophages, thus leading to a reduction in the glycolytic pathway and ROS liberation from damaged mitochondria. ${ }^{232,233}$ Since mTOR inhibition promotes Treg cell differentiation, a relationship between IL-10 from TAMs and mTOR in tumor progression may be established. ${ }^{148}$ 
In addition, as tumor cells, TAMs also express PD-L1, contributing to immunosuppression (Fig. 2). ${ }^{234}$ Lactate secreted by cancer cells is able to increase IL-23 secretion by TAMs, a tumor-promoting cytokine involved in the generation of Th17 cells, thus contributing to tumor progression. ${ }^{235}$

Fatty acid and glutamine metabolism in TAMs are also important for tumor progression. For example, an elevated FA biosynthesis, uptake or storage contributes to the pro-tumorigenic profile of these cells. ${ }^{225}$ On the other hand, TAMs show high levels of GS expression, thus liberating glutamine to the media for feeding tumor cells and contributing to nitrogen metabolism in these cells, as CAFs do (Fig. 3). ${ }^{138,219}$

All these facts indicate that TAMs can help tumor cells to evade the immune response, to trigger tumor angiogenesis and to promote invasiveness.

\subsection{Other examples of "friendly neighbors" of tumors}

Not mentioned above, ECs are able to help tumor cells within the TME. For example, they can extrude mitochondria to tumor cells through tunneling nanotubes and thus they can acquire resistance to chemotherapy (Fig. 3) ${ }^{236}$ However, the already mentioned stromal cells are not the only ones able to help tumors to grow. Depending on the type of cancer, there can be other cells that feed tumor cells. They could be called "friendly neighbors", as in the title of a comment regarding a letter which described the alanine release from pancreatic stellate cells to tumor cells in the pancreas. ${ }^{237,238}$ Some mesenchymal stromal cells have been shown to take up cystine and convert it into cysteine, which is released and taken up by tumor cells from chronic lymphocytic leukemia (CLL). These cancer cells use this cysteine for glutathione (GSH) synthesis, involved in cell survival and resistance to drug cytotoxicity. ${ }^{239}$ As CAFs and TAMs do, adipocytes in pancreatic cancer synthetize and secrete glutamine to the media and thus they can feed tumor cells. ${ }^{240}$ But that is not all: it has been seen in several types of cancer that adipocytes release fatty acids that are used as fuels by tumor cells, thus contributing to invasiveness, as in the case of CAFs. ${ }^{241-244}$ Moreover, NO-mediated Snitrosylation triggers adipocyte formation, thus providing tumor cells a source of fatty acids. ${ }^{245}$ In addition, adipocytes also secrete arginine that are used by tumor cells to NO synthesis, and the resulting citrulline is taken up by adipocytes in a cross-talk between both cells (Fig. 3). ${ }^{190}$

\section{HOST METABOLISM ALTERATIONS AFTER TUMOR DEVELOPMENT}

We have already revised some features and implications of the metabolism of the cells within the TME. However, it should not be forgotten that this TME is just a small 
part of the organism bearing the tumor. Tumor angiogenesis developed by ECs in the TME allows the secretion of several soluble factors to the circulation, which leads to pathological endocrine effects and an interaction of this microenvironment with the rest of the tissues. So, we cannot just talk about a TME, but a tumor macroenvironment should be as well (or even more importantly) considered, since cancer-associated systemic syndromes develop in this disease. ${ }^{246}$

The concept of the "systemic effect" was firstly proposed by Shapot. He affirmed that all malignant tumors alter host homeostasis and metabolism even in the absence of metastasis, whereas benign tumors do not share this property. ${ }^{247} \mathrm{He}$ distinguished between two manifestations of this systemic effect: i) the alteration of the host metabolism by competence of the tumor with host tissues, and ii) a dysregulation of endocrine gland activities and, therefore, a diminished sensitivity to hormones. ${ }^{247}$ Recently, the concept of solid tumors as systemic metabolic dictators has been proposed. $^{248}$

The most classical feature of tumors in the context of their interaction with the host is the concept of tumors acting as "nitrogen traps". As early as 1889, Müller observed a negative nitrogen balance in patients with malignant tumors. ${ }^{\text {referred in } 249}$ Nevertheless, the concept of nitrogen trap was firstly demonstrated by Mider. ${ }^{250}$ Moreover, because glutamine is the most abundant amino acid in blood, some authors consider tumors as "glutamine traps". ${ }^{251}$ Early results obtained by our group in Ehrlich ascites tumors suggested that tumors elicit a specific response from the host tissues, so that the whole organism contributes to supply glutamine to the tumor. ${ }^{33}$ Indeed, glutamine content in the host decreases in fast growing tumors due to a flux of glutamine from the host to the tumor, low or null GS activity in the tumor and faster transport of glutamine through the plasma membrane of tumor cells in comparison with non-tumor cells (Fig. 5). ${ }^{12,252}$ There is the exception of some tumors that present a GS upregulation as an adaptation to glutamine depletion, a feature that is not specific to tumor cells. ${ }^{253,254}$ In spite of the importance of glutamine for tumors, changes in concentrations of other amino acids are also observed in plasma after tumor transplantation due to the host-tumor interaction. ${ }^{255}$

This nitrogen trap may have other effects in the organism. For example, it has been seen that tumors intercept uridine from lymphoid organs, thus inhibiting RNA synthesis, and DNA synthesis is suppressed in the spleen of tumor-bearing mice. ${ }^{256,257}$ Due to the avid host glutamine consumption by the tumor, concentration of glutathione in natural killer cells diminishes, with the consequent loss of activity of these cells. ${ }^{258}$ All these data support that tumors acting as glutamine traps also compromise the immune system response and, therefore, there is an immunosuppression helped by the alteration of nitrogen metabolism in the host (Fig. 5). Some authors have observed that an oral supplement of glutamine in the diet can have benefits in tumor-bearing animals and cancer patients, although a consensus about this has not been achieved. ${ }^{259,260}$

But tumors not only take nitrogen from the diet. They are also able to take it from host tissues with the consequent body weight loss. ${ }^{250,261}$ However, tumor grows to a 
lesser extent when there is no nitrogen available from the diet. ${ }^{262}$ This loss in body weight leads to cancer-associated cachexia. ${ }^{263}$ Nitrogen from host tissues proceeds from protein catabolism, stimulated by an upregulated production of adrenocortical hormones $(\mathrm{ACH})$ resulted from a dysregulation of the endocrine system (Fig. 5). ${ }^{264}$ This dysregulation can lead to other harmful effects in the organism, such us thrombosis and immunosuppression. ${ }^{265,266}$ Now we know that this upregulation of glucocorticoid production is caused by IL- 6 secretion from the tumor through inhibition of some hepatic functions such as ketogenesis (Fig. 5). ${ }^{267}$ As a matter of fact, inhibition of IL-6 diminishes tumor growth and cachexia. ${ }^{268}$

It has been seen that IL- 6 from lung adenocarcinoma is able to inhibit another characteristic of liver metabolome, such as hepatic insulin signaling. ${ }^{269}$ This insulin resistance contributes to protein catabolism and induction of glucogenolisis and gluconeogenesis (Fig. 5). Indeed, gluconeogenesis is induced by glucocorticoids after tumor transplantation, and lower levels of glycogen are found in the liver of tumorbearing animals. ${ }^{249,270}$ Glucose can be synthetized from gluconeogenic amino acids. These amino acids include glutamine, which is used mainly in kidneys, and alanine, used almost exclusively by the liver. ${ }^{271} \mathrm{~A}$ significant part of this gluconeogenic glutamine comes from catabolism of muscle proteins, which reflects the correlation between cachexia and gluconeogenesis. ${ }^{272}$ Very recently, a study of plasma metabolome from breast cancer patients revealed a positive correlation between lactate, pyruvate and alanine levels, and a negative correlation of pyruvate and alanine with glucose. ${ }^{273}$ This corresponds with the Cori cycle, an inter-system cycle active in tumor patients: lactate released from cancer cells, but also from muscles, goes to the liver, as well as alanine from muscle, and these metabolites are used in gluconeogenesis in that organ, increasing the glucose available for cancer cells and their stroma, and thus enhancing tumor malignancy and associated body weight loss (Fig. 5). ${ }^{274}$ Moreover, the use of amino acids for gluconeogenesis limits the protein synthesis in the host, contributing to vital organs dystrophy. ${ }^{249}$ Indeed, a low amount of membrane-bound ribosomes and a defect of the small subunit of ribosomes in muscle were found in tumor-bearing animals. $^{275,276}$

Due to the Warburg effect, many tumors depend on aerobic glycolysis. For that reason, tumors can also be considered as "glucose traps". ${ }^{249}$ The consequent decrease in glucose levels due to its consumption by the tumor is, in part, responsible for the upregulated glycogenolysis and gluconeogenesis. But that is not all. Administration of additional glucose inhibits fatty acid mobilization in the host, showing a modulation of fatty acid metabolism due to glucose depletion caused by the tumor. ${ }^{277}$ As a matter of fact, lipid catabolism in adipocytes promotes cancer-associated cachexia in tumorbearing mice. ${ }^{278}$ This mobilization of fatty acids could also be associated with fatty acid synthesis in tumors, as serum levels of fatty acids were found to be lower in tumorbearing mice as compared to the controls (Fig. 5). ${ }^{279}$ 
Interestingly, supplementation of arginine in the diet inhibits body weight loss and diminishes tumor growth as well as nitrogen trapped by the tumor. On the one hand, increased leucine oxidation due to additional, available arginine leads to a decrease in protein catabolism. ${ }^{280}$ On the other hand, arginine is able to activate the immune system, with the consequent reduction of tumor growth. ${ }^{281}$ Nowadays we know the importance of arginine in T cells activity. ${ }^{152} \mathrm{We}$ would like to highlight the use of arginine for polyamine synthesis, a process enhanced in tumors that could be hence responsible for immunosuppression by depleting extracellular arginine (Fig. 5).

Other amino acids can be taken up by tumors from host tissues. A flux of several essential amino acids, such as valine, leucine, isoleucine, phenylalanine, lysine and arginine, as well as the sulfur amino acid methionine, was observed in Ehrlich carcinoma-bearing mice. ${ }^{255}$ Regarding methionine flux, this could be explained by the active polyamine biosynthesis in the tumor, also demonstrated by the observation of a net flux of ornithine from host to tumor and an increase in ODC activity in the seventh day after tumor transplantation in the same animal model (Fig. 5). ${ }^{282}$ Moreover, tumors can take cysteine and incorporate it through CD44 in order to synthetize glutathione. It has been seen that CD44 interacts with PKM2, increasing the Warburg effect. Therefore, inhibition of this cell marker leads to an increased glucose oxidation and reduced glutathione levels in tumor cells, enhancing the oxidative damage in these cells. $^{283}$

In addition of inducing protein catabolism in the host and hence acquiring amino acids, Ras-mutant tumor cells are able to incorporate extracellular proteins (mostly serum albumin) by macropinocytosis, and to obtain amino acids from their lysosomal degradation for sustaining cell proliferation even in the absent of extracellular glutamine. ${ }^{284,285}$ Indeed, Holm et al observed that the amount of nitrogen excreted in colorectal cancer was 10-fold higher than the equivalent amino acid uptake, pointing out the possible incorporation of extracellular proteins. ${ }^{286}$ PIKfyve has been demonstrated to promote recovery and redistribution of nutrients from vacuoles after lysosomal degradation of engulfed proteins, thus supporting Ras-mutant cell proliferation. ${ }^{287}$ On the other hand, an input of amino acids results in mTORC1 activation, which inhibits lysosomal catabolism of extracellular proteins. ${ }^{288}$ Besides, oncogene Ras does not only induce macropinocytosis of extracellular proteins, but it also induces lipid scavenging, thus conferring resistance to inhibition of stearoyl-CoA desaturase 1 (SCD1), a key enzyme in fatty acid metabolism. ${ }^{289}$ Novel therapeutic strategies are emerging based on these discoveries. For example, drug conjugation with albumin (e.g. paclitaxel) increases intratumoral drug concentration and enhances anti-tumoral activity. ${ }^{290,291}$ mTORC1 inhibitors have sometimes failed in suppressing tumor growth. Combination of mTORC1 inhibitors with blockade of extracellular proteins macropinocytosis or PIKfyve inhibitors could be a promising combined strategy for Ras-mutant tumors. ${ }^{287,288}$ 
In summary, host-tumor interactions and the presence of extracellular substrates are of great importance for tumor progression, and metabolism plays an essential role. Despite the relevance of host metabolism in tumors, just a few studies have been performed in the last years, and the vast majority of research regarding this issue is previous to the present century. Therefore, more research would be necessary in order to improve treatment for cancer patients taking into account the whole organism homeostasis.

\section{TARGETING METABOLISM OF TUMOR MICROENVIRONMENT CELLS FOR CANCER THERAPY}

The "re-discovery" of the Warburg effect and increased glutaminolysis and the identification of tumor metabolism reprogramming as a hallmark of cancer renewed the interest in cancer metabolism after decades of oversight and has led to a renewed interest in targeting tumor metabolism in the last two decades. Many compounds targeting cancer metabolism have been tested in vitro, in vivo and in clinical trials. These compounds include glycolysis inhibitors like 2-DG, lonidamine, 3bromopyruvate and dichloroacetate and inhibitors of GLS such as 968, BPTES and other glutamine analogues, including DON, acivicin and azaserine, among many others. $^{7,11-13}$ However, the search for anti-glutamine cancer therapies, despite good results in in vivo models, was soon forgotten. ${ }^{292}$ A renewed interest in these agents has been recently triggered by the observation that GLS inhibitors may help to overcome acquired resistance to anti-tumor drugs in ovarian and non-small-cell lung cancer. ${ }^{293-296}$ Inhibiting polyamine metabolism has also been shown to decrease tumor growth, and its targeting is considered of great relevance for cancer therapy. ${ }^{85,297}$ Additionally, treatment using asparaginase has been proved to be useful against leukemia. Moreover, this enzyme has a well-known immunosuppressor role, that can be explained by an almost undetectable ASNS activity in lymphoid tissues and the glutaminase activity presented in most asparaginases. ${ }^{298-300}$ Therefore, since treatment with asparagine inhibits $\mathrm{T}$ cell activation as well as cytokine production and proper function of M1 macrophages, it should be taken into account that targeting asparagine metabolism in tumors could also affect the immune system. ${ }^{301,302}$

Furthermore, the concept of "oncometabolites" has opened a new window for tumor treatment. We could define the term oncometabolite as a molecule from normal metabolism that is able to allow tumor progression through its accumulation due to a metabolic dysregulation. The best and first known oncometabolite is 2-HG, which causes changes in gene function in tumors by epigenetic regulation. ${ }^{43}$ One of the consequences of the accumulation of $2-\mathrm{HG}$ to limit the production of chemokines CXCL9 and CXCL10, so preventing $\mathrm{CD}^{+} \mathrm{T}$ cell recruitment to the tumor, for example. ${ }^{303}$ In the last years, efforts to inhibit the newly gained function of the mutant IDH enzymes (IDH1 and IDH2) have led to the development of IDH inhibitors which 
are already in clinical trials. ${ }^{304-306}$ Other molecules are also considered as oncometabolites, and their targeting should also be researched. ${ }^{307,308}$

However, in the last years alternatives have emerged with the new understanding of the complex metabolic interactions within the TME. As we have shown above, overall TME metabolic features are sometimes determined by cytokines or pro-angiogenic factors production. In fact, chemoresistance is sometimes enhanced due to interactions with stromal cells and components of the ECM. ${ }^{309}$ On the other hand, it is known that non-tumor cells are genetically more stable than tumor cells, and thus it is less likely that these cells could develop adaptive mutations to treatments. ${ }^{224}$ Therefore, targeting metabolism of TME stromal cells, instead of tumor cell metabolism or in addition to it, could be a promising strategy against tumor progression.

Since metabolism and angiogenesis are related, it could be expected that metabolic modulators were also able to affect different steps of the angiogenic process. Among other examples, 3-bromopyruvate, an inhibitor of hexoquinase, and a-cyano-4hydroxycinnamic acid (CHC), which blocks MCT lactate transporter, inhibit angiogenesis in HUVEC. ${ }^{310}$ 2-DG, the most well-known glycolytic inhibitor, inhibits angiogenesis in vitro and in vivo. ${ }^{311}$ The glycolytic pathway is not the only possible target. For instance, acivicin, a glutamine analogue, disrupts angiogenesis in vivo, and chloroquine, a GDH inhibitor, enhances the anti-angiogenic effect of sunitinib. ${ }^{312,313}$ In addition, some statins, HMG-CoA reductase inhibitors that affect metabolism of cholesterol, and DFMO, an inhibitor of ODC, involved in polyamine metabolism, are capable of suppressing the angiogenic process. ${ }^{314-316}$

Recently, three articles simultaneously published in Cell Reports have demonstrated that the induction of metabolic symbiosis could be responsible for acquired resistance to anti-angiogenic drugs. ${ }^{317-319}$ Treatment with inhibitors of angiogenesis, including sunitinib, may give rise to an extensive vascular collapse that will produce hypoxic and normoxic regions in the tumor. In the hypoxic cancer cells, HIF-1 $\alpha$ induction will upregulate GLUT1 and MCT4, leading to high levels of lactate secretion. This lactate will be imported by the normoxic cancer cells, which express the lactate transporter MCT1, and catabolized with consequent induction of mTOR signaling to promote tumor metabolism. In this way, normoxic cancer cells save glucose for the hypoxic cells and use the lactate produced by hypoxic cells in conjunction with glutamine. ${ }^{317}$ Targeting metabolic symbiosis may therefore be a new strategy to overcome the resistance development to anti-angiogenic therapy in patients.

Targeting EC metabolism could be, as well, a way to inhibit tumor angiogenesis. ${ }^{197}$ Inhibition of PFKFB3 and pharmacological blockade of MCT1 disrupt angiogenesis in vitro and in vivo, and LDH-A inhibition impairs proliferation of pulmonary microvascular ECs. ${ }^{93,199,320}$ Indeed, taking EC metabolism as a target for modulating pathological angiogenesis may improve chemotherapy, as seen for a PFKFB3 inhibitor, 3-PO, which impairs metastasis without affecting proliferation of tumor cells. ${ }^{321}$ After uncovering the importance of fatty acid metabolism in ECs, targeting fatty acid 
synthesis and oxidation is emerging as a novel therapeutic approach to inhibit EC metabolism and angiogenesis. ${ }^{106,322}$ Furthermore, etomoxir, a CPT1a inhibitor, represses angiogenesis. ${ }^{106}$ Glutamine and asparagine metabolism are also emerging targets for inhibition of the angiogenesis process. ${ }^{99,100}$

Many anti-angiogenic compounds are available and already approved for their use in patients. ${ }^{192,323}$ Moreover, a combinatory strategy is also being explored, since sometimes anti-angiogenic therapy may be not enough to treat tumors. ${ }^{5}$ This antiangiogenic therapy could result in i) the recovery of the normal perfusion in tissue, with the consequent reduction in hypoxia and an improvement of the immunosupportive immune system, ii) no change or iii) excessive pruning of the vasculature, with a decrease in blood flow and an increase in hypoxia. ${ }^{324}$ Therefore, its combination with metabolic modulators or with immunotherapy could improve the treatment. ${ }^{324-326}$

The use of inhibitors of lactate transport and production could be a good strategy to target the reverse Warburg effect in stromal cells, and not just lactate metabolism in tumor cells. An inhibitor of MCT1 (AZD3965) is already in phase I trials to this aim. ${ }^{327}$ Similarly, metformin can also be used to target stromal cells in addition of tumor cells. It has been shown that this drug can block lipid accumulation in ovarian cancer cells adjacent to adipocytes, and reverse the malignant phenotype of CAFs by restoring caveolin-1 expression in these cells. ${ }^{328,329}$ Other possibilities are targeting GS in CAFs, as well as GLS in tumor cells, in order to avoid glutamine transfer from CAFs to cancer cells. ${ }^{120}$ Other suggested therapies based on targeting stromal cell metabolism (such as CAFs and CAAs) are collected in the bibliography. ${ }^{330}$

The denominated checkpoint blockade therapy using antibodies against PD-L1 has emerged as a strategy to restore glucose in the TME and recover T cell effector function in order to suppress tumor progression. ${ }^{25}$ Since tumor and $\mathrm{T}$ cells share many metabolic features, targeting their metabolism can have undesired effects. For example, administration of mTOR inhibitors can either promote effector T cells or inhibit them. Furthermore, blocking glycolysis could affect $\mathrm{T}$ cell metabolism and lead to a poor prognosis of cancer. However, the use of glycolytic inhibitors before the induction of an immune response may allow T cells to enter a TME with higher glucose concentration, favoring a proper anti-tumor immune response. ${ }^{15}$ Combining an anti-metabolic strategy with a checkpoint blockade therapy could improve the $\mathrm{T}$ cell function and cancer prognosis. For example, it has been reported that targeting CD73 in tumors enhances the efficacy of anti-PD-1 and anti-CTLA-4 treatments. ${ }^{331}$

Anti-tumor T cell function can be also partially recovered by inhibiting Arg1 with tadalafil. ${ }^{14}$ Inhibitors of IDO have been proposed to restore $\mathrm{T}$ cell proliferation and cytokine production, and dimethylfumarate (DMF), an anti-angiogenic compound, is able to inhibit IDO activity in human immune cells. ${ }^{17,332,333}$ Moreover, very recently an inhibitor of IDO, erianin, has also been shown to inhibit tumor angiogenesis. ${ }^{334}$ 
In summary, targeting stromal cell metabolism and development of immunotherapy with metabolism as a target may improve cancer therapies by inhibiting angiogenesis and recovering anti-tumor immune response, leading to tumor regression. Several compounds able to modulate metabolic features with proved anti-tumor activity are collected in Table 1. However, it is always important to be careful with secondary effects and to make sure that normal metabolism is not affected by the treatment. Further research will be necessary to progress on cancer treatment via inhibition of the TME metabolism.

\section{CONCLUDING REMARKS AND OUTSTANDING QUESTIONS}

In this review we have tried to explore metabolism within the TME and how it affects tumor growth and progression. Four major kinds of cells have been analyzed: ECs, TILs, CAFs and TAMs, apart from tumor cells. Summarizing, all these cells rely mainly on aerobic glycolysis with the exception of Treg cells, which mainly depend on an oxidative metabolism. Lactate production by tumor cells would contribute to promote tumor angiogenesis via NF- $\mathrm{KB}$ and HIF-1 $\alpha$ stabilization. TAMs and CAFs also collaborate by secreting pro-angiogenic factors. During tumor progression a process termed immunosuppression occurs, by which $\mathrm{T}$ cells are unable to exert a proper antitumor immune response. Tumor cells, by glucose competition and lactate secretion, as well as other metabolic features of these and other cells, are responsible for this. PD1/PD-L1 interaction is also a way to immunosuppression, in which tumor cells, $\mathrm{T}$ cells and TAMs are implicated. CAFs also fuel tumor cells by a phenomenon called reverse Warburg effect and by glutamine synthesis and secretion, along with TAMs and CAAs.

Although in this review we have focused on the changes regarding metabolism in the TME, metabolism is considered a complex and dynamic network able to adapt in response to shifts and metabolic demands. ${ }^{330}$ Therefore, cancer metabolic reprogramming is just an example of the flexibility and adaptability of metabolism. Circadian rhythms, hypoxia, exercise, hibernation period and many other factors are able to modulate gene expression and metabolic features of healthy cells. ${ }^{335-338}$ The lactate shuttle between tumor cells and other cells of their microenvironment is also present in healthy tissues, such as muscle and brain. ${ }^{339-342}$ Moreover, it has been recently demonstrated that there are also changes in metabolism during developmental progression and not just during differentiation, and a loss of metabolic flexibility could lead to pathologies associated to metabolic syndrome. ${ }^{343}$ Actually, this metabolic flexibility is not only found in animals, but in all organisms. Plants, for example, are able to modify their metabolism in response to environmental stress. ${ }^{344,345}$ Due to this metabolic flexibility, tumors can modulate the metabolism of the tissues in the so-called systemic effect. Therefore, not only metabolism of the sole TME, but also the changes in the metabolism of the whole organism triggered by the tumor should be studied. 


\section{NOTES ADDED IN PROOF}

During the revision period of this article a study showing an interaction between metabolic reprogramming and transcriptional regulation has been published. Dasgupta et al. have shown that the metabolic enzyme 6-phosphofructo-2-kinase/fructose-2,6biphosphatase 4 (PFKFB4) regulates transcriptional programming by activating the oncogenic steroid receptor coactivator-3 (SRC-3) through its phosphorylation at serine 857. An active glucose metabolism allows this phosphorylation, which leads to upregulation of some of the key enzymes of the pentose phosphate pathway (PPP). This activation of purine metabolism is essential for tumor growth and metastasis in breast cancer models, since ablation of SRC-3 or PFKFB4 leads to a decrease in cell growth and the metastatic progression of the disease. ${ }^{431}$ Another enzyme of the same family, PFKFB3, was shown to be involved in angiogenesis. ${ }^{93}$ Hence, we would like to remark the importance of metabolism in the development of diseases such as cancer and angiogenic-dependent pathologies through different mechanisms. 
We have also become aware of the approval by FDA of enasidenib for the treatment of oncologic patients with tumor $I D H 2$ gene mutations. ${ }^{432}$

\section{References}

1. Warburg O. The metabolism of carcinoma cells. J Cancer Res 1925;9:148-163.

2. Warburg O. On the origin of cancer cells. Science 1956;123(3191):309-314.

3. Gatenby RA, Gillies RJ. Why do cancers have high aerobic glycolysis? Nat Rev Cancer 2004;4:891-899.

4. Hanahan D, Weinberg RA. Hallmarks of cancer: The next generation. Cell 2011;144:646-674.

5. Quesada AR, Medina MA, Alba E. Playing only one instrument may be not enough: Limitations and future of the antiangiogenic treatment of cancer. BioEssays 2007;29:1159-1168.

6. Nyberg P, Salo T, Kalluri R. Tumor microenvironment and angiogenesis. Front Biosci 2008;13:6537-6553.

7. López-Lázaro M. A new view of carcinogenesis and an alternative approach to cancer therapy. Mol Med 2010;16(3-4):144-153.

8. Moreno-Sánchez R, Rodríguez-Enríquez S, Marín-Hernández A, Saavedra E. Energy metabolism in tumor cells. FEBS J 2007;274:1393-1418.

9. Pelicano H, Martin DS, Xu RH, Huang P. Glycolysis inhibition for anticancer treatment. Oncogene 2006;25:4633-4646.

10. Schulze A, Harris AL. How cancer metabolism is tuned for proliferation and vulnerable to disruption. Nature 2012;491(7424):364-373.

11. Vander Heiden MG. Targeting cancer metabolism: a therapeutic window opens. Nat Rev Drug Discov 2011;10:671-684.

12. Medina MA, Sánchez-Jiménez F, Márquez J, Quesada AR, Núñez de Castro I. Relevance of glutamine metabolism to tumor cell growth. Mol Cell Biochem 1992;113:1-15.

13. Katt WP, Cerione RA. Glutaminase regulation in cancer cells: a druggable chain of events. Drug Discov Today 2013;19(4):450-457.

14. Buqué A, Bloy N, Aranda F, et al. Trial Watch-Small molecules targeting the immunological tumor microenvironment for cancer therapy. Oncoimmunology 
2016;5(6):e1149674.

15. Chang $\mathrm{CH}$, Pearce EL. Emerging concepts of $\mathrm{T}$ cell metabolism as a target of immunotherapy. Nat Immunol 2016;17(4):364-368.

16. Noy R, Pollard JW. Tumor-Associated Macrophages: From Mechanisms to Therapy. Immunity 2014;41(1):49-61.

17. Mockler MB, Conroy MJ, Lysaght J. Targeting T cell immunometabolism for cancer immunotherapy; understanding the impact of the tumor microenvironment. Front Oncol 2014;4:107.

18. Pavlova NN, Thompson CB. The emerging hallmarks of cancer metabolism. Cell Metab 2016;23:27-47.

19. Dell' Antone P. Energy metabolism in cancer cells: How to explain the Warburg and Crabtree effects? Med Hypotheses 2012;79:388-392.

20. Arora R, Schmitt D, Karanam B, Tan M, Yates C, Dean-Colomb W. Inhibition of the Warburg effect with a natural compound reveals a novel measurement for determining the metastatic potential of breast cancers. Oncotarget 2015;6(2):662-678.

21. Guppy M, Leedman P, Zu X, Russell V. Contribution by different fuels and metabolic pathways to the total ATP turnover of proliferating MCF-7 breast cancer cells. Biochem J 2002;364:309-315.

22. Chen Z, Odstrcil E a, Tu BP, McKnight SL. Restriction of DNA replication to the reductive phase of the metabolic cycle protects genome integrity. Science 2007;316:1916-1919.

23. Lunt SY, Vander Heiden MG. Aerobic glycolysis: Meeting the metabolic requirements of cell proliferation. Annu Rev Cell Dev Biol 2011;27:441-464.

24. Vander Heiden MG, Cantley L, Thompson C. Understanding the Warburg effect: The metabolic requiremetns of cell proliferation. Science 2009;324(5930):10291033.

25. Chang $\mathrm{CH}$, Qiu J, O'Sullivan $\mathrm{D}$, et al. Metabolic competition in the tumor microenvironment is a driver of cancer progression. Cell 2015;162:1-13.

26. Laing RE, Nair-Gill E, Witte ON, Radu CG. Visualizing cancer and immune cell function with metabolic positron emission tomography. Curr Opin Genet Dev 2010;20(1):100-105.

27. Reitzer LJ, Wice BM, Kennell D. Evidence that glutamine, not sugar, is the major energy source for cultured HeLa cells. J Biol Chem 1979;254(8):2669- 
2676.

28. Gentric G, Mieulet V, Mechta-Grigoriou F. Heterogeneity in cancer metabolism: new concepts in an old field. Antioxid Redox Signal 2016;0(0):1-24.

29. Pérez-escuredo J, Hée VF Van, Sboarina M, et al. Monocarboxylate transporters in the brain and in cancer. Biochmica Biophys Acta 2016;1863:2481-2497.

30. Hui S, Ghergurovich JM, Morscher RJ, et al. Glucose feeds the TCA cycle via circulating lactate. Nature 2017;551:115-118.

31. Lu W, Pelicano H, Huang P. Cancer metabolism: Is glutamine sweeter than glucose? Cancer Cell 2010;18:199-200.

32. Carrascosa JM, Martínez P, Núñez de Castro I. Nitrogen movement between host and tumor in mice inoculated with Ehrlich ascitic tumor cells. Cancer Res 1984;44:3831-3835.

33. Quesada AR, Medina MA, Márquez J, Sánchez-Jiménez FM, Núñez de Castro I. Contribution by host tissues to circulating glutamine in mice inoculated with Ehrlich ascites tumor cells. Cancer Res 1988;48:1551-1553.

34. Segura JA, Medina MA, Alonso FJ, Sanchez-Jimenez F, Núñez de Castro I. Glycolysis and glutaminolysis in perifused Ehrlich ascites tumour cells. Cell Biochem Funct 1989;7(1):7-10.

35. DeBerardinis RJ, Cheng T. Q's next: The diverse functions of glutamine in metabolism, cell biology and cancer. Oncogene 2010;29(3):313-324.

36. Filipp F V, Ratnikov B, De Ingeniis J, Smith JW, Osterman AL, Scott DA. Glutamine-fueled mitochondrial metabolism is decoupled from glycolysis in melanoma. Pigment Cell Melanoma Res 2012;25(6):732-739.

37. DeBerardinis RJ, Mancuso A, Daikhin E, et al. Beyond aerobic glycolysis: Transformed cells can engage in glutamine metabolism that exceeds the requirement for protein and nucleotide synthesis. Proc Natl Acad Sci 2007;104(49):19345-19350.

38. Spinelli JB, Yoon H, Ringel AE, Jeanfavre S, Clish CB, Haigis MC. Metabolic recycling of ammonia via glutamate dehydrogenase supports breast cancer biomass. Science 2017.

39. Floor SL, Dumont JE, Maenhaut C, Raspe E. Hallmarks of cancer: Of all cancer cells, all the time? Trends Mol Med 2012;18(9):509-515.

40. Elia I, Schmieder R, Christen S, Fendt S-M. Organ-specific cancer metabolism and its potential for therapy. Handb Exp Pharmacol 2016;(233):321-353. 
41. Eason K, Sadanandam A. Molecular or metabolic reprograming: what triggers tumor subtypes? Cancer Res 2016;76(18):5195-5200.

42. Ruiz-Pérez MV, Sánchez-Jimenez F, Alonso FJ, Segura JA, Márquez J, Medina MA. Glutamine, glucose and other fuels for cancer. Curr Pharm Des 2014;20(15):2557-2579.

43. Yun J, Johnson JL, Hanigan CL, Locasale JW. Interactions between epigenetics and metabolism in cancers. Front Oncol 2012;2:163.

44. Vasudevan D, Bovee RC, Thomas DD. Nitric oxide, the new architect of epigenetic landscapes. Nitric Oxide 2016;59:54-62.

45. Bloch-Frankenthal L, Langan J, Morris HP, Weinhouse S. Fatty acid oxidation and ketogenesis in transplantable liver tumors. Cancer Res 1965;25:732-736.

46. Caro P, Kishan AU, Norberg E, et al. Metabolic signatures uncover distinct targets in molecular subsets of diffuse large B cell lymphoma. Cancer Cell 2012;22:547-560.

47. Fields ALA, Wolman SL, Cheema-Dhadli S, Morris HP, Halperin ML. Regulation of energy metabolism in Morris hepatoma 7777 and 7800. Cancer Res 1981;41:2762-2766.

48. Tisdale MJ, Brennan RA. Metabolic substrate utilization by a tumour cell line which induces cachexia in vivo. Br J Cancer 1986;54:601-606.

49. Beloribi-Djefaflia S, Vasseur S, Guillaumond F. Lipid metabolic reprogramming in cancer cells. Oncogenesis 2016;5:e189.

50. Shurbaji MS, Kalbfleisch JH, Thurmond TS. Immunohistochemical detection of a fatty acid synthase (OA-519) as a predictor of progression of prostate cancer. Hum Pathol 1996;27(9):917-921.

51. Rashid A, Pizer ES, Moga M, et al. Elevated expression of fatty acid synthase and fatty acid synthetic activity in colorectal neoplasia. Am $J$ Pathol 1997;150(1):201-208.

52. Wang Y, Kuhajda FP, Li JN, et al. Fatty acid synthase (FAS) expression in human breast cancer cell culture supernatants and in breast cancer patients. Cancer Lett 2001;167:99-104.

53. Santos CR, Schulze A. Lipid metabolism in cancer. FEBS J 2012;279:26102623.

54. Samudio I, Harmancey R, Fiegl M, et al. Pharmacologic inhibition of fatty acid oxidation sensitizes human leukemia cells to apoptosis induction. $J$ Clin Invest 
2010;120(1):142-156.

55. Uray IP, Liang Y, Hyder SM. Estradiol down-regulates CD36 expression in human breast cancer cells. Cancer Lett 2004;207(1):101-107.

56. Pascual G, Avgustinova A, Mejetta S, et al. Targeting metastasis stem cells through the fatty acid receptor CD36. Nature 2016;541:41-45.

57. Zhang J, Fan J, Venneti S, et al. Asparagine plays a critical role in regulating cellular adaptation to glutamine depletion. Mol Cell 2014;56:205-218.

58. Broome J. Evidence that the L-asparaginase of guinea pig serum is responsible for its antilymphoma effects. $J$ Exp Med 1963;118:99-120.

59. Haskell C, Canellos G. L-Asparaginase resistance in human leukemia Asparagine synthetase. Biochem Pharmacol 1969;18:2578-2580.

60. Aslanian AM, Fletcher BS, Kilberg MS. Asparagine synthetase expression alone is sufficient to induce L-asparaginase resistance in MOLT-4 human leukaemia cells. Biochem J 2001;357:321-328.

61. Balasubramanian MN, Butterworth EA, Kilberg MS. Asparagine synthetase: regulation by cell stress and involvement in tumor biology. Am J Physiol Endocrinol Metab 2013;304:E789-799.

62. Dufour E, Gay F, Aguera K, Scoazec J. Pancreatic tumor sensitivity to plasma Lasparagine starvation. Pancreas 2012;41(6):940-948.

63. Karpel-massler G, Ramani D, Shu C, et al. Metabolic reprogramming of glioblastoma cells by L-asparaginase sensitizes for apoptosis in vitro and in vivo. Oncotarget 2017;7(23):33512-33528.

64. Amelio I, Cutruzzolá F, Antonov A, Agostini M, Melino G. Serine and glycine metabolism in cancer. Trends Biochem Sci 2014;39(4):191-198.

65. Farber S, Diamond L., Mercer R., Sylvester R., Wolff J. Temporary remissions in acute leukemia in children produced by folic acid antagonist, 4-aminopteroylglutamic acid (aminopterin). N Engl J Med 1948;238(23):787-793.

66. Possemato R, Marks KM, Shaul YD, et al. Functional genomics reveal that the serine synthesis pathway is essential in breast cancer. Nature 2011;476:346-350.

67. Polyak K, Xia Y, Zweier JL, Kinzler KW, Vogelstein B. A model for p53induced apoptosis. Nature 1997;389:300-305.

68. Liu W, Le A, Hancock C, et al. Reprogramming of proline and glutamine metabolism contributes to the proliferative and metabolic responses regulated by 
oncogenic transcription factor c-MYC. Proc Natl Acad Sci 2012;109(23):89838988.

69. Salimian Rizi B, Achreja A, Nagrath D. Nitric oxide: The forgotten child of tumor metabolism. Trends in Cancer 2017;3(9):659-672.

70. Thomas DD, Espey MG, Ridnour LA, et al. Hypoxic inducible factor $1 \alpha$, extracellular signal-regulated kinase, and p53 are regulated by distinct threshold concentrations of nitric oxide. Proc Natl Acad Sci 2004;101(24):8894-8899.

71. Tanese K, Grimm EA, Ekmekcioglu S. The role of melanoma tumor-derived nitric oxide in the tumor inflammatory microenvironment: its impact on the chemokine expression profile, including suppression of CXCL10. Int J Cancer 2012;131:891-901.

72. Sanuphan A, Chunhacha P, Pongrakhananon V, Chanvorachote P. Long-term nitric oxide exposure enhances lung cancer cell migration. Biomed Res Int 2013;2013:186972.

73. Berchner-Pfannschmidt U, Yamac H, Trinidad B, Fandrey J. Nitric oxide modulates oxygen sensing by hypoxia-inducible factor 1-dependent induction of prolyl hydroxylase 2. J Biol Chem 2007;282(3):1788-1796.

74. Nisoli E, Carruba MO. Nitric oxide and mitochondrial biogenesis. J Cell Sci 2006;119(14):2855-2862.

75. Russell D, Snyder SH. Amine synthesis in rapidly growing tissues: Ornithine decarboxylase activity in regenerating rat liver, chick embryo, and various tumors. Proc Natl Acad Sci 1968;60(4):1420-1427.

76. Gerner EW, Meyskens Jr FL. Polyamines and cancer: Old molecules, new understanding. Nat Rev Cancer 2004;4:781-792.

77. García-Faroldi G, Sánchez-Jiménez F, Fajardo I. The polyamine and histamine metabolic interplay in cancer and chronic inflammation. Curr Opin Clin Nutr Metab Care 2009;12:59-65.

78. Auvinen M, Paasinen A, Andersson LC, Hölttä E. Ornithine decarboxylase activity is critical for cell transformation. Nature 1992;360:355-358.

79. McCann PP, Pegg AE. Ornithine decarboxylase as an enzyme target for therapy. Pharmacol Ther 1992;54:195-215.

80. Babbar N, Ignatenko NA, Casero RA, Gerner EW. Cyclooxygenase-independent induction of apoptosis by sulindac sulfone is mediated by polyamines in colon cancer. J Biol Chem 2003;278(48):47762-47775. 
81. Ignatenko NA, Babbar N, Mehta D, Casero RA, Gerner EW. Suppression of polyamine catabolism by activated Ki-ras in human colon cancer cells. Mol Carcinog 2004;39:91-102.

82. Bello-Fernandez C, Packham G, Cleveland JL. The ornithine decarboxylase gene is a transcriptional target of c-Myc. Proc Natl Acad Sci 1993;90:7804-7808.

83. Bauer PM, Buga GM, Fukuto JM, Pegg AE, Ignarro LJ. Nitric oxide inhibits ornithine decarboxylase via S-nitrosylation of cysteine 360 in the active site of the enzyme. J Biol Chem 2001;276(37):34458-34464.

84. Saulnier Sholler GL, Gerner EW, Bergendahl G, et al. A phase I trial of DFMO targeting polyamine addiction in patients with relapsed/refractory neuroblastoma. PLoS One 2015;10(5):e0127246.

85. Zabala-Letona A, Arruabarrena-Aristorena A, Martín-Martín N, et al. mTORC1dependent AMD1 regulation sustains polyamine metabolism in prostate cancer. Nature 2017;547:109-113.

86. Carmeliet P, Jain RK. Angiogenesis in cancer and other diseases. Nature 2000;407:249-257.

87. Spolarics Z, Lang CH, Bagby GJ, Spitzer JJ. Glutamine and fatty acid oxidation are the main sources of energy for Kupffer and endothelial cells. Am J Physiol 1991;261(2):G185-G190.

88. Leighton B, Curi R, Hussein A, Newsholme EA. Maximum activities of some key enzymes of glycolysis, glutaminolysis, Krebs cycle and fatty acid utilization in bovine pulmonary endothelial cells. FEBS Lett 1987;225(1-2):93-96.

89. Dobrina A, Rossi F. Metabolic properties of freshly isolated bovine endothelial cells. Biochim Biophys Acta 1983;762:295-301.

90. Krützfeldt A, Spahr R, Mertens S, Siegmund B, Piper HM. Metabolism of exogenous substrates by coronary endothelial cells in culture. J Mol Cell Cardiol 1990;22:1393-1404.

91. Peters K, Kamp G, Berz A, et al. Changes in human endothelial cell energy metabolic capacities during in vitro cultivation. The role of aerobic glycolysis and proliferation. Cell Physiol Biochem 2009;24:483-492.

92. Harjes U, Bensaad K, Harris AL. Endothelial cell metabolism and implications for cancer therapy. Br J Cancer 2012;107:1207-1212.

93. De Bock K, Georgiadou M, Schoors S, et al. Role of PFKFB3-driven glycolysis in vessel sprouting. Cell 2013;154:651-663. 
94. Van Hée VF, Pérez-Escuredo J, Cacace A, Copetti T, Sonveaux P. Lactate does

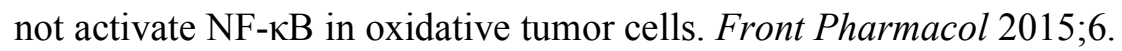

95. Leopold JA, Zhang YY, Scribner AW, Stanton RC, Loscalzo J. Glucose-6phosphate dehydrogenase overexpression decreases endothelial cell oxidant stress and increases bioavailable nitric oxide. Arterioscler Thromb Vasc Biol 2003;23(3):411-417.

96. Nacev BA, Grassi P, Dell A, Haslam SM, Liu JO. The antifungal drug itraconazole inhibits Vascular Endothelial Growth Factor Receptor 2 (VEGFR2) glycosylation, trafficking, and signaling in endothelial cells. $J$ Biol Chem 2011;286(51):44045-44056.

97. Polet F, Feron O. Endothelial cell metabolism and tumour angiogenesis: glucose and glutamine as essential fuels and lactate as the driving force. $J$ Intern Med 2013;273:156-165.

98. Maity P, Chakraborty S, Bhattacharya P. Angiogenesis - A putative new approach in glutamine related therapy. Pathol Oncol Res 1999;5(4):309-314.

99. Huang H, Vandekeere S, Kalucka J, et al. Role of glutamine and interlinked asparagine metabolism in vessel formation. EMBO J 2017;1-19.

100. Kim B, Li J, Jang C, Arany Z. Glutamine fuels proliferation but not migration of endothelial cells. EMBO J 2017;36:2321-2333.

101. Morrison RF, Seidel ER. Vascular endothelial cell proliferation: regulation of cellular polyamines. Cardiovasc Res 1995;29:841-847.

102. Urdiales JL, Medina MA, Sánchez-Jiménez F. Polyamine metabolism revisited. Eur J Gastroenterol Hepatol 2001;13(9):1015-1019.

103. $\mathrm{Li} \mathrm{H}$, Meininger $\mathrm{CJ}$, Bazer FW, Wu G. Intracellular sources of ornithine for polyamine synthesis in endothelial cells. Amino Acids 2016;48:2401-2410.

104. Wu G, Haynes TE, Li H, Meininger CJ. Glutamine metabolism in endothelial cells: ornithine synthesis from glutamine via pyrroline-5-carboxylate synthase. Comp Biochem Physiol Part A Mol Integr Physiol 2000;126(1):115-123.

105. Spahr R, Krtitzfeldt A, Mertens S, Siegmund B, Piper HM. Fatty acids are not an important fuel for coronary microvascular endothelial cells. Mol Cell Biochem 1989;88:59-64.

106. Schoors S, Bruning U, Missiaen R, Queiroz KCS. Fatty acid carbon is essential for dNTP synthesis in endothelial cells. Nature 2015;520(7546):192-197.

107. Missiaen R, Rodriguez FM, Eelen G, Carmeliet P. Targeting endothelial 
metabolism for anti-angiogenesis therapy: A pharmacological perspective. Vascul Pharmacol 2017;90:8-18.

108. De Bock K, Georgiadou M, Carmeliet P. Role of endothelial cell metabolism in vessel sprouting. Cell Metab 2013;18(5):634-647.

109. Eelen G, Cruys B, Welti J, De Bock K, Carmeliet P. Control of vessel sprouting by genetic and metabolic determinants. Trends Endocrinol Metab 2013;24(12):589-596.

110. Potente M, Carmeliet P. The link between angiogenesis and endothelial metabolism. Аnпu Rev Physiol 2017;79:43-66.

111. Cadamuro M, Nardo G, Indraccolo S, et al. Platelet-derived growth factor-D and Rho GTPases regulate recruitment of cancer-associated fibroblasts in cholangiocarcinoma. Hepatology 2013;58(3):1042-1053.

112. Wagner EF. Cancer: Fibroblasts for all seasons. Nature 2016;530(7588):42-43.

113. Koliaraki V, Pasparakis M, Kollias G. IKK $\beta$ in intestinal mesenchymal cells promotes initiation of colitis-associated cancer. J Exp Med 2015;212(13):22352251 .

114. Pallangyo CK, Ziegler PK, Greten FR. IKK $\beta$ acts as a tumor suppressor in cancer-associated fibroblasts during intestinal tumorigenesis. $J$ Exp Med 2015;212(13):2253-2266.

115. Carito V, Bonuccelli G, Martinez-Outschoorn UE, et al. Metabolic remodeling of the tumor microenvironment: Migration stimulating factor (MSF) reprograms myofibroblasts toward lactate production, fueling anabolic tumor growth. Cell Cycle 2012;11(18):3403-3414.

116. Whitaker-Menezes D, Martinez-Outschoorn UE, Lin Z, et al. Evidence for a stromal-epithelial "lactate shuttle" in human tumors: MCT4 is a marker of oxidative stress in cancer-associated fibroblasts. Cell Cycle 2011;10(11):17721783.

117. Zhang D, Wang Y, Shi Z, et al. Metabolic reprogramming of cancer-associated fibroblasts by IDH3 $\alpha$ downregulation. Cell Rep 2015;10:1335-1348.

118. Koukourakis MI, Giatromanolaki A, Harris AL, Sivridis E. Comparison of metabolic pathways between cancer cells and stromal cells in colorectal carcinomas: A metabolic survival role for tumor-associated stroma. Cancer Res 2006;66(2):632-637.

119. Rattigan YI, Patel BB, Ackerstaff E, et al. Lactate is a mediator of metabolic cooperation between stromal carcinoma associated fibroblasts and glycolytic 
tumor cells in the tumor microenvironment. Exp Cell Res 2012;318:326-335.

120. Yang L, Achreja A, Yeung TL, et al. Targeting stromal glutamine synthetase in tumors disrupts tumor microenvironment-regulated cancer cell growth. Cell Metab 2016;24:685-700.

121. Liu Y, Cao X. The origin and function of tumor-associated macrophages. Cell Mol Immunol 2015;12:1-4.

122. Quatromoni JG, Eruslanov E. Tumor-associated macrophages: function, phenotype, and link to prognosis in human lung cancer. Am J Transl Res 2012;4(4):376-389.

123. Grivennikov SI, Greten FR, Karin M. Immunity, inflammation, and cancer. Cell 2010;140(6):883-899.

124. Wang YC, He F, Feng F, et al. Notch signaling determines the M1 versus M2 polarization of macrophages in antitumor immune responses. Cancer Res 2010;70(12):4840-4849.

125. Franklin RA, Liao W, Sarkar A, et al. The cellular and molecular origin of tumor-associated macrophages. Science 2014;344(6186):921-925.

126. Chittezhath M, Dhillon MK, Lim JY, et al. Molecular profiling reveals a tumorpromoting phenotype of monocytes and macrophages in human cancer progression. Immunity 2014;41:815-829.

127. Lampropoulou V, Sergushichev A, Bambouskova M, et al. Itaconate Links Inhibition of Succinate Dehydrogenase with Macrophage Metabolic Remodeling and Regulation of Inflammation. Cell Metab 2016;24:158-166.

128. Rodríguez-Prados J-C, Través PG, Cuenca J, et al. Substrate fate in activated macrophages: a comparison between innate, classic, and alternative activation. $J$ Immunol 2010;185:605-614.

129. Tannahill GM, Curtis AM, Adamik J, et al. Succinate is an inflammatory signal that induces IL-1 $\beta$ through HIF-1 $\alpha$. Nature 2013;496(7444):238-242.

130. Selak MA, Armour SM, MacKenzie ED, et al. Succinate links TCA cycle dysfunction to oncogenesis by inhibiting HIF- $\alpha$ prolyl hydroxylase. Cancer Cell 2005;7(1):77-85.

131. Luo W, Hu H, Chang R, et al. Pyruvate kinase M2 is a PHD3-stimulated coactivator for hypoxia-inducible factor 1. Cell 2011;145:732-744.

132. Alves-Filho JC, Pålsson-McDermott EM. Pyruvate Kinase M2: A Potential Target for Regulating Inflammation. Front Immunol 2016;7:1-7. 
133. Kelly B, O’Neill LA. Metabolic reprogramming in macrophages and dendritic cells in innate immunity. Cell Res 2015;25(7):771-784.

134. Ocaña MC, Martínez-Poveda B, Quesada AR, Medina MA. Metabolism in the tumor microenvironment: What is known about stromal and immune cells? Clin Immunol Endocr Metab Drugs 2017;4.

135. Arts RJW, Plantinga TS, Tuit S, et al. Transcriptional and metabolic reprogramming induce an inflammatory phenotype in non-medullary thyroid carcinoma-induced macrophages. Oncoimmunology 2016;5(12):e1229725.

136. Liu D, Chang C, Lu N, et al. Comprehensive proteomics analysis reveals metabolic reprogramming of tumor-associated macrophages stimulated by the tumor microenvironment. J Proteome Res 2017;16:288-297.

137. Daurkin I, Eruslanov E, Stoffs T, et al. Tumor-associated macrophages mediate immunosuppression in the renal cancer microenvironment by activating the 15 lipoxygenase-2 pathway. Microenviron Immunol 2011;71(20):6400-6410.

138. Choi J, Stradmann-bellinghausen B, Yakubov E, Savaskan NE, Anne R. Glioblastoma cells induce differential glutamatergic gene expressions in human tumor-associated microglia/macrophages and monocyte-derived macrophages. Cancer Biol Ther 2015;16(8):1205-1213.

139. Covarrubias AJ, Aksoylar HI, Yu J, et al. Akt-mTORC1 signaling regulates Acly to integrate metabolic input to control of macrophage activation. eLife 2016;5:e11612.

140. Covarrubias AJ, Aksoylar HI, Horng T. Control of macrophage metabolism and activation by mTOR and Akt signaling. Semin Immunol 2015;27(4):286-296.

141. Delgoffe GM, Powell JD. Sugar, fat, and protein: New insights into what T cells crave. Curr Opin Immunol 2015;33:49-54.

142. Pennisi E. Metabolic shift may train immune cells. Science 2014;345(6204):1550-1551.

143. Kouidhi S, Elgaaied AB, Chouaib S. Impact of Metabolism in on T-Cell Differentiation and Function and Cross Talk with Tumor Microenvironment. Front Immunol 2017;8:270.

144. Hubler MJ, Kennedy AJ. Role of Lipids in the Metabolism and Activation of Immune Cells. J Nutr Biochem 2016;34:1-7.

145. Ho PC, Liu PS. Metabolic communication in tumors: a new layer of immunoregulation for immune evasion. J Immunother Cancer 2016;4(1):1. 
146. Ho PC, Bihuniak JD, MacIntyre AN, et al. Phosphoenolpyruvate is a metabolic checkpoint of anti-tumor T cell responses. Cell 2015;162:1-12.

147. Ganeshan K, Chawla A. Metabolic regulation of immune responses. Annu Rev Immunol 2014;32(1):609-634.

148. Delgoffe GM, Kole TP, Zheng Y, et al. The mTOR kinase differentially regulates effector and regulatory T cell lineage commitment. Immunity 2009;30:832-844.

149. Dang E V., Barbi J, Yang HY, et al. Control of TH17/Treg balance by hypoxiainducible factor 1. Cell 2011;146:772-784.

150. Wang R, Dillon CP, Shi LZ, et al. The transcription factor Myc controls metabolic reprogramming upon $\mathrm{T}$ lymphocyte activation. Immunity 2011;35:871-882.

151. Newsholme P. Why is L-glutamine metabolism important to cells of the immune system in health, postinjury, surgery or infection? J Nutr 2001;131:2515S$2522 \mathrm{~S}$.

152. Geiger R, Rieckmann JC, Wolf $\mathrm{T}$, et al. L-Arginine modulates $\mathrm{T}$ cell metabolism and enhances survival and anti-tumor activity. Cell 2016;167:829-842.

153. Varricchi G, Galdiero MR, Loffredo S, et al. Are mast cells MASTers in cancer? Front Immunol 2017;8:424.

154. Liu J, Zhang Y, Zhao J, et al. Mast cell: insight into remodeling a tumor microenvironment. Cancer Metastasis Rev 2011;30:177-184.

155. Ribatti D, Crivellato E. Mast cells, angiogenesis, and tumour growth. Biochim Biophys Acta 2012;1822:2-8.

156. Norrby K, Jakobsson A, Sörbo J. Mast-cell secretion and angiogenesis, a quantitative study in rats and mice. Virchows Arch B Cell Pathol 1989;57:251256.

157. Chakravarty N. Glycolysis in rat peritoneal mast cells. J Cell Biol 1965;25:123128.

158. Chakravarty N. Further observations on the inhibition of histamine release by 2deoxyglucose. Acta Physiol Scand 1968;72:425-432.

159. Chakravarty N, Sorensen J. Stimulation of glucose metabolism in rat mast cells by antigen, dextran and compound 48/80, used as histamine releasing agents. Acta Physiol Scand 1974;91:339-353.

160. Yoshizaki K, Arizono N, Hayano T, Watari H. Allergen-induced histamine 
secretion associated with lactate production in mast cells detected by $1 \mathrm{H}-\mathrm{NMR}$. Magn Reson Med 1993;29:732-736.

161. Johansen T. Dependence of anaphylactic histamine release from rat mast cells on cellular energy metabolism. Eur J Pharmacol 1981;72:281-286.

162. Mitra R, Pal S. Inhibition of mast cell population by L-glutamine in aspirininduced ulceration in rat stomach. Indian J Physiol Pharmacol 1977;21(4):374378.

163. Lechowski S, Feilhauer K, Staib L, Coëffier M, Bischoff SC, Lorentz A. Combined arginine and glutamine decrease release of de novo synthesized leukotrienes and expression of proinflammatory cytokines in activated human intestinal mast cells. Eur J Nutr 2013;52:505-512.

164. Kawasaki H, Chang H., Tseng H., et al. A tryptophan metabolite , kynurenine, promotes mast cell activation through aryl hydrocarbon receptor. Allergy 2014;69:445-452.

165. Opitz CA, Litzenburger UM, Sahm F, et al. An endogenous tumour-promoting ligand of the human aryl hydrocarbon receptor. Nature 2011;478:197-203.

166. Sekar Y, Moon TC, Slupsky CM, Befus AD. Protein tyrosine nitration of aldolase in mast cells: A plausible pathway in nitric oxide-mediated regulation of mast cell function. J Immunol 2010;185:578-587.

167. Ryu SY, Hong GU, Kim DY, Ro JY. Enolase 1 and calreticulin regulate the differentiation and function of mouse mast cells. Cell Signal 2012;24:60-70.

168. Sharkia I, Erlich TH, Landolina N, et al. Pyruvate dehydrogenase has a major role in mast cell function, and its activity is regulated by mitochondrial microphthalmia transcription factor. J Allergy Clin Immunol 2017;140(1):204214.

169. Zheng M, Cho D-I, Le HT, Cheon SH, Kim K-M. Dual regulation of mast cell degranulation through IgE receptor-mediated modulation of M2-type pyruvate kinase. Arch Pharm Res 2014;37:1177-1182.

170. García-Faroldi G, Rodríguez CE, Urdiales JL, et al. Polyamines are present in mast cell secretory granules and are important for granule homeostasis. PLoS One 2010;5(11):e15071.

171. Hosono J, Morikawa S, Ezaki T, Kawamata T, Okada Y. Pericytes promote abnormal tumor angiogenesis in a rat RG2 glioma model. Brain Tumor Pathol 2017;34(3):120-129.

172. Caspani EM, Crossley PH, Redondo-Garcia C, Martinez S. Glioblastoma: A 
pathogenic crosstalk between tumor Cells and pericytes. PLoS One 2014;9(7):e101402.

173. Ribeiro AL, Kaid C, Silva PBG, Cortez BA, Okamoto OK. Inhibition of lysyl oxidases impairs migration and angiogenic properties of tumor-associated pericytes. Stem Cells Int 2017;2017.

174. Berrone E, Beltramo E, Solimine C, Ape AU, Porta M. Regulation of intracellular glucose and polyol pathway by thiamine and benfotiamine in vascular cells cultured in high glucose. J Biol Chem 2006;281(14):9307-9313.

175. Trudeau K, Molina AJA, Roy S. High glucose induces mitochondrial morphology and metabolic changes in retinal pericytes. Invest Ophthalmol Vis Sci 2011;52(12):8657-8664.

176. Yuan K, Shao N, Hennigs JK, et al. Increased pyruvate dehydrogenase kinase 4 expression in lung pericytes is associated with reduced endothelial-pericyte interactions and small vessel loss in pulmonary arterial hypertension. Am J Pathol 2016;186(9):2500-2514.

177. Hanahan D, Coussens LM. Accessories to the crime: Functions of cells recruited to the tumor microenvironment. Cancer Cell 2012;21:309-322.

178. Burnet FM. The concept of immunological surveillance. Prog Exp Tumor Res 1970;13:1-27.

179. Thomas L. On immunosurveillance in human cancer. Yale $J$ Biol Med 1982;55:329-333.

180. Sukumar M, Roychoudhuri R, Restifo NP. Nutrient competition: A new axis of tumor immunosuppression. Cell 2015;162:1206-1208.

181. Chang C, Curtis JD, Maggi Jr LB, et al. Posttranscriptional control of $\mathrm{T}$ cell effector function by aerobic glycolysis. Cell 2013;153:1239-1251.

182. Fischer K, Hoffmann P, Voelkl S, et al. Inhibitory effect of tumor cell-derived lactic acid on human T cells. Blood 2007;109(9):3812-3820.

183. Chaudhary B, Elkord E. Regulatory T cells in the tumor microenvironment and cancer progression: Role and therapeutic targeting. Vaccines 2016;4:28.

184. Ahmadzadeh M, Johnson LA, Heemskerk B, et al. Tumor antigen - specific CD8 $\mathrm{T}$ cells infiltrating the tumor express high levels of PD-1 and are functionally impaired Tumor antigen - specific CD8 T cells infiltrating the tumor express high levels of PD-1 and are functionally impaired. Blood 2009;114:1537-1544.

185. Dong H, Strome SE, Salomao DR, et al. Tumor-associated B7-H1 promotes T- 
cell apoptosis: A potential mechanism of immune evasion. Nat Med 2002;8(8):793-800.

186. Parry RV, Chemnitz JM, Frauwirth KA, et al. CTLA-4 and PD-1 Receptors Inhibit T-Cell Activation by Distinct Mechanisms CTLA-4 and PD-1 Receptors Inhibit T-Cell Activation by Distinct Mechanisms. Mol Cell Biol 2005;25(21):9543-9553.

187. Patsoukis N, Bardhan K, Chatterjee P, et al. PD-1 alters T-cell metabolic reprogramming by inhibiting glycolysis and promoting lipolysis and fatty acid oxidation. Nat Commun 2015;6:6692.

188. Fallarino F, Grohmann U, You S, et al. The combined effects of tryptophan starvation and tryptophan catabolites down-regulate $\mathrm{T}$ cell receptor $\zeta$-chain and induce a regulatory phenotype in naive T cells. J Immmunology 2006;176:67526761.

189. Häusler SFM, Montalbán Del Barrio I, Strohschein J, et al. Ectonucleotidases CD39 and CD73 on OvCA cells are potent adenosine-generating enzymes responsible for adenosine receptor 2A-dependent suppression of $\mathrm{T}$ cell function and NK cell cytotoxicity. Cancer Immunol Immunother 2011;60:1405-1418.

190. Salimian Rizi B, Caneba C, Nowicka A, et al. Nitric oxide mediates metabolic coupling of omentum-derived adipose stroma to ovarian and endometrial cancer cells. Cancer Res 2015;75:456-471.

191. Folkman J. Tumor angiogenesis: therapeutic implications. $N$ Engl J Med 1971;285(21):1182-1186.

192. Folkman J. Angiogenesis: an organizing principle for drug discovery? Nat Rev Drug Discov 2007;6:273-286.

193. Ribatti D, Nico B, Crivellato E, Roccaro AM, Vacca A. The history of the angiogenic switch concept. Leukemia 2007;21:44-52.

194. Chappell JC, Wiley DM, Bautch VL. Regulation of blood vessel sprouting. Semin Cell Dev Biol 2011;22:1005-1011.

195. Carmeliet P. Angiogenesis in life, disease and medicine. Nature 2005;438:932936.

196. Potente M, Gerhardt H, Carmeliet P. Basic and therapeutic aspects of angiogenesis. Cell 2011;146:873-87.

197. Goveia J, Stapor P, Carmeliet P. Principles of targeting endothelial cell metabolism to treat angiogenesis and endothelial cell dysfunction in disease. EMBO Mol Med 2014;6(9):1105-1120. 
198. Végran F, Boidot R, Michiels C, Sonveaux P, Feron O. Lactate influx through the endothelial cell monocarboxylate transporter MCT1 supports an NF-kB/IL-8 pathway that drives tumor angiogenesis. Cancer Res 2011;71(7):2550-2560.

199. Sonveaux P, Copetti T, de Saedeleer CJ, et al. Targeting the lactate transporter MCT1 in endothelial cells inhibits lactate-induced HIF-1 activation and tumor angiogenesis. PLoS One 2012;7(3):e33418.

200. Ruan GX, Kazlauskas A. Lactate engages receptor tyrosine kinases Axl, Tie2, and vascular endothelial growth factor receptor 2 to activate phosphoinositide 3kinase/AKT and promote angiogenesis. J Biol Chem 2013;288(29):21161-21172.

201. Reihill JA, Ewart M-A, Salt IP. The role of AMP-activated protein kinase in the functional effects of vascular endothelial growth factor-A and -B in human aortic endothelial cells. Vasc Cell 2011;3(1):9.

202. Yamanishi S, Katsumura K, Kobayashi T, Puro DG. Extracellular lactate as a dynamic vasoactive signal in the rat retinal microvasculature. Am J Physiol Hear Circ Physiol 2006;290:H925-H934.

203. Hayakawa Y, Wang TC. Nerves switch on angiogenic metabolism. Science 2017;358(6361):305-306.

204. Zahalka AH, Arnal-Estapé A, Maryanovich M, et al. Adrenergic nerves activate an angio-metabolic switch in prostate cancer. Science 2017;358(6361):321-326.

205. Martinez-Outschoorn UE, Pestell RG, Howell A, et al. Energy transfer in "parasitic" cancer metabolism. Cell Cycle 2011;10(24):4208-4216.

206. Pavlides S, Whitaker-Menezes D, Castello-Cros R, et al. The reverse Warburg effect: Aerobic glycolysis in cancer associated fibroblasts and the tumor stroma. Cell Cycle 2009;8(23):3984-4001.

207. Bonuccelli G, Avnet S, Grisendi G, et al. Role of mesenchymal stem cells in osteosarcoma and metabolic reprogramming of tumor cells. Oncotarget 2014;5(17):7575-7588.

208. Romero-García S, Moreno-Altamirano MMB, Prado-García H, Sánchez-García FJ. Lactate contribution to the tumor microenvironment: Mechanisms, effects on immune cells and therapeutic relevance. Front Immunol 2016;7.

209. Stern R, Shuster S, Neudecker BA, Formby B. Lactate stimulates fibroblast expression of hyaluronan and CD44: the Warburg effect revisited. Exp Cell Res 2002;276:24-31.

210. Scherz-Shouval R, Santagata S, Mendillo ML, et al. The reprogramming of tumor stroma by HSF1 is a potent enabler of malignancy. Cell 2014;158:564- 
578.

211. Orimo A, Gupta PB, Sgroi DC, et al. Stromal fibroblasts present in invasive human breast carcinomas promote tumor growth and angiogenesis through elevated SDF-1/CXCL12 secretion. Cell 2005;121:335-348.

212. Attieh Y, Vignjevic DM. The hallmarks of CAFs in cancer invasion. Eur J Cell Biol 2016;95:493-502.

213. Roy A, Bera S. CAF cellular glycolysis: linking cancer cells with the microenvironment. Tumor Biol 2016;37:8503-8514.

214. Guo X, Oshima H, Kitmura T, Taketo MM, Oshima M. Stromal fibroblasts activated by tumor cells promote angiogenesis in mouse gastric cancer. $J$ Biol Chem 2008;283(28):19864-19871.

215. Zhang Y, Tang H, Cai J, et al. Ovarian cancer-associated fibroblasts contribute to epithelial ovarian carcinoma metastasis by promoting angiogenesis, lymphangiogenesis and tumor cell invasion. Cancer Lett 2011;303:47-55.

216. Lopes-Coelho F, André S, Félix A, Serpa J. Breast cancer metabolic cross-talk: Fibroblasts are hubs and breast cancer cells are gatherers of lipids. Mol Cell Endocrinol 2017.

217. Augsten M, Sjöberg E, Frings O, et al. Cancer-associated fibroblasts expressing CXCL14 rely upon NOS1-derived nitric oxide signaling for their tumorsupporting properties. Cancer Res 2014;74:2999-3010.

218. Penny HL, Sieow JL, Adriani G, et al. Warburg metabolism in tumor-conditioned macrophages promotes metastasis in human pancreatic ductal adenocarcinoma. Oncoimmunology 2016;5(8):e1191731.

219. Colegio OR, Chu N-Q, Szabo AL, et al. Functional polarization of tumourassociated macrophages by tumour-derived lactic acid. Nature 2014;513(7519):559-563.

220. Leek RD, Lewis CE, Whitehouse R, Greenall M, Clarke J, Harris AL. Association of macrophage infiltration with angiogenesis and prognosis in invasive breast carcinoma. Cancer Res 1996;56:4625-4629.

221. Pollard JW. Tumour-educated macrophages promote tumour progression and metastasis. Nat Rev Cancer 2004;4:71-78.

222. Lin L, Chen YS, Yao YD, et al. CCL18 from tumor-associated macrophages promotes angiogenesis in breast cancer. Oncotarget 2015;6(33):34758-34773.

223. Casazza A, Laoui D, Wenes M, et al. Impeding macrophage entry into hypoxic 
tumor areas by Sema3A/Nrp1 signaling blockade inhibits angiogenesis and restores antitumor immunity. Cancer Cell 2013;24:695-709.

224. Yuan Y, Jiang YC, Sun CK, Chen QM. Role of the tumor microenvironment in tumor progression and the clinical applications. Oncol Rep 2016;35:2499-2515.

225. Rabold K, Netea MG, Adema GJ, Netea-Maier RT. Cellular metabolism of tumor-associated macrophages: functional impact and consequences. FEBS Lett 2017.

226. Albina E. Modulation by products of glucose metabolism in macrophages of nitric oxide synthase. Am J Physiol 1993;264:C1594-C1599.

227. Klimp AH, Hollema H, Kempinga C, van der Zee AGJ, de Vries EGE, Daemen T. Expression of cyclooxygenase- 2 and inducible nitric oxide synthase in human ovarian tumors and tumor-associated macrophages. Cancer Res 2001;61:73057309.

228. DiNapoli MR, Calderón CL, López DM. The altered tumoricidal capacity of macrophages isolated from tumor-bearing mice is related to reduced expression of the inducible nitric oxide synthase gene. J Exp Med 1996;183:1323-1329.

229. Kannan Y, Perez-Lloret J, Li Y, et al. TPL-2 regulates macrophage lipid metabolism and M2 differentiation to control TH2-mediated immunopathology. PLoS Pathog 2016;12(8):e1005783.

230. Zhao Q, Kuang D, Wu Y, et al. Activated CD69+ T cells foster immune privilege by regulating IDO expression in tumor-associated macrophages. J Immunol 2011;188:1117-1124.

231. Zhu Q, Wu X, Wu Y, Wang X. Interaction between Treg cells and tumorassociated macrophages in the tumor microenvironment of epithelial ovarian cancer. Oncol Rep 2016;36:3472-3478.

232. Kabat AM, Pearce EJ. Inflammation by way of macrophage metabolism. Science 2017;356(6337):488-489

233. Ip WKE, Hoshi N, Shouval DS, Snapper S. Anti-inflammatory effect of IL-10 mediated by metabolic reprogramming of macrophages. Science 2017;356:513519.

234. Noman MZ, Desantis G, Janji B, et al. PD-L1 is a novel direct target of HIF-1, and its blockade under hypoxia enhanced MDSC-mediated T cell activation. $J$ Exp Med 2014;211(5):781-790.

235. Shime H, Yabu M, Akazawa T, et al. Tumor-Secreted Lactic Acid Promotes IL23/IL-17 Proinflammatory Pathway. J Immunol 2008;180:7175-7183. 
236. Pasquier J, Guerrouahen BS, Al Thawadi H, et al. Preferential transfer of mitochondria from endothelial to cancer cells through tunneling nanotubes modulates chemoresistance. J Transl Med 2013;11(1):94.

237. Kamphorst JJ, Gottlieb E. Cancer metabolism: Friendly neighbours feed tumour cells. Nature 2016;536:401-402.

238. Sousa CM, Biancur DE, Wang X, et al. Pancreatic stellate cells support tumour metabolism through autophagic alanine secretion. Nature 2016;536:479-83.

239. Zhang W, Trachootham D, Liu J, et al. Stromal control of cystine metabolism promotes cancer cell survival in chronic lymphocytic leukaemia. Nat Cell Biol 2012;14(3):276-286.

240. Meyer KA, Neeley CK, Baker NA, et al. Adipocytes promote pancreatic cancer cell proliferation via glutamine transfer. Biochem Biophys Reports 2016;7:144149.

241. Gazi E, Gardner P, Lockyer NP, Hart CA, Brown MD, Clarke NW. Direct evidence of lipid translocation between adipocytes and prostate cancer cells with imaging FTIR microspectroscopy. J Lipid Res 2007;48:1846-1856.

242. Nieman KM, Kenny HA, Penicka CV, et al. Adipocytes promote ovarian cancer metastasis and provide energy for rapid tumor growth. Nat Med 2011;17(11):1498-1503.

243. Wen Y-A, Xing X, Harris JW, et al. Adipocytes activate mitochondrial fatty acid oxidation and autophagy to promote tumor growth in colon cancer. Cell Death Dis 2017;8(2):e2593.

244. Dirat B, Bochet L, Dabek M, et al. Cancer-associated adipocytes exhibit an activated phenotype and contribute to breast cancer invasion. Cancer Res 2011;71(7):2455-2465.

245. Choi MS, Jung J, Kim H, Ham MR, Lee TR, Shin DW. S-nitrosylation of fatty acid synthase regulates its activity through dimerization. $J$ Lipid Res 2016;57:607-615.

246. Al-zhoughbi W, Huang J, Paramasivan GS, Till H, Pichler M, Guertl-lackner B. Tumor macroenvironment and metabolism. Semin Oncol 2014;41(2):281-295.

247. Shapot VS. Systemic effect of the tumor on the host: Biochemical and endocrine manifestations. Adv Enzyme Regul 1975;13:67-75.

248. Lee Y, Chang W-C, Ma W-L. Hypothesis: solid tumours behave as systemic metabolic dictators. J Cell Mol Med 2016;20(6):1076-1085. 
249. Shapot VS. Biochemical aspects of tumour growth. Mir Publishers; 1980.

250. Mider GB. Some aspects of nitrogen and energy metabolism in cancerous subjects: A review. Cancer Res 1951;11:821-829.

251. Souba WW. Glutamine and Cancer. Ann Surg 1993;218(6):715-728.

252. Wu C, Morris HP. Responsiveness of glutamine-metabolizing enzymes in Morris hepatomas to metabolic modulations. Cancer Res 1970;30:2675-2684.

253. Collins CL, Wasa M, Souba WW, Abcouwer SF. Regulation of glutamine synthetase in human breast carcinoma cells and experimental tumors. Surgery 1997;122(2):451-463.

254. Labow BI, Souba WW, Abcouwer SF. Mechanisms governing the expression of the enzymes of glutamine metabolism - glutaminase and glutamine synthetase. $J$ Nutr 2001;131:2467S-2474S.

255. Márquez J, Sánchez-Jiménez F, Medina MA, Quesada AR, Núñez de Castro I. Nitrogen metabolism in tumor bearing mice. Arch Biochem Biophys 1989;268(2):667-675.

256. Vornovitskaya GI, Dubinina IG, Gershtein ES, Grekhova N V, Shapot VS. Changes in relations between two pathways of synthesis of RNA precursors in the tissues of animals with fast growing hepatomas. Bull Exp Biol Med 1979;87(3):264-266.

257. Gershtein ES, Vornovitskaya GI, Shapot VS. Kinetics of (C14) thymidine metabolism in hepatomas and tissues from normal and tumor-bearing animals. Biokhimiia 1978;43(7):1303-1311.

258. Medina MA. Glutamine and Cancer. J Nutr 2001;131(9):2539S-2542S.

259. Yoshida S, Kaibara A, Yamasaki K, Ishibashi N, Noake T, Kakegawa T. Effect of glutamine supplementation on protein metabolism and glutathione in tumorbearing rats. J Parenter Enter Nutr 1995;19:492-497.

260. Ziegler TR. Glutamine supplementation in cancer patients receiving bone marrow transplantation and high dose chemotherapy. $J$ Nutr 2001;131(9):2578S-2584S.

261. LePage GA, Potter VR, Busch H, Heidelberger C, Hurlbert RB. Growth of carcinoma implants in fed and fasted rats. Cancer Res 1952;12:153-157.

262. Torosian MH, Nguyen HQ. Tumors - Effective nitrogen traps independent of protein Intake. J Surg Res 1989;47:456-459.

263. De Lerma Barbaro A. The complex liaison between cachexia and tumor burden. 
Oncol Rep 2015;34:1635-1649.

264. Saez S. Adrenal function in cancer: Relation to the evolution. Eur $J$ Cancer 1971;7:381-387.

265. Grieninger G, Hertzberg KM, Pindyck J. Fibrinogen synthesis in serum-free hepatocyte cultures: Stimulation by glucocorticoids. Proc Natl Acad Sci 1978;75(11):5506-5510.

266. Ioannesyants IA, Adler V V, Él'kina ZI, Artamonova SI, Kadagidze ZG, Shapot VS. Sensitivity of RNA-synthesizing system of the lymphocytes of patients with malignant neoplasms to phytohemagglutinin and dexamethasone. Bull Exp Biol Med 1977;83(4):529-532.

267. Flint TR, Janowitz T, Connell CM, et al. Tumor-induced IL-6 reprograms host metabolism to suppress anti-tumor immunity. Cell Metab 2016;24:672-684.

268. Cahlin C, Körner A, Axelsson H, Wang W, Lundholm K, Svanberg E. Experimental cancer cachexia: The role of host-derived cytokines interleukin (IL)-6, IL-12, interferon- $\gamma$, and tumor necrosis factor $\alpha$ evaluated in gene knockout, tumor-bearing mice on C57 Bl background and eicosanoid-dependent cachexia. Cancer Res 2000;60:5488-5493.

269. Masri S, Papagiannakopoulos T, Kinouchi K, et al. Lung adenocarcinoma distally rewires hepatic circadian homeostasis. Cell 2016;165:896-909.

270. Shapot VS, Blinov VA. Blood glucose levels and gluconeogenesis in animals bearing transplantable tumors. Cancer Res 1974;34:1827-1832.

271. Stumvoll M, Meyer C, Perriello G, Kreider M, Welle S, Gerich J. Human kidney and liver gluconeogenesis: evidence for organ substrate selectivity. Am J Physiol 1998;274:E817-E826.

272. Nurjhan N, Bucci A, Perriello G, et al. Glutamine: A major gluconeogenic precursor and vehicle for interorgan carbon transport in man. $J$ Clin Invest 1995;95:272-277.

273. Richard V, Conotte R, Mayne D, Colet J. Does the 1H-NMR plasma metabolome reflect the host-tumor interactions in human breast cancer? Oncotarget 2017;8(30):49915-49930.

274. Argilés JM, Busquets S, Stemmler B, López-soriano FJ. Cancer cachexia: understanding the molecular basis. Nat Rev Cancer 2014;14:754-762.

275. Clark CM, Goodlad GAJ. Muscle protein biosynthesis in the tumour-bearing rat. A defect in a post-initiation stage of translation. Biochim Biophys Acta 1975;378:230-240. 
276. Pushkina IP, Krechetova CD, Shapot VS. Correlation of membrane-bound and free ribosomes in normal rat liver, Zajdela hepatoma rat liver and ascite cells proper. Biokhimiia 1976;41:1940-1944.

277. Baker N, Hill V, Ookhtens M. Regulation of plasma-free fatty acid mobilization by dietary glucose in Ehrlich ascites tumor-bearing mice. Cancer Res 1978;38:2372-2377.

278. Das SK. Adipose triglyceride lipase contributes to cancer-associated cachexia. Science 2011;333:233-238.

279. Liu L, Wang Y, Zheng T, Cao B, Li M, Shi J, et al. Metabolic shifts induced by human H460 cells in tumor-bearing mice. Biomed Chromatogr 2016;30:337342.

280. Oka T, Ohwada K, Nagao M, Kitazato K. Effect of arginine-enriched total parenteral nutrition host-tumor interaction in cancer-bearing rats. $J$ Parenter Enter Nutr 1993;17:375-383.

281. Tachibana K, Mukai K, Hiraoka I, Moriguchi S, Takama S, Kishino Y. Evaluation of the effect of arginine-enriched amino acid solution on tumor growth. J Parenter Enter Nutr 1985;9:425-434.

282. Márquez J, Matés JM, Quesada AR, Medina MA, Núñez de Castro I, SánchezJiménez F. Altered ornithine metabolism in tumor-bearing mice. Life Sci 1989;45:1877-1884.

283. Ohmura M, Hishiki T, Yamamoto T, et al. Impacts of CD44 knockdown in cancer cells on tumor and host metabolic systems revealed by quantitative imaging mass spectrometry. Nitric Oxide 2014;46:102-113.

284. Commisso C, Davidson SM, Soydaner-Azeloglu RG, et al. Macropinocytosis of protein is an amino acid supply route in Ras-transformed cells. Nature 2013;497(7451):633-637.

285. Kamphorst JJ, Nofal M, Commisso C, et al. Human pancreatic cancer tumors are nutrient poor and tumor cells actively scavenge extracellular protein. Cancer Res 2015;75(3):544-554.

286. Holm E, Hagmãller E, Staedt U, et al. Substrate balances across colonic carcinomas in humans. Cancer Res 1995;55:1373-1378.

287. Krishna S, Palm W, Lee Y, et al. PIKfyve regulates vacuole maturation and nutrient recovery following engulfment. Dev Cell 2016;38(5):536-547.

288. Palm W, Park Y, Wright K, Pavlova NN, Tuveson, David A, Thompson CB. The utilization of extracellular proteins as nutrients is suppressed by mTORC1. Cell 
$2015 ; 162: 259-270$.

289. Kamphorst JJ, Cross JR, Fan J, et al. Hypoxic and Ras-transformed cells support growth by scavenging unsaturated fatty acids from lysophospholipids. Proc Natl Acad Sci 2013;110(22):8882-8887.

290. Desai N, Trieu V, Yao Z, et al. Increased antitumor activity, intratumor paclitaxel concentrations, and endothelial cell transport of cremophor-free, albumin-bound paclitaxel, ABI-007, compared with cremophor-based paclitaxel. Clin Cancer Res 2006;12(4):1317-1325.

291. Von Hoff DD, Ramanathan RK, Borad MJ, et al. Gemcitabine plus nabpaclitaxel is an active regimen in patients with advanced pancreatic cancer: A phase I/II trial. J Clin Oncol 2011;29:4548-4554.

292. Catane R, Von Hoff D, Glaubiger D, Muggia F. Azaserine, DON, and azotomycin: three diazo analogs of L-glutamine with clinical antitumor activity. Cancer Treat Rep 1979;63(6):1033-1038.

293. Guo L, Zhou B, Liu Z, Xu Y, Lu H, Xia M. Blockage of glutaminolysis enhances the sensitivity of ovarian cancer cells to PI3K/mTOR inhibition involvement of STAT3 signaling. Tumor Biol 2016;37:11007-11015.

294. Han T, Guo M, Zhang T, Gan M, Xie C. A novel glutaminase inhibitor-968 inhibits the migration and proliferation of non-small cell lung cancer cells by targeting EGFR/ERK signaling pathway. Oncotarget 2017;8(17):28063-28073.

295. Yuan L, Sheng X, Clark LH, et al. Glutaminase inhibitor compound 968 inhibits cell proliferation and sensitizes paclitaxel in ovarian cancer. Am J Transl Res 2016;8(10):4265-4277.

296. Xie C, Jin J, Bao X, Zhan W, Han T, Gan M. Inhibition of mitochondrial glutaminase activity reverses acquired erlotinib resistance in non-small cell lung cancer. Oncotarget 2016;7:610-621.

297. Murray-Stewart TR, Woster PM, Casero Jr RA. Targeting polyamine metabolism for cancer therapy and prevention. Biochem J 2016;473:2937-2953.

298. Astaldi G, Burgio G., Krc J, Genova R, Astaldi A. J. L-asparaginase and blastogenesis. Lancet 1969;1:423.

299. Prager MD, Derr I. Metabolism of asparagine, aspartate, glutamine, and glutamate in lymphoid tissue: Basis for immunosuppression by L-asparaginase. $J$ Immunol 1971;106:975-979.

300. Kafkewitz D, Bendich A. Enzyme-induced asparagine and glutamine depletion and immune system function. Am J Clin Nutr 1983;37:1025-1030. 
301. Torres A, Luke JD, Kullas AL, et al. Asparagine deprivation mediated by Salmonella asparaginase causes suppression of activation-induced $\mathrm{T}$ cell metabolic reprogramming. J Leukoc Biol 2016;99:387-398.

302. Song $\mathrm{P}$, Wang $\mathrm{Z}$, Zhang $\mathrm{X}$, et al. The role of autophagy in asparaginase-induced immune suppression of macrophages. Cell Death Dis 2017;8:e2721.

303. Lucca L, Hafler D. Resisting fatal attraction: a glioma oncometabolite prevents CD8+ T cell recruitment. J Clin Invest 2017;127(4):1218-1220.

304. Birendra K, Dinardo CD. Evidence for clinical differentiation and differentiation syndrome in patients with acute myeloid leukemia and IDH1 mutations treated with the targeted mutant IDH1 inhibitor, AG-120. Clin Lymphoma, Myeloma Leuk 2016;16(8):460-465.

305. Yen K, Travins J, Wang F, et al. AG-221, a first-in-class therapy targeting acute myeloid leukemia harboring oncogenic IDH2 mutations. Cancer Discov 2017;7:478-493.

306. Dang L, Su SM. Isocitrate dehydrogenase mutation and (R)-2-hydroxyglutarate: From basic discovery to therapeutics development. Annu Rev Biochem 2017;86:305-331.

307. Yang M, Soga T, Pollard PJ, Adam J. The emerging role of fumarate as an oncometabolite. Front Oncol 2012;2:1-7.

308. Mu X, Zhao T, Xu C, Shi W, Geng B, Shen J. Oncometabolite succinate promotes angiogenesis by upregulating VEGF expression through GPR91mediated STAT3 and ERK activation. Oncotarget 2017;8(8):13174-13185.

309. Velaei K, Samadi N, Barazvan B, Soleimani Rad J. Tumor microenvironmentmediated chemoresistance in breast cancer. Breast 2016;30:92-100.

310. El Sayed SM, Abou El-Magd RM, Shishido Y, et al. D-Amino acid oxidaseinduced oxidative stress, 3-bromopyruvate and citrate inhibit angiogenesis, exhibiting potent anticancer effects. J Bioenerg Biomembr 2012;44:513-523.

311. Merchan JR, Kovács K, Railsback JW, et al. Antiangiogenic activity of 2-deoxyD-glucose. PLoS One 2010;5(10):e13699.

312. Roy S, Maity P. Effect of glutamine analogue-acivicin on tumor induced angiogenesis in Ehrlich ascites carcinoma. Indian J Exp Bol 2005;43:407-413.

313. Abdel-Aziz AK, Shouman S, El-Demerdash E, Elgendy M, Abdel-Naim AB. Chloroquine synergizes sunitinib cytotoxicity via modulating autophagic, apoptotic and angiogenic machineries. Chem Biol Interact 2014;217:28-40. 
314. Araújo FA, Rocha MA, Capettini LSA, et al. 3-Hydroxy-3-methylglutaryl coenzyme A reductase inhibitor (fluvastatin) decreases inflammatory angiogenesis in mice. APMIS 2013;121:422-430.

315. Kucharzewska P, Welch JE, Svensson KJ, Belting M. Ornithine decarboxylase and extracellular polyamines regulate microvascular sprouting and actin cytoskeleton dynamics in endothelial cells. Exp Cell Res 2010;316:2683-2691.

316. Takigawa M, Enomoto M, Nishida Y, Pan HO, Kinoshita A, Suzuki F. Tumor angiogenesis and polyamines: $\alpha$-difluoromethylornithine, an irreversible inhibitor of ornithine decarboxylase, inhibits B16 melanoma-induced angiogensis in ovo and the proliferation of vascular endothelial cells in vitro. Cancer Res 1990;50:4131-4138.

317. Allen E, Miéville P, Warren CM, et al. Metabolic symbiosis enables adaptive resistance to anti-angiogenic therapy that is dependent on mTOR signaling. Cell Reports 2016;15:1144-1160

318. Jiménez-Valerio G, Martínez-Lozano $M$, Bassani $N$, et al. Resistance to antiangiogenic therapies by metabolic symbiosis in renal cell carcinoma PDX models and patients. Cell Reports 2016;15-1134-1143

319. Pisarsky L, Bill R, Fagiani E, et al. Targeting metabolic symbiosis to overcome resistance to anti-angiogenic therapy. Cell Reports 2016;15:1161-1174

320. Parra-bonilla G, Alvarez DF, Alexeyev M, Stevens T. Critical role for lactate dehydrogenase A in aerobic glycolysis that sustains pulmonary microvascular endothelial cell proliferation. Am J Physiol Lung Cell Mol Physiol 2010;299:513-522.

321. Cantelmo AR, Conradi L-C, Brajic A, et al. Inhibition of the glycolytic activator PFKFB3 in endothelium induces tumor vessel normalization, impairs metastasis, and improves chemotherapy. Cancer Cell 2016;30:1-18.

322. Harjes U, Kalucka J, Carmeliet P. Targeting fatty acid metabolism in cancer and endothelial cells. Crit Rev Oncol Hematol 2016;97:15-21.

323. Gacche RN, Meshram RJ. Angiogenic factors as potential drug target: Efficacy and limitations of anti-angiogenic therapy. Biochim Biophys Acta 2014;1846:161-179.

324. Ramjiawan RR, Griffioen AW, Duda DG. Anti-angiogenesis for cancer revisited: Is there a role for combinations with immunotherapy? Angiogenesis 2017;20:185-204.

325. Jiménez-Valerio G, Casanovas O. Angiogenesis and metabolism: entwined for 
therapy resistance. Trends in Cancer 2017;3(1):10-18.

326. Bueno MJ, Mouron S, Quintela-Fandino M. Personalising and targeting antiangiogenic resistance: A complex and multifactorial approach. $\mathrm{Br} J$ Cancer 2017;116:1119-1125.

327. Doherty J, Cleveland J. Targeting lactate metabolism for cancer therapeutics. $J$ Clin Invest 2013;123(9):3685-3692.

328. Tebbe C, Chhina J, Dar SA, et al. Metformin limits the adipocyte tumorpromoting effect on ovarian cancer. Oncotarget 2014;5(13):4746-4764.

329. Martinez-Outschoorn UE, Balliet RM, Rivadeneira DB, et al. Oxidative stress in cancer associated fibroblasts drives tumor-stroma co-evolution: A new paradigm for understanding tumor metabolism, the field effect and genomic instability in cancer cells. Cell Cycle 2010;9(16):3256-3276.

330. Romero IL, Mukherjee A, Kenny HA, Litchfield LM, Lengyel E. Molecular pathways: Trafficking of metabolic resources in the tumor microenvironment. Clin Cancer Res 2015;21(4):680-686.

331. Allard B, Pommey S, Smyth MJ, Stagg J. Targeting CD73 enhances the antitumor activity of anti-PD-1 and anti-CTLA-4 mAbs. Clin Cancer Res 2013;19(20):5626-5635.

332. García-Caballero M, Marí-Beffa M, Medina MA, Quesada AR. Dimethylfumarate inhibits angiogenesis in vitro and in vivo: a possible role for its antipsoriatic effect? J Invest Dermatol 2011;131:1347-1355.

333. Eminel S, Jin N, Rostami M, Dibbert S, Mrowietz U, Suhrkamp I. Dimethyl- and monomethylfumarater regulate indolamine 2,3-dioxygenase (IDO) activity in human immune cells. Exp Dermatol 2016.

334. Su C, Zhang P, Liu J, Cao Y. Erianin inhibits indoleamine 2,3-dioxygenaseinduced tumor angiogenesis. Biomed Pharmacother 2017;88:521-528.

335. Panda S. Circadian physiology of metabolism. Science 2016;354(6315):317-322.

336. Ullah MS, Davies AJ, Halestrap AP. The plasma membrane lactate transporter MCT4, but not MCT1, is up-regulated by hypoxia through a HIF-1 $\alpha$-dependent mechanism. J Biol Chem 2006;281(14):9030-9037.

337. Wakil SJ, Abu-Elheiga LA. Fatty acid metabolism: target for metabolic syndrome. J Lipid Res 2009;50:S138-S143.

338. Rider MH. Role of AMP-activated protein kinase in metabolic depression in animals. J Comp Physiol B 2016;186(1):1-16. 
339. Draoui N, Feron O. Lactate shuttles at a glance: from physiological paradigms to anti-cancer treatments. Dis Model Mech 2011;4:727-732.

340. Skelton MS, Kremer DE, Smith EW, Gladden LB. Lactate influx into red blood cells of athletic and nonathletic species. Am J Physiol 1995;268(5):R1121R1128.

341. Brooks GA. Cell-cell and intracellular lactate shuttles. $J$ Physiol 2009;587(23):5591-5600.

342. Pellerin L, Magistretti PJ. Glutamate uptake into astrocytes stimulates aerobic glycolysis: a mechanism coupling neuronal activity to glucose utilization. Proc Natl Acad Sci 1994;91:10625-10629.

343. Sieber MH, Spradling AC. The role of metabolic states in development and disease. Curr Opin Genet Dev 2017;45:58-68.

344. Hessini K, Kronzucker HJ, Abdelly C, Cruz C. Drought stress obliterates the preference for ammonium as an N source in the C4 plant Spartina alterniflora. $J$ Plant Physiol 2017;213:98-107.

345. Alkan N, Fortes AM. Insights into molecular and metabolic events associated with fruit response to post-harvest fungal pathogens. Front Plant Sci 2015;6:114.

346. Zhan T, Digel M, Küch E-M, Stremmel W, Füllekrug J. Silybin and dehydrosilybin decrease glucose uptake by inhibiting GLUT proteins. $J$ Cell Biochem 2011;112:849-859.

347. Liu Y, Cao Y, Zhang W, et al. A small-molecule inhibitor of glucose transporter 1 downregulates glycolysis, induces cell-cycle arrest, and inhibits cancer cell growth in vitro and in vivo. Ther Discov 2012;11(8):1672-1683.

348. Wood TE, Dalili S, Simpson CD, et al. A novel inhibitor of glucose uptake sensitizes cells to FAS-induced cell death. Mol Cancer Ther 2008;7(11):35463555 .

349. Cao X, Fang L, Gibbs S, et al. Glucose uptake inhibitor sensitizes cancer cells to daunorubicin and overcomes drug resistance in hypoxia. Cancer Chemother Pharmacol 2007;59:495-505.

350. Vera JC, Reyes AM, Ca JG, et al. Genistein is a natural inhibitor of hexose and dehydroascorbic acid transport through the glucose transporter, GLUT1. J Biol Chem 1996;271(15):8719-8724.

351. Gunnink LK, Alabi OD, Kuiper BD, et al. Curcumin directly inhibits the transport activity of GLUT1. Biochimie 2016;125:179-185. 
352. Woodward GE, Cramer FB. 2-Desoxy-D-glucose as an inhibitor of anaerobic glycolysis in tumor tissue. J Franklin Inst 1952;254(3):259-260.

353. Ko YH, Pedersen PL, Geschwind JF. Glucose catabolism in the rabbit VX2 tumor model for liver cancer: characterization and targeting hexokinase. Cancer Lett 2001;173:83-91.

354. Floridi A, Paggi MG, Atri SD, et al. Effect of lonidamine on the energy metabolism of Ehrlich ascites tumor cells. Cancer Res 1981;41:4661-4666.

355. Cohen S, Flescher E. Methyl jasmonate: A plant stress hormone as an anti-cancer drug. Phytochemistry 2009;70:1600-1609.

356. Clem BF, Neal JO, Tapolsky G, et al. Targeting 6-phosphofructo-2-kinase (PFKFB3) as a therapeutic strategy against cancer. Mol Cancer Ther 2013;12(8):1461-1471.

357. McKee RW, Wong W, Landman M. Effects of iodoacetate on glycolysis and respiration in Ehrlich-lettré ascites carcinoma cells. Biochim Biophys Acta $1965 ; 105: 410-423$.

358. Chen J, Xie J, Jiang Z, Wang B, Wang Y, Hu X. Shikonin and its analogs inhibit cancer cell glycolysis by targeting tumor pyruvate kinase-M2. Oncogene 2011;30:4297-4306.

359. Le A, Cooper CR, Gouw AM, et al. Inhibition of lactate dehydrogenase A induces oxidative stress and inhibits tumor progression. Proc Natl Acad Sci 2010;107(5):2037-2042.

360. Farabegoli F, Vettraino M, Manerba M, Fiume L, Roberti M, Stefano G Di. Galloflavin, a new lactate dehydrogenase inhibitor, induces the death of human breast cancer cells with different glycolytic attitude by affecting distinct signaling pathways. Eur J Pharm Sci 2012;47:729-738.

361. Boudreau A, Purkey HE, Hitz A, et al. Metabolic plasticity underpins innate and acquired resistance to LDHA inhibition. Nat Chem Biol 2016;12:779-786.

362. Yu Y, Deck JA, Hunsaker LA, et al. Selective active site inhibitors of human lactate dehydrogenases. Biochem Pharmacol 2001;62:81-89.

363. Granchi C, Calveresi EC, Tuccinardi T, et al. Assessing the differential action of cancer cells of LDH-A inhibitors based on the N-hydroxyindole-2-carboxylate (NHI) and malonic (Mal) scaffolds. Org Biomol Chem 2013;11:6588-6596.

364. Elwood JC. Effect of oxamate on glycolysis and respiration in sarcoma 37 ascites cells. Cancer Res 1968;28:2056-2060. 
365. Sasaki S, Futagi Y, Ideno M, et al. Effect of diclofenac on SLC16A3/MCT4 by the Caco-2 cell line. Drug Metab Pharmacokinet 2016;31(3):218-223.

366. Nancolas B, Guo L, Zhou R, et al. The anti-tumour agent lonidamine is a potent inhibitor of the mitochondrial pyruvate carrier and plasma membrane monocarboxylate transporters. Biochem J 2016;473(7):929-936.

367. Baltazar F, Pinheiro C, Queirós O, Preto A, Casal M. Monocarboxylate transporters as targets and mediators in cancer therapy response. Histol Histopathol 2014;29:1511-1524.

368. Polanski R, Hodgkinson CL, Fusi A, et al. Activity of the monocarboxylate transporter 1 inhibitor AZD3965 in small cell lung cancer. Clin Cancer Res 2014;20(4):926-938.

369. Sonveaux P, Végran F, Schroeder T, et al. Targeting lactate-fueled respiration selectively kills hypoxic tumor cells in mice. J Clin Invest 2008;118:3930-3942.

370. Lee KC, Shorr R, Rodriguez R, Maturo C, Boteju LW, Sheldon A. Formation and anti-tumor activity of uncommon in vitro and in vivo metabolites of CPI-613, a novel anti-tumor compound that selectively alters tumor energy metabolism. Drug Metab Lett 2011;5:163-182.

371. Papandreou I, Goliasova T, Denko NC. Anticancer drugs that target metabolism: is dichloroacetate the new paradigm? Int J Cancer 2011;128:1001-1008.

372. Stacpoole PW, Harman EM, Curry SH, Baumgartner TG, Misbin RI. Treatment of lactic acidosis with dichloroacetate. N Engl J Med 1983;309(7):390-396.

373. Stuart SD, Schauble A, Gupta S, et al. A strategically designed small molecule attacks alpha-ketoglutarate dehydrogenase in tumor cells through a redox process. Cancer Metab 2014;2:4.

374. Rohle D, Popovici-Muller J, Palaskas N, et al. An inhibitor of mutant IDH1 delays growth and promotes differentiation of glioma cells. Science 2013;340(6132):626-630.

375. Wang F, Travins J, DeLaBarre B, et al. Targeted inhibition of mutant IDH2 in leukemia cells induces cellular differentiation. Science 2013;340(6132):622-626.

376. Halestrap AP. The mitochondrial pyruvate carrier. Kinetics and specificity for substrates and inhibitors. Biochem J 1975;148:85-96.

377. Britten CD, Rowinsky EK, Baker SD, et al. A phase I and pharmacokinetic study of the mitochondrial-specific rhodacyanine dye analog MKT 077. Clin Cancer Res 2000;6:42-49. 
378. Boukalova S, Stursa J, Werner L, et al. Mitochondrial targeting of metformin enhances its activity against pancreatic cancer. Mol Cancer Ther 2016;15(12):2875-2886.

379. Marchiq I, Floch R Le, Simon M, Pouyssegur J. Genetic disruption of lactate/H+ symporters (MCTs) and their subunit CD147/BASIGIN sensitizes glycolytic tumor cells to phenformin. Cancer Res 2015;75(1):171-181.

380. Figueras MJ, Gosalvez M. Inhibition of the growth of Ehrlich ascites tumors by treatment with the respiratory inhibitor rotenone. Eur J Cancer 1973;9:529-531.

381. Prager R, Schernthaner G. Insulin receptor binding to monocytes, insulin secretion, and glucose tolerance following metformin treatment. Results of a double-blind cross-over study in type II diabetics. Diabetes 1983;32:1083-1086.

382. Kroemer G, de Thé H. Arsenic trioxide, a novel mitochondriotoxic anticancer agent? J Natl Cancer Inst 1999;91(9):743-745.

383. Seltzer MJ, Bennett BD, Joshi AD, et al. Inhibition of glutaminase preferentially slows growth of glioma cells with mutant IDH1. Cancer Res 2010;70(22):89818988 .

384. Gross MI, Demo SD, Dennison JB, et al. Antitumor activity of the glutaminase inhibitor CB-839 in triple-negative breast cancer. Mol Cancer Ther 2014;13:890901.

385. Altman BJ, Stine ZE, Dang C V. From Krebs to clinic: glutamine metabolism to cancer therapy. Nat Rev Cancer 2016;16:619-634.

386. Zhang J, Wang G, Mao Q, et al. Glutamate dehydrogenase (GDH) regulates bioenergetics and redox homeostasis in human glioma. Oncotarget 2016;1-12.

387. Thornburg JM, Nelson KK, Clem BF, et al. Targeting aspartate aminotransferase in breast cancer. Breast Cancer Res 2008;10:R84.

388. Guth PS, Risey J, Briner W, et al. Evaluation of amino-oxyacetic acid as a palliative in tinnitus. Ann Otol Rhinol Laryngol 1990;99(1):74-79.

389. Berge K, Tronstad KJ, Bohov P, Madsen L, Berge RK. Impact of mitochondrial $\beta$-oxidation in fatty acid-mediated inhibition of glioma cell proliferation. J Lipid Res 2003;44:118-127.

390. Flaig TW, Salzmann-sullivan M, Su L, et al. Lipid catabolism inhibition sensitizes prostate cancer cells to antiandrogen blockade. Oncotarget 2017

391. Roberts LN, Mason GP. Clinical trial of a new antianginal drug: Perhexiline maleate. J Clin Pharmacol 1972;12(8):342-348. 
392. Jones SF, Infante JR. Molecular pathways: Fatty acid synthase. Clin Cancer Res 2015;21(24):5434-5439.

393. Pizer ES, Chrest FJ, DiGiuseppe JA, Han WF. Pharmacological inhibitors of mammalian fatty acid synthase suppress DNA replication and induce apoptosis in tumor cell lines. Cancer Res 1998;58:4611-4615.

394. Kridel SJ, Axelrod F, Rozenkrantz N, Smith JW. Orlistat is a novel inhibitor of fatty acid synthase with antitumor activity. Cancer Res 2004;64:2070-2075.

395. Hanai J, Doro N, Seth P, Sukhatme VP. ATP citrate lyase knockdown impacts cancer stem cells in vitro. Cell Death Dis 2013;4:e696.

396. Hatzivassiliou G, Zhao F, Bauer DE, et al. ATP citrate lyase inhibition can suppress tumor cell growth. Cancer Cell 2005;8:311-321.

397. Zhou W, Simpson PJ, McFadden JM, et al. Fatty acid synthase inhibition triggers apoptosis during S phase in human cancer cells. Cancer Res 2003;63:7330-7337.

398. Clem BF, Clem AL, Yalcin A, et al. A novel small molecule antagonist of choline kinase- $\alpha$ that simultaneously suppresses MAPK and PI3K/AKT signaling. Oncogene 2011;30:3370-3380.

399. Rodríguez-González A, Ramírez de Molina A, Fernández F, et al. Inhibition of choline kinase as a specific cytotoxic strategy in oncogene-transformed cells. Oncogene 2003;22:8803-8812.

400. Sánchez-López E, Zimmerman T, Gómez del Pulgar T, Moyer MP, Lacal Sanjuan JC, Cebrian A. Choline kinase inhibition induces exacerbated endoplasmic reticulum stress and triggers apoptosis via CHOP in cancer cells. Cell Death Dis 2013;4:e933.

401. de la Cueva A, Ramírez de Molina A, Álvarez-Ayerza N, et al. Combined 5-FU and ChoK $\alpha$ inhibitors as a new alternative therapy of colorectal cancer: evidence in human tumor-derived cell lines and mouse xenografts. PLoS One 2013;8(6):e64961.

402. Mashima T, Oh-hara T, Sato S, et al. p53-defective tumors with a functional apoptosome-mediated pathway: A new therapeutic target. $J$ Natl Cancer Inst 2005;97(10):765-777.

403. Matusewicz L, Meissner J, Toporkiewicz M, Sikorski AF. The effect of statins on cancer cells — review. Tumor Biol 2015;36(7):4889-4904.

404. Kubatka P, Kruzliak P, Rotrekl V, Jelinkova S, Mladosievicova B. Statins in oncological research: From experimental studies to clinical practice. Crit Rev Oncol Hematol 2014;92:296-311. 
405. Chen $\mathrm{Y}, \mathrm{Xu} \mathrm{Q}$, Ji D, et al. Inhibition of pentose phosphate pathway suppresses acute myelogenous leukemia. Tumor Biol 2016;37(5):6027-6034.

406. Ghashghaeinia M, Giustarini D, Koralkov P, et al. Pharmacological targeting of glucose-6-phosphate dehydrogenase in human erythrocytes by Bay 11-7082, parthenolide and dimethyl fumarate. Sci Rep 2016;6:28754.

407. Shin ES, Park J, Shin JM, et al. Catechin gallates are NADP+-competitive inhibitors of glucose-6-phosphate dehydrogenase and other enzymes that employ NADP+ as a coenzyme. Bioorg Med Chem 2008;16:3580-3586.

408. Boros LG, Puigjaner J, Cascante $\mathrm{M}$, et al. Oxythiamine and dehydroepiandrosterone inhibit the nonoxidative synthesis of ribose and tumor cell proliferation. Cancer Res 1997;57:4242-4248.

409. Hitosugi T, Zhou L, Elf S, et al. Phosphoglycerate mutase 1 coordinates glycolysis and biosynthesis to promote tumor growth. Cancer Cell 2012;22:585600 .

410. Feun LG, Kuo MT, Savaraj N. Arginine deprivation in cancer therapy. Curr Opin Clin Nutr Metab Care 2015;18:78-82.

411. Yau T, Cheng PN, Chan P, et al. A phase 1 dose-escalating study of pegylated recombinant human arginase 1 (Peg-rhArg1) in patients with advanced hepatocellular carcinoma. Invest New Drugs 2013;31:99-107.

412. Lukey MJ, Katt WP, Cerione RA. Targeting amino acid metabolism for cancer therapy. Drug Discov Today 2017;22(5):796-804.

413. Serafini P, Meckel K, Kelso M, et al. Phosphodiesterase-5 inhibition augments endogenous antitumor immunity by reducing myeloid-derived suppressor cell function. J Exp Med 2006;203(12):2691-2702.

414. Jochems C, Fantini M, Fernando RI, et al. The IDO1 selective inhibitor epacadostat enhances dendritic cell immunogenicity and lytic ability of tumor antigen-specific T cells. Oncotarget 2016;7(25):37762-37772.

415. Löb S, Königsrainer A, Rammensee H, Opelz G, Terness P. Inhibitors of indoleamine-2,3-dioxygenase for cancer therapy: can we see the wood for the trees? Nat Rev Cancer 2009;9:445-452.

416. Liu X, Shin N, Koblish HK, et al. Selective inhibition of IDO1 effectively regulates mediators of antitumor immunity. Blood 2010;115(17):3520-3531.

417. Williams-Ashman HG, Schenone A. Methyl glyoxal bis(guanylhydrazone) as a potent inhibitor of mammalian and yeast S-adenosylmethionine decarboxylases. Biochem Biophys Res Commun 1972;46(1):288-295. 
418. Siu LL, Rowinsky EK, Hammond LA, et al. A phase I and pharmacokinetic study of SAM486A, a novel polyamine biosynthesis inhibitor, administered on a daily-times-five every-three-week schedule in patients with advanced solid malignancies. Clin Cancer Res 2002;8:2157-2166.

419. Samal K, Zhao P, Kendzicky A, et al. AMXT-1501, a novel polyamine transport inhibitor, synergizes with DFMO in inhibiting neuroblastoma cell proliferation by targeting both ornithine decarboxylase and polyamine transport. Int $J$ Cancer 2013;133:1323-1334.

420. Tang K-C, Pegg E, Coward JK. Specific and potent inhibition of spermidine synthase by the transitio-state analog, S-adenosyl-3-thio-1,8-diaminooctane. Biochem Biophys Res Commun 1980;96(3):1371-1377.

421. Woster PM, Black AY, Duff KJ, Coward JK, Pegg AE. Synthesis and biological evaluation of S-adenosyl-1,12-diamino-3-thio-9-azadodecane, a multisubstrate adduct inhibitor of spermine synthase. $J$ Med Chem 1989;32(6):1300-1307.

422. Gonen N, Assaraf YG. Antifolates in cancer therapy: Structure, activity and mechanisms of drug resistance. Drug Resist Updat 2012;15:183-210.

423. Wilson PM, Danenberg P V, Johnston PG, Lenz H, Ladner RD. Standing the test of time: targeting thymidylate biosynthesis in cancer therapy. Nat Rev Clin Oncol 2014;11:282-298.

424. Ma J, Wang S, Zhao M, et al. Therapeutic potential of cladribine in combination with STAT3 inhibitor against multiple myeloma. BMC Cancer 2011;11:255.

425. Cavalcante LDS, Monteiro G. Gemcitabine: Metabolism and molecular mechanisms of action, sensitivity and chemoresistance in pancreatic cancer. Eur J Pharmacol 2014;741:8-16.

426. Madaan K, Kaushik D, Verma T. Hydroxyurea: a key player in cancer chemotherapy. Expert Rev Anticancer Ther 2012;12(1):19-29.

427. McLaughlin B, Im A, Raptis A, et al. Fludarabine and cytarabine in patients with relapsed acute myeloid leukemia refractory to initial salvage therapy. Int $J$ Hematol 2012;96:743-747.

428. Talekar M, Boreddy SR, Singh A, Amiji M. Tumor aerobic glycolysis: new insights into therapeutic strategies with targeted delivery. Expert Opin Biol Ther 2014;14(8):1145-1159.

429. Chiarini F, Evangelisti C, Mccubrey JA, Martelli AM. Current treatment strategies for inhibiting mTOR in cancer. Trends Pharmacol Sci 2015;36(2):124135. 
430. Maráz A, Csejtei A, Kocsis J, et al. Assessment of the role of everolimus therapy in patients with renal cell carcinoma based on daily routine and recent research results. Pathol Oncol Res 2017.

431. Dasgupta S, Rajapakshe K, Zhu B, et al. Metabolic enzyme PFKFB4 activates transcriptional coactivator SRC-3 to drive breast cancer. Nature 2018;556:249254

432. Garber K. First metabolic oncology inhibitor gets FDA green light, with record price tag. Nat Biotech 2017;35:895 


\section{AUTHOR BIOSKETCHES}

\section{$M^{a}$ Carmen Ocaña}

$\mathrm{M}^{\mathrm{a}}$ Carmen Ocaña, BS in Biology and Master in Cell and Molecular Biology by the University of Málaga (Spain) in 2014 and 2016, respectively, is a $\mathrm{PhD}$ student in the Molecular Biology and Biochemistry Department at University of Málaga (Spain). She is currently studying the metabolism of endothelial cells and its relationship with the angiogenic process. Moreover, she is testing the capacity of different compounds to affect metabolism, angiogenesis and/or inflammation. She is also interested in studying metabolism of endothelial cells in the context of the tumor microenvironment.

\section{Beatriz Martínez Poveda}

Beatriz Martínez Poveda was graduated in Biology at the University of Malaga (Spain) in 2002 and she achieved her international PhD at the same University in 2007 working on characterization of new natural compounds with anti-angiogenic potential. Then she moved to Madrid for a first post-doctoral period in the Biomedical Research Institute (IIB, Madrid), focusing on the study of hypoxia and anti-angiogenic therapy in tumors using in vivo imaging techniques. In 2009, she started a second post-doctoral period in the Cardiovascular Research National Institute (CNIC, Madrid) working mainly in the molecular characterization of cardiovascular diseases, with significant contributions in the field of aortic valve stenosis and calcification, atherosclerosis and left ventricle noncompaction. Since 2015 Dr. Martínez-Poveda is working as Assistant Professor in the Department of Molecular Biology and Biochemistry at the University of Málaga, and as a post-doctoral researcher in projects related to tumoral angiogenesis and inflammation.

\section{Ana Rodríguez Quesada}

Ana R. Quesada graduated in chemistry at the University of Granada (Spain) in 1982 and obtained her Ph.D. in Biochemistry at University of Malaga (Spain) in 1987. She was visiting scientist at the University of Bristol (UK) in 1987 and at the UWM (Wisconsin, USA) in 1991. After working seven years in research departments of pharmaceutical companies, she moved to the University of Malaga in 2004, where she is holding a Full Professor position at the Department of Molecular Biology and Biochemistry. Ana has a special interest in the search and characterization of new antiangiogenic drug candidates.

\section{Miguel Ángel Medina}

Miguel Ángel Medina graduated in Biology at the University of Málaga (Spain) in 1985, where he later obtained his Ph.D. in Biochemistry in 1989. He has been visiting scientist at McGill University (Canada, 1987), the Max Planck Institut für Ernhärungsphysiologie (Dortmund, Germany, 1989), the University of Heidelberg (Germany, 1992) and the Max Planck Institut für biophysikalisches-Chemie (Göttingen, Germany, 2001). He was Assistant (1990-94) and Associate (1995-2009) Professor and 
he is currently holding a Full Professor position (2009-today) at the Department of Molecular Biology and Biochemistry (University of Málaga, Spain). Miguel Ángel has a special interest in the search and characterization of new anti-angiogenic drug candidates. Other research interests include cancer metabolism, systems biology, metabolic modeling and rare diseases. He is the (co)-author of around 200 articles in international science journals. 
Table 1. Metabolic modulators with proved anti-tumor activity.

\begin{tabular}{|c|c|c|c|}
\hline Target & Drug & Observations & References \\
\hline \multicolumn{4}{|l|}{ Glycolysis } \\
\hline GLUT1 & $\begin{array}{l}\text { Curcumin } \\
\text { Fasentin } \\
\text { Genistein } \\
\text { Phloretin } \\
\text { Silibinin } \\
\text { WZB117 }\end{array}$ & $\begin{array}{l}\text { Silibinin is in Phase II of } \\
\text { clinical trials (prostate } \\
\text { cancer). } \\
\text { Curcumin }^{\mathrm{b}} \text { and genistein } \\
\text { are in clinical trials } \\
\text { (multiple kinds of } \\
\text { cancer). }\end{array}$ & $346-351$ \\
\hline Hexokinases & $\begin{array}{c}\text { 2-DG } \\
\text { 3-bromopyruvate } \\
\text { Lonidamine } \\
\text { Methyl jasmonate }\end{array}$ & $\begin{array}{l}\text { Lonidamine is in Phase } \\
\text { III of clinical trials } \\
\text { (prostate cancer). } \\
\text { 2-DG is in clinical trials } \\
\text { (multiple kinds of } \\
\text { cancer). }\end{array}$ & $352-355$ \\
\hline PFKFB3 & $\begin{array}{c}\text { 3PO } \\
\text { PFK15 }\end{array}$ & & 321,356 \\
\hline G3PDH & Iodoacetate & & 357 \\
\hline PKM2 & Shikonin & & 358 \\
\hline LDH-A & $\begin{array}{c}\text { FX11 } \\
\text { Galloflavin } \\
\text { GNE-140 } \\
\text { Gossypol } \\
\text { NHI } \\
\text { Oxamate } \\
\text { Panepoxydone }\end{array}$ & $\begin{array}{l}\text { Gossypol is in clinical } \\
\text { trials (multiple kinds of } \\
\text { cancer). }{ }^{\mathrm{f}}\end{array}$ & $20,359-364$ \\
\hline \multicolumn{4}{|l|}{ Lactate secretion } \\
\hline MCT4 & $\begin{array}{l}\text { Diclofenac } \\
\text { Lonidamine }\end{array}$ & $\begin{array}{l}\text { Diclofenac is FDA } \\
\text { approved (anti- } \\
\text { inflammatory drug). } \\
\text { Lonidamine is in Phase } \\
\text { III of clinical trials } \\
\text { (prostate cancer). }^{\mathrm{d}}\end{array}$ & 365,366 \\
\hline \multicolumn{4}{|l|}{ Lactate uptake } \\
\hline MCT1 & $\begin{array}{c}\text { AR-C155858 } \\
\text { AZD3965 } \\
\text { CHC }\end{array}$ & $\begin{array}{c}\text { AR-C155858 is in } \\
\text { preclinical studies. } \\
\text { AZD3965 is in Phase I of }\end{array}$ & $366-369$ \\
\hline
\end{tabular}




\begin{tabular}{|c|c|c|c|}
\hline & Lonidamine & $\begin{array}{l}\text { clinical trials (gastric } \\
\text { cancer, prostate cancer } \\
\text { and lymphoma). } \\
\text { Lonidamine is in Phase } \\
\text { III of clinical trials } \\
\text { (prostate cancer). }{ }^{\mathrm{d}}\end{array}$ & \\
\hline \multicolumn{4}{|l|}{ TCA cycle } \\
\hline $\mathrm{PDH}$ & $\begin{array}{l}\text { CPI-613 } \\
\end{array}$ & $\begin{array}{l}\text { Clinical trials (multiple } \\
\text { kinds of cancer). }{ }^{\mathrm{h}}\end{array}$ & 370 \\
\hline PDK1 & $\overline{\mathrm{DCA}}$ & $\begin{array}{l}\text { Approved for the } \\
\text { treatment of lactic } \\
\text { acidosis. }\end{array}$ & 371,372 \\
\hline KGDH & CPI-613 & $\begin{array}{l}\text { Clinical trials (multiple } \\
\text { kinds of cancer). }{ }^{\mathrm{h}}\end{array}$ & 373 \\
\hline IDH & $\begin{array}{c}\text { AG-120 (ivosidenib) } \\
\text { AG-221 (enasidenib) } \\
\text { AGI-5198 } \\
\text { AGI-6780 }\end{array}$ & $\begin{array}{c}\text { Ivosidenib }^{1} \text { and } \\
\text { enasidenib }^{\mathrm{j}} \text { are in Phase } \\
\text { III of clinical trials } \\
\text { (leukemia).* }\end{array}$ & $04,305,374,37$ \\
\hline MPC & $\begin{array}{l}\text { Lonidamine } \\
\text { UK-5099 }\end{array}$ & $\begin{array}{l}\text { Lonidamine is in Phase } \\
\text { III of clinical trials } \\
\text { (prostate cancer). }{ }^{\mathrm{d}}\end{array}$ & 36,376 \\
\hline \multicolumn{4}{|l|}{ OXPHOS } \\
\hline $\begin{array}{l}\text { Mitochondrial } \\
\text { potential } \\
\text { membrane }\end{array}$ & MKT-077 & & 377 \\
\hline $\begin{array}{l}\text { Mitochondrial } \\
\text { complex I }\end{array}$ & $\begin{array}{l}\text { Metformin } \\
\text { Phenformin } \\
\text { Rotenone }\end{array}$ & $\begin{array}{l}\text { Metformin is approved } \\
\text { for the treatment of type } \\
2 \text { diabetes. } \\
\text { Phenformin is in Phase I } \\
\text { of clinical trials } \\
\text { (melanoma). }{ }^{\mathrm{k}}\end{array}$ & $378-381$ \\
\hline $\begin{array}{l}\text { Mitochondrial } \\
\text { complex III }\end{array}$ & Arsenic trioxide & $\begin{array}{l}\text { FDA approved for the } \\
\text { treatment of acute } \\
\text { promyelocytic leukemia. }\end{array}$ & 382 \\
\hline \multicolumn{4}{|l|}{$\begin{array}{l}\text { Glutamine } \\
\text { metabolism }\end{array}$} \\
\hline $\begin{array}{c}\text { Glutamine } \\
\text { antimetabolite }\end{array}$ & $\begin{array}{l}\text { Acivicin } \\
\text { Azaserine } \\
\text { DON }\end{array}$ & $\begin{array}{l}\text { Not approved for clinical } \\
\text { due to toxicity. }\end{array}$ & 12 \\
\hline GLS1 & $\begin{array}{c}968 \\
\text { BPTES } \\
\text { CB-839 }\end{array}$ & $\begin{array}{l}\text { CB-839 is in clinical } \\
\text { trials (multiple kinds of } \\
\text { cancer). }{ }^{1}\end{array}$ & $293-296,383,384$ \\
\hline
\end{tabular}




\begin{tabular}{|c|c|c|c|}
\hline SLC1A5 & $\begin{array}{c}\text { Benzylserine } \\
\gamma \text {-FBP } \\
\text { GPNA }\end{array}$ & & 385 \\
\hline GLUD & $\begin{array}{c}\text { EGCG } \\
\text { R162 }\end{array}$ & $\begin{array}{l}\text { EGCG is in clinical trials } \\
\text { (multiple kinds of } \\
\text { cancer). }{ }^{\mathrm{m}}\end{array}$ & 386 \\
\hline Aminotransferases & $\mathrm{AOA}$ & $\begin{array}{l}\text { Approved for the } \\
\text { treatment of tinnitus. }\end{array}$ & 387,388 \\
\hline \multicolumn{4}{|l|}{$\begin{array}{c}\text { Fatty acid } \beta \text { - } \\
\text { oxidation }\end{array}$} \\
\hline CPT1 & $\begin{array}{c}\text { Aminocarnitine } \\
\text { Etomoxir } \\
\text { Perhexiline } \\
\text { Ranolazine }\end{array}$ & $\begin{array}{c}\text { Perhexiline and } \\
\text { ranolazine are approved } \\
\text { for use as an } \\
\text { anti-angina therapy. }\end{array}$ & 389-391 \\
\hline \multicolumn{4}{|l|}{ Lipid synthesis } \\
\hline FAS & $\begin{array}{c}\text { C75 } \\
\text { Cerulenin } \\
\text { Orlistat } \\
\text { TVB-2640 }\end{array}$ & $\begin{array}{l}\text { Orlistat is approved for } \\
\text { the treatment of obesity. } \\
\text { TVB-2640 is in Phase II } \\
\text { of clinical trials (multiple } \\
\text { kinds of cancer). }{ }^{\text {. }}\end{array}$ & $392-394$ \\
\hline$\overline{\mathrm{ACL}}$ & $\begin{array}{l}\text { Hydroxycitrate } \\
\text { SB-204990 }\end{array}$ & & 395,396 \\
\hline ACC & TOFA & & 397 \\
\hline Choline kinase & $\begin{array}{c}\text { CK37 } \\
\text { MN58b } \\
\text { RSM932A } \\
\text { TCD-717 }\end{array}$ & $\begin{array}{l}\text { TCD-717 is in Phase I of } \\
\text { clinical trials (advanced } \\
\text { solid tumors). }\end{array}$ & $398-401$ \\
\hline ACS & Triacsin $\mathrm{C}$ & & 402 \\
\hline \multicolumn{4}{|l|}{$\begin{array}{c}\text { Mevalonate } \\
\text { pathway }\end{array}$} \\
\hline HMGCR & Statins & $\begin{array}{c}\text { Approved for } \\
\text { the treatment of } \\
\text { hypercholesterolaemia }\end{array}$ & 403,404 \\
\hline \multicolumn{4}{|l|}{$\begin{array}{c}\text { Pentose } \\
\text { phosphate } \\
\text { pathway }\end{array}$} \\
\hline G6PDH & $\begin{array}{c}6- \\
\text { aminonicotinamide } \\
\text { DHEA } \\
\text { DMF } \\
\text { EGCG }\end{array}$ & $\begin{array}{l}\text { EGCG is in clinical trials } \\
\text { (multiple kinds of } \\
\text { cancer). }{ }^{\mathrm{m}} \\
\text { Dimethylfumarate is } \\
\text { FDA approved (multiple }\end{array}$ & $405-408$ \\
\hline
\end{tabular}




\begin{tabular}{|c|c|c|c|}
\hline & & sclerosis). & \\
\hline PGAM1 & PGMI-004A & & 409 \\
\hline \multicolumn{4}{|l|}{$\begin{array}{l}\text { Amino acid } \\
\text { metabolism }\end{array}$} \\
\hline $\begin{array}{l}\text { Asparagine } \\
\text { availability }\end{array}$ & L-asparaginase & $\begin{array}{c}\text { FDA approved for the } \\
\text { treatment of acute } \\
\text { lymphoblastic leukemia, } \\
\text { acute myeloid leukemia, } \\
\text { and non-Hodgkin's } \\
\text { lymphoma. }\end{array}$ & 58,63 \\
\hline $\begin{array}{c}\text { Arginine } \\
\text { availability }\end{array}$ & $\begin{array}{l}\text { Pegylated arginine } \\
\text { deiminase } \\
\text { (ADI@PEG20) } \\
\text { rhArg1-PEG (BCT- } \\
\text { 100) }\end{array}$ & $\begin{array}{l}\text { BCT-100 is in Phase II of } \\
\text { clinical trials (multiple } \\
\text { kinds of cancer). }{ }^{\mathrm{p}} \\
\text { ADI-PEG20 is in clinical } \\
\text { trials (multiple kinds of } \\
\text { cancer). }{ }^{\mathrm{q}}\end{array}$ & $410-412$ \\
\hline Arginase & Tadalafil (Cialis) & $\begin{array}{l}\text { FDA approved for the } \\
\text { treatment of benign } \\
\text { prostatic hypertrophy. }\end{array}$ & 14,413 \\
\hline IDO & $\begin{array}{l}\text { 1-methyl-trytophan } \\
\text { (Indoximod) } \\
\text { DMF } \\
\text { Epacadostat } \\
\text { Erianin }\end{array}$ & $\begin{array}{c}\text { Indoximod }^{\mathrm{r}} \text { and } \\
\text { epacadostat } \\
\text { clinical are in } \\
\text { kinds of cancer). } \\
\text { Dimethylfumarate is } \\
\text { FDA approved (multiple } \\
\text { sclerosis). }\end{array}$ & $333,334,414$ \\
\hline \multicolumn{4}{|l|}{$\begin{array}{l}\text { Polyamine } \\
\text { metabolism }\end{array}$} \\
\hline ODC & DFMO & $\begin{array}{l}\text { Phase II of clinical trials } \\
\text { (neuroblastoma). }{ }^{t}\end{array}$ & 84 \\
\hline AMD1 & $\begin{array}{c}\text { MGBG } \\
\text { SAM486A }\end{array}$ & $\begin{array}{l}\text { MGBG is toxic for } \\
\text { clinical development. }\end{array}$ & $85,417,418$ \\
\hline $\begin{array}{l}\text { Polyamine } \\
\text { transport }\end{array}$ & AMXT-1501 & . & 419 \\
\hline $\begin{array}{l}\text { Aminopropyltrans- } \\
\text { ferases }\end{array}$ & $\begin{array}{l}\text { AdoDATAD } \\
\text { AdoDATO }\end{array}$ & & 420,421 \\
\hline Polyamine analogs & $\begin{array}{l}\text { BENSpm } \\
\text { CPENSpm } \\
\text { PG-11047 } \\
\text { PG-11093 }\end{array}$ & $\begin{array}{l}\text { PG-11047 is in Phase I of } \\
\text { clinical trials (advanced } \\
\text { refractory solid tumors } \\
\text { and lymphoma). }\end{array}$ & \\
\hline $\begin{array}{l}\text { Nucleid acid } \\
\text { synthesis }\end{array}$ & & & \\
\hline
\end{tabular}




\begin{tabular}{|c|c|c|c|}
\hline DHFR & $\begin{array}{l}\text { Methotrexate } \\
\text { Pemetrexed } \\
\text { Pralatrexate } \\
\text { Trimitrexate } \\
\text { (antifolates) }\end{array}$ & $\begin{array}{l}\text { Methotrexate is FDA } \\
\text { approved for treatment of } \\
\text { cancer, autoimmune } \\
\text { diseases, ectopic } \\
\text { pregnancy, and for } \\
\text { medical abortions. } \\
\text { Pemetrexed is FDA } \\
\text { approved for the } \\
\text { treatment of pleural } \\
\text { mesothelioma and non- } \\
\text { small cell lung cancer. } \\
\text { Pralatrexate is FDA } \\
\text { approved relapsed or } \\
\text { refractory peripheral T- } \\
\text { cell lymphoma. }\end{array}$ & 422 \\
\hline $\begin{array}{c}\text { Thymidylate } \\
\text { synthase }\end{array}$ & $\begin{array}{c}\text { 5-fluorouracil } \\
\text { Raltitrexed }\end{array}$ & $\begin{array}{l}\text { 5-fluorouracil is FDA } \\
\text { approved for the } \\
\text { treatment of several } \\
\text { kinds of cancer. } \\
\text { Raltitrexed is in Phase IV } \\
\text { of clinical trials (multiple } \\
\text { kinds of cancer). }{ }^{\mathrm{v}}\end{array}$ & 423 \\
\hline $\begin{array}{c}\text { Adenine/adenosine } \\
\text { deaminase }\end{array}$ & Cladribine & $\begin{array}{l}\text { FDA approved for the } \\
\text { treatment of hairy cell } \\
\text { leukemia and B-cell } \\
\text { chronic lymphocytic } \\
\text { leukemia. }\end{array}$ & 424 \\
\hline $\begin{array}{c}\text { DNA polymerase/ } \\
\text { ribonucleotide } \\
\text { reductase }\end{array}$ & $\begin{array}{l}\text { Cytarabine } \\
\text { Fludarabine } \\
\text { Gemcitabine } \\
\text { Hydroxyurea }\end{array}$ & $\begin{array}{l}\text { Cytarabine is FDA } \\
\text { approved for the } \\
\text { treatment of acute } \\
\text { myeloid leukemia, acute } \\
\text { lymphocytic leukemia, } \\
\text { chronic myelogenous } \\
\text { leukemia, and non- } \\
\text { Hodgkin's lymphoma. } \\
\text { Fludarabine is FDA } \\
\text { approved for the } \\
\text { treatment of leukemia } \\
\text { and lymphoma. } \\
\text { Gemcitabine is FDA } \\
\text { approved for the } \\
\text { treatment of several } \\
\text { kinds of cancer. }\end{array}$ & $425-427$ \\
\hline
\end{tabular}




\begin{tabular}{|c|c|c|c|}
\hline & & $\begin{array}{l}\text { Hydroxyurea is FDS } \\
\text { approved for the } \\
\text { treatment of sickle-cell } \\
\text { disease, chronic } \\
\text { myelogenous leukemia, } \\
\text { cervical cancer, and } \\
\text { polycythemia vera. }\end{array}$ & \\
\hline \multicolumn{4}{|l|}{$\begin{array}{l}\text { Nitric oxide } \\
\text { metabolism }\end{array}$} \\
\hline NOS & L-NAME & & 190 \\
\hline \multicolumn{4}{|l|}{$\begin{array}{l}\text { Metabolic } \\
\text { signaling } \\
\text { pathways }\end{array}$} \\
\hline HIF-1 & $\begin{array}{c}\text { Digoxin } \\
\text { Irinotecan } \\
\text { PX478 } \\
\text { Topotecan }\end{array}$ & $\begin{array}{l}\text { PX478 is in Phase I of } \\
\text { clinical trials (advanced } \\
\text { solid tumors and } \\
\text { lymphoma). } \\
\text { Digoxin is FDA } \\
\text { approved for the } \\
\text { treatment of several heart } \\
\text { diseases. } \\
\text { Irinotecan is FDA } \\
\text { approved for the } \\
\text { treatment of colon and } \\
\text { small cell lung cancer. } \\
\text { Topotecan is FDA } \\
\text { approved for the } \\
\text { treatment of several } \\
\text { kinds of cancer. }\end{array}$ & 428 \\
\hline mTOR & $\begin{array}{c}\text { Everolimus } \\
\text { PP242 } \\
\text { Temsirolimus }\end{array}$ & $\begin{array}{c}\text { Everolimus and } \\
\text { temsirolimus are also } \\
\text { approved } \\
\text { immunosuppressants. } \\
\text { Everolimus is approved } \\
\text { for the treatment of } \\
\text { advanced kidney cancer. }\end{array}$ & $293,429,430$ \\
\hline
\end{tabular}

2-DG, 2-deoxyglucose; ACC, acetyl-CoA carboxylase; ACL, ATP citrate lyase; ACS, acyl-CoA synthetase; AdoDATAD, S-adenosyl-1,12-diamino-3-thio-9-azadodecane; AdoDATO, S-adenosyl-3-thio-1,8-diaminooctane; AMD1, adenosylmethionine decarboxylase; AOA, aminooxyacetate; BPTES, bis-2-(5-phenylacetamido-1,3,4thiadiazol-2-yl)ethyl sulfide; CHC, $\alpha$-cyano-4-hydroxycinnamic acid; CPT1, carnitine palmitoyltransferase 1; DCA, dichloroacetate; DFMO, difluoromethylornithine; DHEA, 
dehydroepiandrosterone; DHFR, dihydrofolate reductase; DMF, dimethylfumarate; DON, 6-diazo-5-oxo-L-norleucine; EGCG, epigallocatechin gallate; FAS, fatty acid synthase; $\gamma$-FBP, $\gamma$ ? folate binding protein; G3PDH, glyceraldehyde-3-phosphate dehydrogenase; GLS1, glutaminase; G6PDH, glucose-6-phosphate dehydrogenase; GPNA, L- $\gamma$-glutamyl-p-nitroanilide; GLUD, glutamate dehydrogenase; HIF-1, hypoxiainducible factor 1; HMGCR, HMG-CoA reductase; IDH, isocitrate dehydrogenases; IDO, indoleamine-2,3-dioxygenase; KGDH, $\alpha$-ketoglutarate dehydrogenase; LDH-A, lactate dehydrogenase A; L-NAME, L-NG-nitroarginine methyl ester; MGBG, methylglyoxal(bis)guanylhydrazone; MPC, mitochondrial pyruvate carrier; mTOR, mammalian target of rapamycin; NHI, N-hydroxy-2-carboxy-substituted indoles; NOS, nitric oxide synthase; ODC, ornithine decarboxylase; OXPHOS, oxidative phosphorylation; PDH, pyruvate dehydrogenase; PDK1, pyruvate dehydrogenase kinase 1; PFKFB3, phosphofructokinase-2/fructose-2,6-bisphosphatase 3; PGAM1, phosphoglycerate mutase; PKM2, pyruvate kinase M2; TCA, tricarboxylic acid cycle.

${ }^{a}$ ClinicalTrials.gov Identifier: NCT00487721; ${ }^{b}$ pancreatic cancer, phase II, ClinicalTrials.gov Identifier: NCT00192842; breast cancer, phase II, ClinicalTrials.gov Identifier: NCT01042938; endometrial carcinoma, phase II, ClinicalTrials.gov Identifier: NCT02017353; head and neck cancer, early phase I, ClinicalTrials.gov Identifier: NCT01160302; pancreatic cancer, phase II, ClinicalTrials.gov Identifier: NCT00094445; colorectal cancer, phase I, ClinicalTrials.gov Identifier: NCT00027495; multiple myeloma, ClinicalTrials.gov Identifier: NCT00113841; prostate cancer, phase III, ClinicalTrials.gov Identifier: NCT02064673; osteosarcoma, phase II, ClinicalTrials.gov Identifier: NCT00689195; 'prostate cancer, phase III, ClinicalTrials.gov Identifier: NCT00584532; kidney cancer and melanoma, early phase I, ClinicalTrials.gov Identifier: NCT00276835; breast cancer, phase II, ClinicalTrials.gov Identifier: NCT00244933; bladder cancer, phase II, ClinicalTrials.gov Identifier: NCT00118040; non small cell lung cancer, phase II, ClinicalTrials.gov Identifier: NCT01628471; pancreatic cancer, phase II, ClinicalTrials.gov Identifier: NCT00376948; colorectal cancer, phase II, ClinicalTrials.gov Identifier: NCT01985763; ${ }^{\mathrm{d}}$ ClinicalTrials.gov Identifier: NCT00435448; e prostate cancer, phase II, ClinicalTrials.gov Identifier: NCT00633087; lung cancer, breast cancer, pancreatic cancer, gastric cancer and head and neck cancer, phase I, ClinicalTrials.gov Identifier: NCT00096707; fadult glioblastoma, phase II, ClinicalTrials.gov Identifier: NCT00540722; lymphoma, phase II, ClinicalTrials.gov Identifier: NCT00275431; adrenocortical carcinoma, phase II, ClinicalTrials.gov Identifier: NCT00848016; leukemia, phase II, ClinicalTrials.gov Identifier: NCT00286780; laryngeal cancer, phase II, ClinicalTrials.gov Identifier: NCT01633541; small cell lung cancer, phase II, ClinicalTrials.gov Identifier: NCT00773955; prostate cancer, phase II, ClinicalTrials.gov Identifier: NCT00666666; ${ }^{\mathrm{g}}$ ClinicalTrials.gov Identifier: NCT01791595; ${ }^{\text {}}$ small cell lung cancer, phase I, ClinicalTrials.gov Identifier: NCT01931787; pancreatic cancer, phase I, ClinicalTrials.gov Identifier: NCT01839981; colorectal cancer, phase I, ClinicalTrials.gov Identifier: NCT02232152; adult acute myeloid leukemia, phase I, ClinicalTrials.gov Identifier: NCT01768897; lymphoma, phase I, ClinicalTrials.gov Identifier: NCT02168140; ${ }^{\mathrm{i} C l i n i c a l T r i a l s . g o v}$ Identifier: 


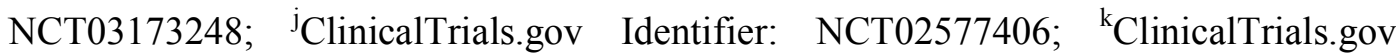
Identifier: NCT03026517; ' colorectal cancer, phase II, ClinicalTrials.gov Identifier: NCT02861300; lymphoma, phase I, ClinicalTrials.gov Identifier: NCT02071888; leukemia, phase I, ClinicalTrials.gov Identifier: NCT02071927; breast cancer, phase II, ClinicalTrials.gov Identifier: NCT03057600; renal cell carcinoma, phase II, ClinicalTrials.gov Identifier: NCT03428217; mcolon cancer, early phase I, ClinicalTrials.gov Identifier: NCT02891538; bladder cancer, phase II, ClinicalTrials.gov Identifier: NCT00666562; breast cancer, phase II, ClinicalTrials.gov Identifier: NCT00917735; prostate cancer, phase II, ClinicalTrials.gov Identifier: NCT00676780; " breast cancer, phase II, ClinicalTrials.gov Identifier: NCT03179904; colon cancer, phase I, ClinicalTrials.gov Identifier: NCT02980029; astrocytoma, phase II, ClinicalTrials.gov Identifier: NCT03032484; ${ }^{\circ}$ ClinicalTrials.gov Identifier: NCT01215864; ${ }^{\mathrm{p}}$ hepatocellular carcinoma, phase II, ClinicalTrials.gov Identifier: NCT01092091; leukemia, phase II, ClinicalTrials.gov Identifier: NCT02899286; renal cell carcinoma, melanoma and prostate adenocarcinoma, phase I, ClinicalTrials.gov Identifier: NCT02285101; ${ }^{\mathrm{q}}$ melanoma, phase II, ClinicalTrials.gov Identifier: NCT00520299; prostate cancer, phase I, ClinicalTrials.gov Identifier: NCT01497925; breast cancer, phase I, ClinicalTrials.gov Identifier: NCT01948843; acute myeloid leukemia, phase I, ClinicalTrials.gov Identifier: NCT02875093; hepatocellular carcinoma, phase III, ClinicalTrials.gov Identifier: NCT01287585; ${ }^{\mathrm{r}}$ glioblastoma, phase II, ClinicalTrials.gov Identifier: NCT02052648; pancreatic cancer, phase II, ClinicalTrials.gov Identifier: NCT02077881; prostate cancer, phase II, ClinicalTrials.gov Identifier: NCT01560923; melanoma, phase III, ClinicalTrials.gov Identifier: NCT03301636; acute myeloid leukemia, phase II, ClinicalTrials.gov Identifier: NCT02835729; 's sarcoma, phase II, ClinicalTrials.gov Identifier: NCT03414229; lymphoma and solid tumors, phase II, ClinicalTrials.gov Identifier: NCT03322384; renal cell carcinoma, phase III, ClinicalTrials.gov Identifier: NCT03260894; urothelial cancer, phase III, ClinicalTrials.gov Identifier: NCT03374488; head and neck cancer, phase III, ClinicalTrials.gov Identifier: NCT03342352; lung cancer, phase III, ClinicalTrials.gov Identifier: NCT03322566; pancreatic cancer, phase II, ClinicalTrials.gov Identifier: NCT03006302; prostate cancer, phase II, ClinicalTrials.gov Identifier: NCT03493945; ovarian cancer, phase I, ClinicalTrials.gov Identifier: NCT02118285; ${ }^{\mathrm{t}}$ ClinicalTrials.gov Identifier: NCT02679144; " advanced refractory solid tumors, phase I, ClinicalTrials.gov Identifier: NCT00705653; lymphoma, phase I, ClinicalTrials.gov Identifier: NCT00293488; ' head and neck cancer, phase IV, ClinicalTrials.gov Identifier: NCT03196843; nasopharyngeal carcinoma, phase II, ClinicalTrials.gov Identifier: NCT02562599; childhood leukemia, phase I, ClinicalTrials.gov Identifier: NCT00003528; gastric cancer, phase II, ClinicalTrials.gov Identifier: NCT03392103; colorectal cancer, phase IV, ClinicalTrials.gov Identifier: NCT01959061; ${ }^{\mathrm{w}}$ ClinicalTrials.gov Identifier: NCT00522652; *enasidenib has already been approved by FDA (see Notes added in proof). 


\section{FIGURE CAPTIONS}

Figure 1. Important aspects regarding metabolism of tumor cells and several cells of the tumor microenvironment.

Figure 2. Role of different cells of the tumor microenvironment in immunosuppression. Different cells of the tumor microenvironment are able to affect the immune activity. Proliferation of Treg cells is modulated by TGF- $\beta$ from cancer-associated fibroblasts (CAFs) and tumor cells and by IL-10 secreted by tumor-associated macrophages (TAMs). Tumor cells consume high amounts of tryptophan and arginine, thus depleting them from the media. TAMs also consume tryptophan, and HIF-1 $\alpha$ induces the expression of arginase 1 (Arg1), hence diminishing arginine concentration in the extracellular media. Part of the arginine consumed by tumor cells can be leaded to nitric oxide (NO) synthesis, which inhibits effector T cells activity. Additionally, the high uptake of glutamine by tumor cells decreases glutamine availability in the media, inhibiting glutaminolysis in effector $\mathrm{T}$ cells, which, in turn, impairs polyamine and nucleotide synthesis in these cells. Tumor cells also express CD73 marker, responsible for increasing AMP concentration in the media, which will be converted to adenosine, capable of inhibiting immune response by effector $\mathrm{T}$ cells. Regarding glucose metabolism, TAMs and tumor cells express PD-L1, the ligand for PD-1, and their interaction inhibits glycolysis in effector T cells. PD-L1 favors the high glycolytic rate in tumor cells, thus depleting glucose from the media, and then the transcription of IFN$\gamma$ and IL-2 is inhibited. All these facts lead to immunosuppression. Solid arrows show production or secretion; dashed arrows represent induction or inhibition; dotdashed arrows indicate a substrate or process integrated to another process; thicker arrows depict a higher rate of incorporation of the indicated substrate.

Figure 3. Metabolite exchange between tumor cells and different cells of the tumor microenvironment and its relation with tumor progression. There are multiple metabolic interactions between the different cells of the tumor microenvironment. For example, endothelial cells (ECs) consume lactate produced by tumor cells, thus enhancing the angiogenic process, and ECs extrude mitochondria to tumor cells, conferring them chemoresistance. Lactate from tumor cells are also consumed by tumor-associated macrophages (TAMs) and cancer-associated fibroblasts (CAFs). On the one hand, in TAMs, lactate stabilizes HIF- $1 \alpha$, thus promoting angiogenesis and immunosuppression. On the other hand, in CAFs lactate induces hyaluronic acid production, which contributes to tumor invasiveness along with kynurenine, a tryptophan metabolite produced by tumor cells and TAMs. Lactate production by CAFs is also promoted by ROS liberation from tumor cells. Additionally, cancer-associated adipocytes (CAAs), TAMs and CAFs synthetize glutamine, which is uptaken by tumor cells. CAAs and CAFs also provide fatty acids (FAs) to tumor cells. Moreover, CAAs supply tumor cells with citrulline and arginine, hence contributing to polyamine and nitric oxide (NO) synthesis in these cells. Solid arrows show production or secretion; dashed arrows represent induction or inhibition; dotdashed arrows indicate a substrate or process 
integrated to another process.

Figure 4. Role of different cells of the tumor microenvironment in promoting angiogenesis. Tumor cells contribute to activation of angiogenesis through lactate secretion to the media, which is consumed by endothelial cells (ECs). ECs are also able to produce lactate via glycolysis, and this lactate promotes the phosphorylation of Akt, which, in turn, promotes the glycolytic process in a positive feed-back. Indirectly, lactate inhibits prolyl hydroxylases (PHD). PHD inhibition enables stabilization of HIF$1 \alpha$ and the liberation of the active form of NF- $\kappa B$, thus allowing the transcription of pro-angiogenic factors such as basic fibroblast growth factor (bFGF), vascular endothelial growth factor receptor 2 (VEGFR2), vascular endothelial growth factor (VEGF) and interleukin 8 (IL-8). VEGF, as well, promotes fatty acid (FA) uptake in ECs. Oxidation of these fatty acids leads to nucleotide synthesis, increasing EC proliferation. Moreover, expression of $\beta 2$-adrenergic receptor (ADR $\beta 2$ ) favors the glycolytic phenotype through inhibition of OXPHOS. Additionally, other cells of the tumor microenvironment are also able to modulate angiogenesis. For example, stabilization of HIF-1 $\alpha$ by ROS liberation from tumors increases the glycolytic rate in cancer-associated fibroblasts (CAFs), and the resulting lactate promotes the liberation of metalloproteinase-9 (MMP9) to the media. Furthermore, TGF- $\beta$ expressed in these cells activates urokinase-type plasminogen activator (uPA). Both molecules are involved in extracellular matrix degradation. On the other hand, tumor-associated macrofages (TAMs) produce TNF- $\alpha$, which allows the expression of MMP9 and uPA as well, and of IL-1, which upregulates HIF-1 $\alpha$, hence increasing transcription of VEGF and other pro-angiogenic factors. It has to be taken into account that many other factors produced by the different cells of the microenvironment regulate the angiogenic process, but they are not represented here for the sake of clarity. Solid arrows show production or secretion; dashed arrows represent induction or inhibition; dotdashed arrows indicate a substrate or process integrated to another process.

Figure 5. Interactions between tumor and host metabolism. Tumor growth is promoted by means of different metabolic interactions of tumor with host tissues. Tumors secrete IL-6, which has two effects on the liver: i) inhibiting ketogenesis, which stimulates the secretion of adrenocortical hormones $(\mathrm{ACH})$, therefore promoting protein catabolism in muscles, which results in free amino acids for their use by the tumor, and ii) promoting insulin liberation, which induces gluconeogenesis in the liver, thus supplying the tumor with glucose. In addition, gluconeogenesis in the liver also uses alanine from muscles and lactate from muscles and the tumor (all this corresponding to the so-called Cori cycle), and gluconeogenesis is also carried out in the kidneys. Moreover, tumors act as "nitrogen traps", consuming high amounts of glutamine from the blood. Liver and kidneys have a high glutamine synthetase (GS) and a low glutaminase (GLS) expression, and muscles present high GS expression, thus providing tumors with glutamine. This high uptake of glutamine by the tumor decreases glutamine available for natural-killer (NK) cells, thus diminishing glutathione (GSH) concentration and affecting NK cells activity. Tumors also consume arginine, depleting the arginine 
available for other tissues. In addition, tumors take up uridine from lympohid organs, leading to a decrease in RNA synthesis in these organs. All this contributes to immunosuppression. The arginine consumed can be used for nitric oxide (NO) and polyamine synthesis, helped by a high uptake of ornithine and methionine from the tissues, as well as a high ornithine decarboxylase (ODC) activity. Besides, lipid catabolism is promoted in the adipose tissue, thus liberating free fatty acids (FAs) to the blood that are uptaken by the tumor. Solid arrows show production or secretion; dashed arrows represent induction or inhibition; dotdashed arrows indicate a substrate or process integrated to another process; thicker arrows depict a higher rate of incorporation of the indicated substrate. 


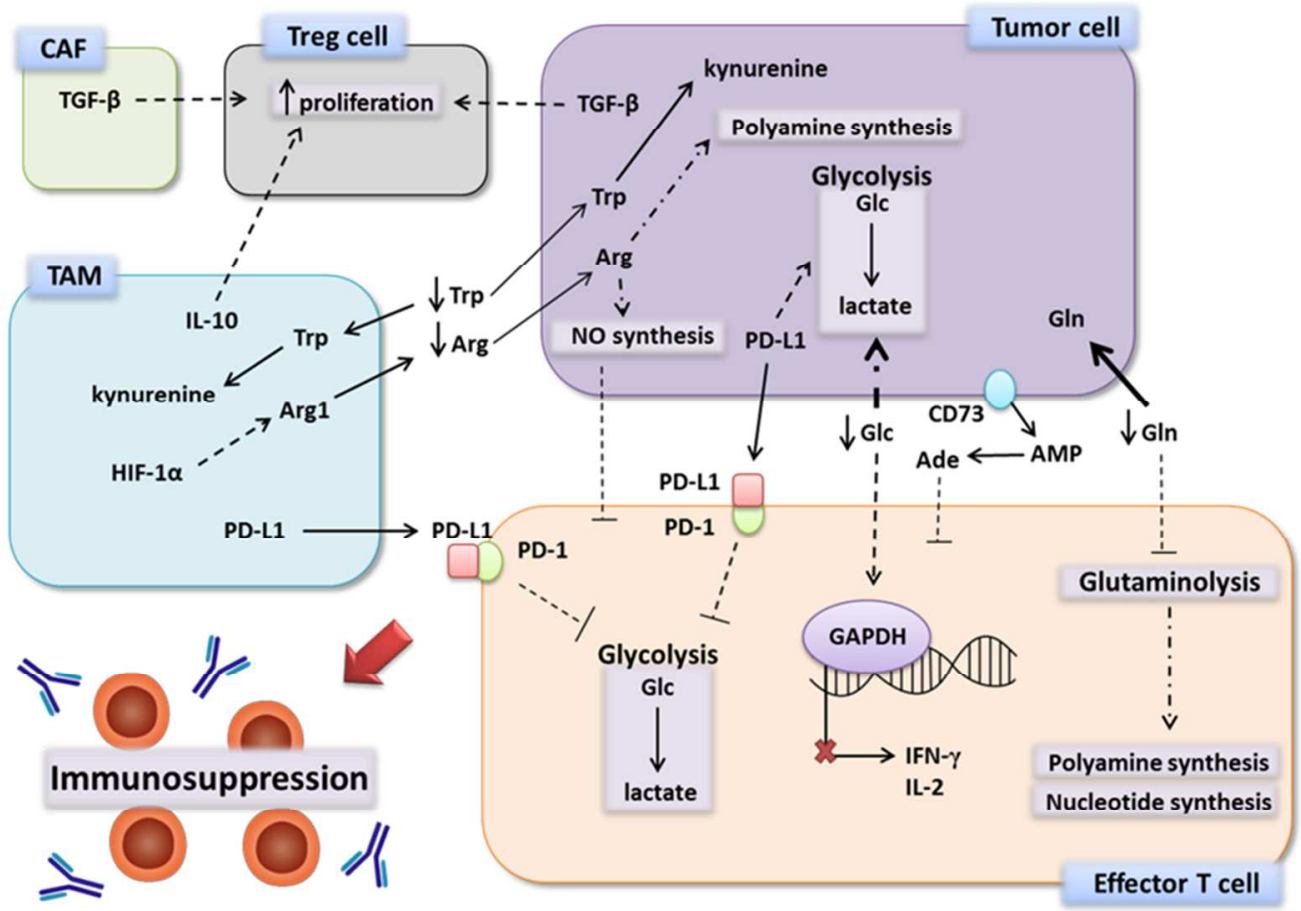

$152 \times 111 \mathrm{~mm}(300 \times 300$ DPI $)$ 


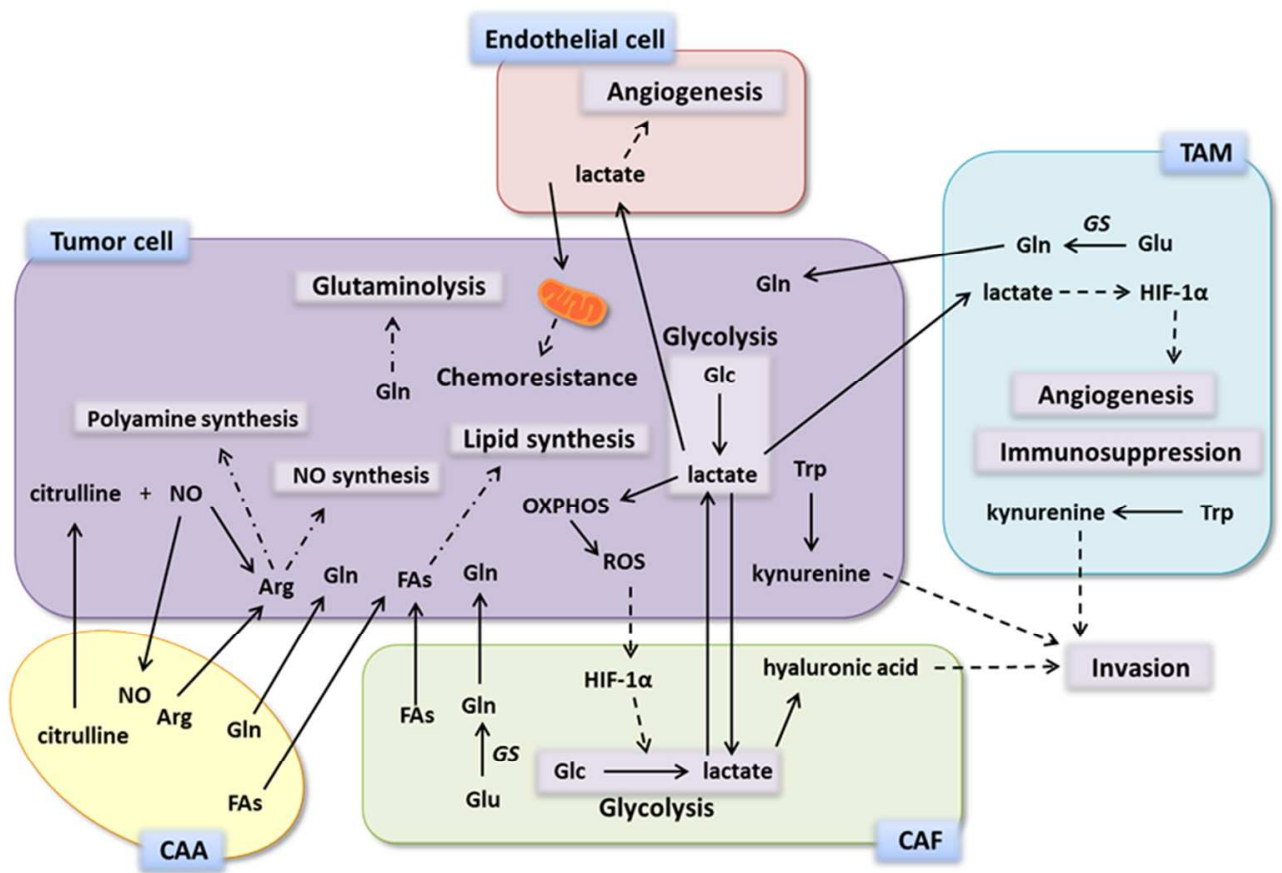

$152 \times 103 \mathrm{~mm}(300 \times 300$ DPI $)$ 


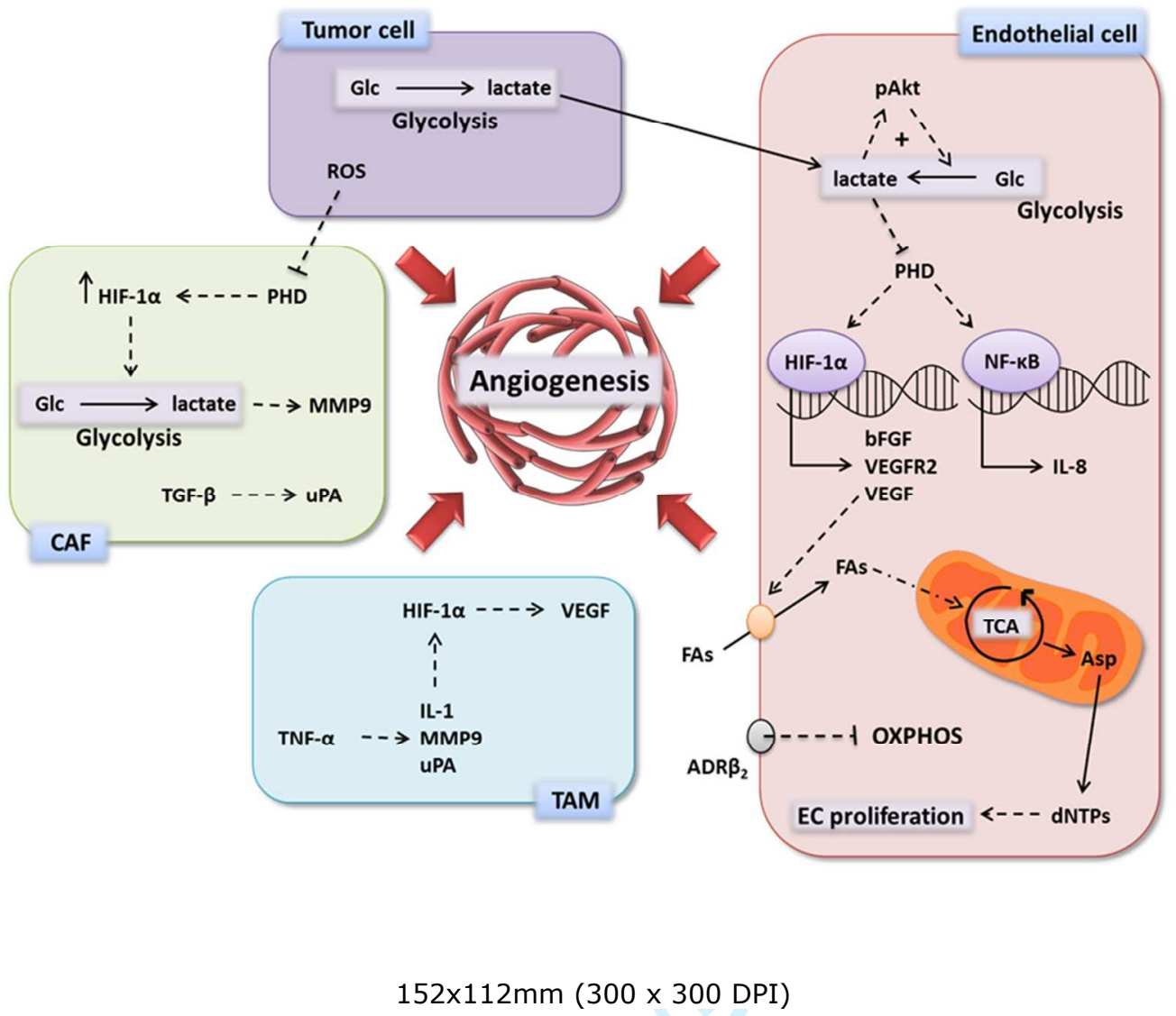

John Wiley \& Sons 